University of Rhode Island

DigitalCommons@URI

Open Access Dissertations

2020

\title{
INVESTIGATION OF ELECTROLYTE ADDITIVES AND LITHIUM METAL ANODES FOR LITHIUM ION BATTERIES
}

Satu Kristiina Heiskanen

University of Rhode Island, Satu.Heiskanen0@gmail.com

Follow this and additional works at: https://digitalcommons.uri.edu/oa_diss

\section{Recommended Citation}

Heiskanen, Satu Kristiina, "INVESTIGATION OF ELECTROLYTE ADDITIVES AND LITHIUM METAL ANODES FOR LITHIUM ION BATTERIES" (2020). Open Access Dissertations. Paper 1171.

https://digitalcommons.uri.edu/oa_diss/1171

This Dissertation is brought to you for free and open access by DigitalCommons@URI. It has been accepted for inclusion in Open Access Dissertations by an authorized administrator of DigitalCommons@URI. For more information, please contact digitalcommons-group@uri.edu. 


\section{INVESTIGATION OF ELECTROLYTE ADDITIVES AND \\ LITHIUM METAL ANODES FOR LITHIUM ION \\ BATTERIES \\ BY \\ SATU KRISTIINA HEISKANEN}

A DISSERTATION SUBMITTED IN PARTIAL FULFILLMENT OF THE

REQUIREMENTS FOR THE DEGREE OF

DOCTOR OF PHILOSOPHY

IN

CHEMISTRY

UNIVERSITY OF RHODE ISLAND

2020 


\section{DOCTOR OF PHILOSOPHY DISSERTATION}

OF

SATU KRISTIINA HEISKANEN

APPROVED:

Dissertation Committee:

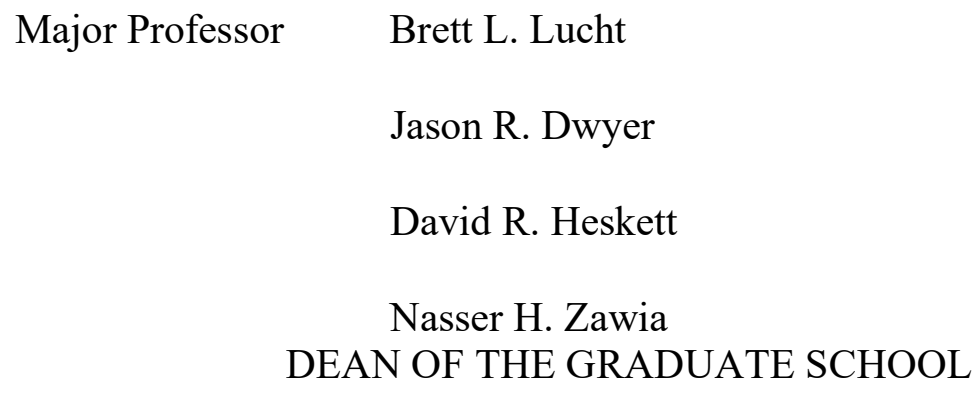

UNIVERSITY OF RHODE ISLAND

2020 


\begin{abstract}
The continued development of energy storage technology is of high importance in order to facilitate the widespread adoption of intermittent renewable energy sources as well as the expansion of electromobility (for example, fully electric vehicles). These applications require a rechargeable cell with high energy density with a long cycling life, based on the electrochemical cycling of lithium ion batteries, which can be improved by modifying the cell chemistry and construction.

Enabling the reversible plating and stripping of lithium metal on the negative electrode substrate - a lithium metal anode - allows for a higher gravimetric capacity necessary for a lightweight battery. However, the application of the lithium metal anode in carbonate-based electrolytes is plagued by the highly reactive nature of lithium metal, causing poor coulombic efficiency and the growth of potentially unsafe lithium dendrites. Another route to achieve a high energy density lithium ion battery is to increase the nickel or lithium content of the layered lithium nickel- manganese cobalt -oxide positive electrode (NMC cathode) materials. Unfortunately, alongside the improved capacity, these compositional changes result in new challenges to overcome such as surface reconstruction, gas evolution, and transition metal dissolution. Electrolyte engineering and surface modifications to the cathode material can help alleviate detrimental reactions, however, the source of the improvements remains unclear.
\end{abstract}

This dissertation attempts to elucidate the relationship between the molecular composition of the solid electrolyte interphase (SEI) and cycling performance of a lithium ion battery, as well as understanding the role of the cathode in anode SEI 
formation. Galvanostatic voltammetry was used to characterize the electrochemistry of the lithium metal anode, with Attenuated Total Reflectance Fourier Transform Infrared Spectroscopy (ATR-FT-IR), X-ray Photoelectron Spectroscopy (XPS), Electrochemical Impedance Spectroscopy (EIS), and Inductively Coupled Plasma Mass Spectrometry (ICP-MS) to investigate the surface of the lithium metal anode, graphite anode cycled with modified and unmodified high energy NMC cathodes, and the cathode materials themselves. Chapter 1 is a perspective-style review which brings together many different studies to propose a scheme by which the anode SEI evolves throughout cycling and offers an explanation behind the varying reports from different research groups. Chapter 2 is a perspective-style review on the interaction of the electrolyte with the NMC cathode material, and its implications in the cycling performance. In chapter 3, novel electrolyte additives, difluoroacetic anhydride (DFAA) and trifluoroacetic anhydride (TFAA), are investigated in carbonate-based electrolytes which help to improve the reversibility of lithium metal plating in $\mathrm{Cu} \mid \mathrm{LiFePO}_{4}$ cells, and using the above-mentioned analytical techniques attempts to uncover the source of improved plating. Finally, chapter 4 investigates the effect of ALD-deposited $\mathrm{Al}_{2} \mathrm{O}_{3}$ coatings on cycling performance of full graphite| $\mathrm{Li}_{1.33} \mathrm{Ni}_{0.27} \mathrm{Co}_{0.13} \mathrm{Mn}_{0.60} \mathrm{O}_{2+\mathrm{d}}$ cells, effect on the molecular composition of the anode SEI, and extent of transition metal deposition on the anode material. 


\section{ACKNOWLEDGMENTS}

First, I wish to thank my supervisor and advisor, Professor Brett Lucht. I cannot imagine having a better advisor. His support and academic guidance have taught me how to answer scientific questions clearly, and how to pursue further branches of my research. Thank you for the countless opportunities you have given me, especially the opportunities to travel to conferences and meetings both domestically and abroad, I really grew as a scientist from these experiences. I am forever grateful for Brett's mentorship

Next, I want to acknowledge BASF, URI, Eagle Picher and US-DOE for the funding which made my research possible. Without your support, none of my work would be possible. I also want to thank all the members of the BASF Electrochemistry Network for teaching me so much.

The members of my PhD committee, Professor Jason Dwyer, Professor David Heskett have all encouraged me to be a better, more precise Scientist. My defense chair Professor Arijit Bose has pushed me to think more fundamentally, thank you. In light of the current global CoVID-19 pandemic, I also thank all of you for your patience and flexibility in organizing my dissertation defense, whether it be in person, teleconferenced, or some combination of these two.

There have been so many people in the URI Chemistry department who have listened to my ramblings, especially my lab mates: Zack, Nina, Julien, Sunhyung, Nuwanthi, Jongjung, Kiran, Alex, Kaveendi, Cao, Taeho, Maheeka, Mickdy, Chamithri, Bharathy, Lea, Audrey, Carsten, Lucas, and Leah. Thank you, you have made my PhD more than just a pursuit of knowledge. 
My undergraduate institution, Western Washington University, has prepared me astonishingly well for my PhD studies. Each and every day I realize how much I really learned and the extent of my training there. In particular, I want to thank my undergraduate research advisor, Professor David Rider for taking me on as an undergraduate researcher and giving me so much freedom over my own work. I also want to thank Professor David Patrick for his detailed instruction on instrumental analysis; those lectures sparked a passion for understanding how the instruments actually work, and how I can use them to my advantage (and troubleshoot, of course!)

Of course, I can't write an acknowledgements section without thanking my family, friends, and friends so close they are my family. Paljon kiitoksia sinulle, äiti, kuin annoit mulle vapauden kehittyä kemistiksi. Ja teille myös kiitoksia Kikka, Markku, Maarit, Vilma ja Veikka. Minä rakastan teitä. 


\section{PREFACE}

This dissertation is written in manuscript format. There are four chapters in this dissertation. Chapter 1 is an is a perspective article on the evolution of the solid electrolyte interphase on the anode of lithium ion batteries and was published in Joule. Chapter 2 is a perspective on the interactions of the surface of the cathode with the electrolyte and is written as a manuscript and is currently submitted to the Journal of the Electrochemical Society for publication. Chapters 1 and 2 serve as a primer on the challenges facing scientists regarding electrolytes and passivation layers, and the current understanding of these phenomena. Chapter 3 is written in manuscript format and is in preparation for submission to the Journal of the Electrochemical Society. Chapter 4 was published in the Journal of the Electrochemical Society. 


\section{TABLE OF CONTENTS}

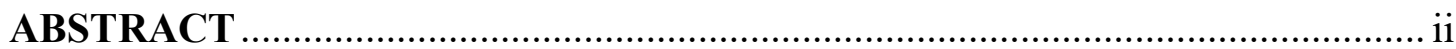

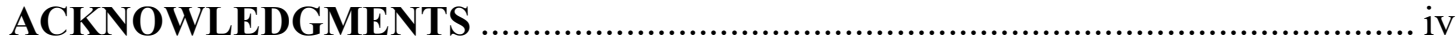

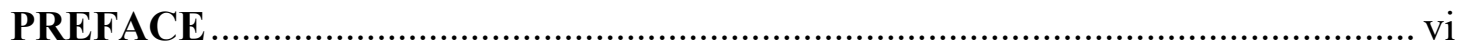

TABLE OF CONTENTS............................................................................ vii

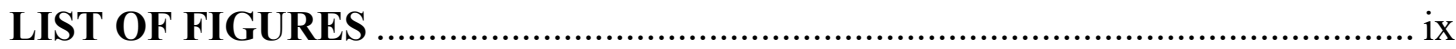

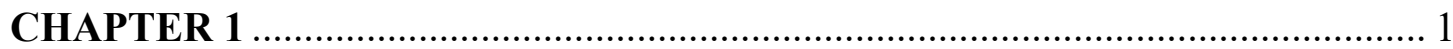

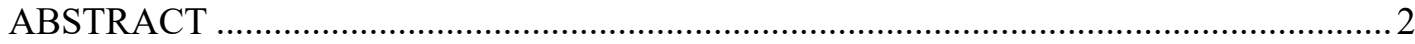

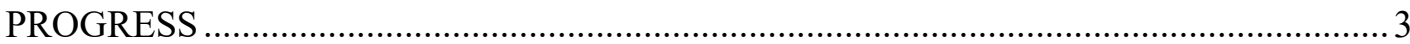

Initial reduction reactions of $\mathrm{LiPF}_{6} /$ carbonate electrolytes on graphite anode ....................3

Independent synthesis of SEI components .......................................................................

Instability of initial SEI components on graphite anodes ................................................ 6

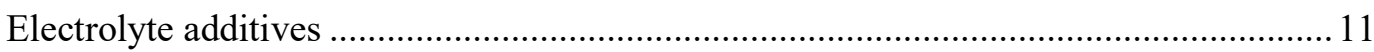

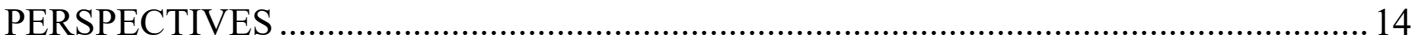

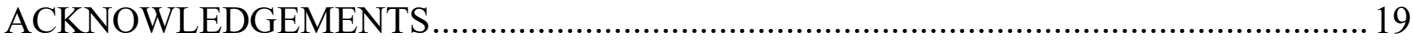

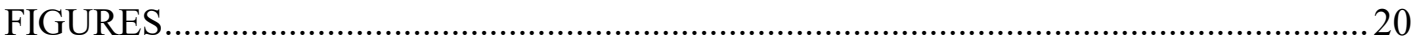

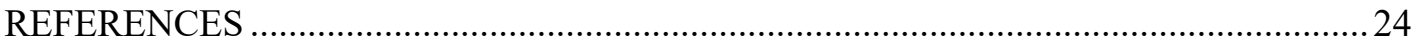

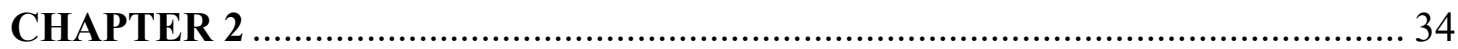

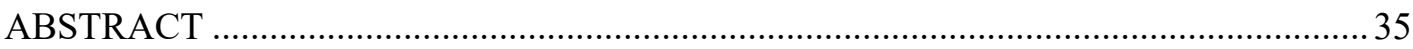

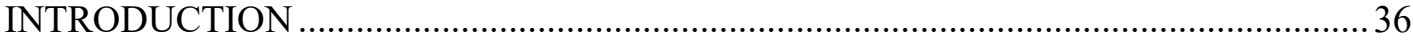

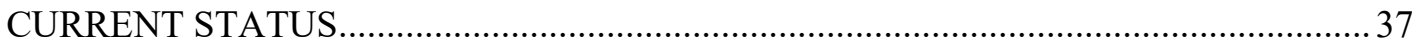

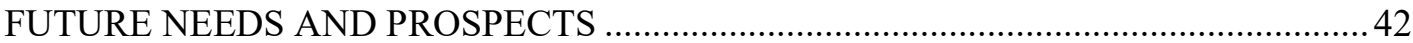

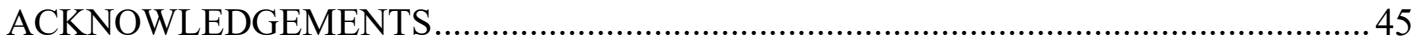

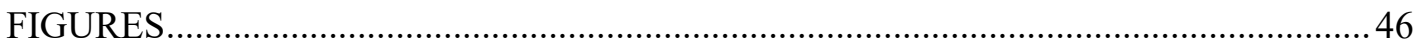

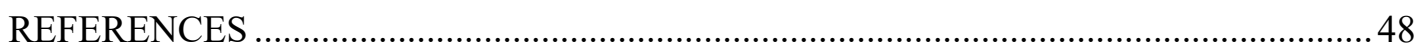




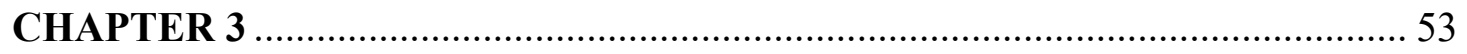

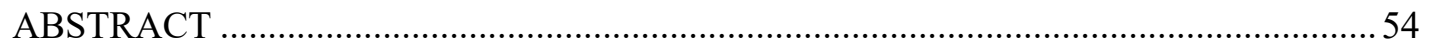

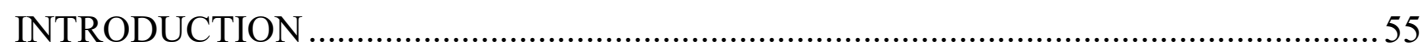

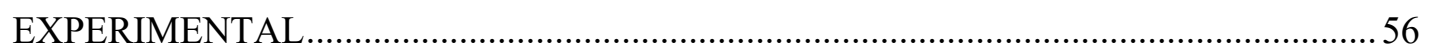

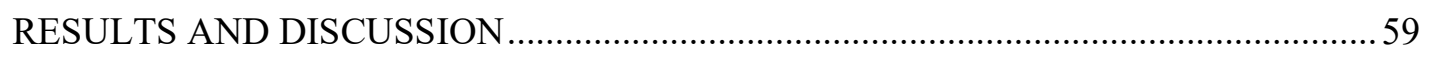

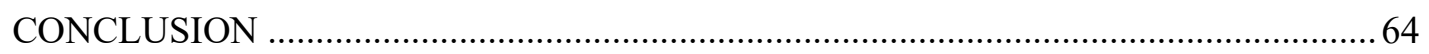

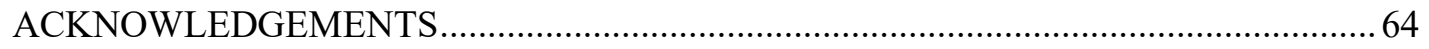

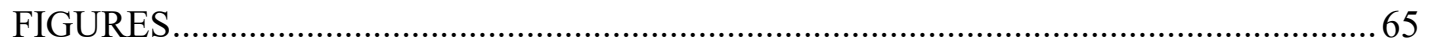

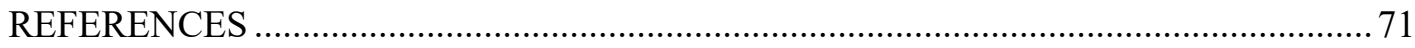

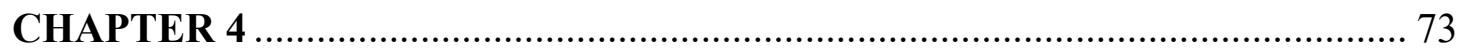

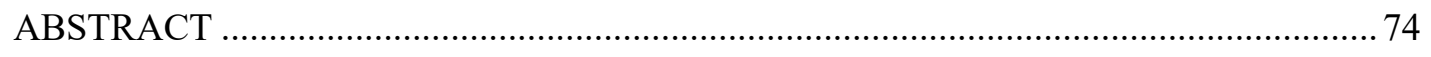

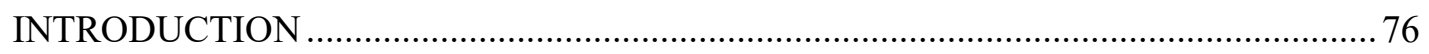

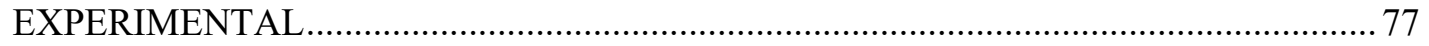

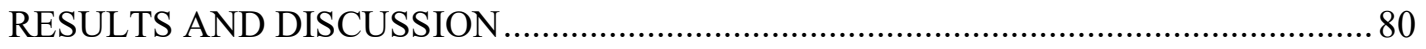

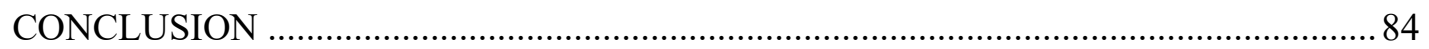

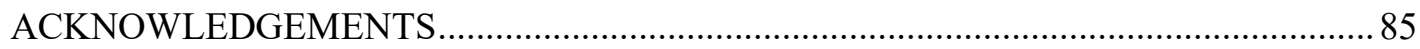

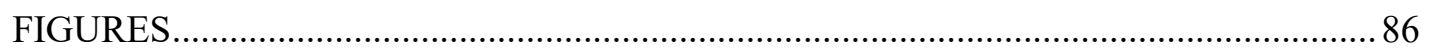

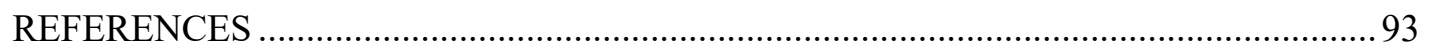




\section{LIST OF FIGURES}

Figure 1-1. a) Initial reduction reactions of EC on the graphite electrode interface. b) Schematic figure of the initial SEI formed on graphite surface during the first cycle of a lithium ion battery.15 Figure 1-1. A) Initial reduction reactions of EC on the graphite

Figure 1-2. The primary decomposition reactions of the SEI components lithium ethylene dicarbonate (LEDC) and Li2CO3. 21

Figure 1-3. Schematic figure of the initial SEI formed on the graphite anode, the effect of acid mediated thermal decomposition reactions on the structure of the SEI, and the further reduction of electrolyte leading to the thickening of the SEI. 22

Figure 1-4. Schematic figures of the initial SEI generated on graphite anodes for electrolytes containing VC (left) or FEC (right). 23

Figure 2-1. Electrochemical performance of Graphite/NCM811 cells cyced at different cut-off voltages of 4.2 and $4.6 \mathrm{~V}$, respectively. a) Galvanostatic cycling at a C-rate of $\mathrm{C} / 2$ after formation cycles at $\mathrm{C} / 20(1), \mathrm{C} / 10$ (2-3) and $\mathrm{C} / 5(4-5), \mathrm{b})$ differential capacity plots of the $1^{\text {st }}$ and $100^{\text {th }}$ cycle. ${ }^{13}$ Figure reproduced with permission of J. Electrochem. Soc 46

Figure 2-2. A schematic representation of the (a) manganese catalyzed degradation of the anode SEI adapted from Solchenbach et al17, and (b) acidic species induced decomposition of anode SEI components. 
Figure 3-1. (a) Stripping specific capacity vs. cycle number for the STD, 0.5\% DFAA, $1 \%$ DFAA, $2.5 \%$ DFAA, and 5\% DFAA, (b) corresponding cycle efficiency vs. cycle number, and (c) sum of reversibly cycled lithium over the first 50 cycles for each electrolyte. 65

Figure 3-2.(a) Stripping specific capacity vs. cycle number for the STD, 2.5\% TFAA, 5\% TFAA, 10\% TFAA, and 15\% TFAA, (b) corresponding cycle efficiency vs. cycle number, and (c) sum of reversibly cycled lithium over the first 50 cycles for each electrolyte. 66

Figure 3-3. Voltage profile of the first charge/plating of a STD, $2.5 \%$

DFAA, and 10\% TFAA, with the inset showing the plateaus more clearly....

Figure 3-4. (a) Stripping specific capacity vs. cycle number for the STD, 5\%

TFAA, 5\% DFAA, and 2.5\% DFAA + 2.5\% TFAA, and (b) sum of

reversibly cycled lithium over the first 50 cycles for each electrolyte. 68

Figure 3-5. C1s, O1s, andF1s XPS spectra after the second plating of lithium on copper foil in STD, 5\% TFAA, 5\% DFAA, and 2.5\% DFAA + 2.5\%

TFAA. 69

Figure 3-6. ATR-FT-IR spectra in the $1900-800 \mathrm{~cm}^{-1}$ region of lithium plated in STD, 5\% DFAA, 5\% TFAA, and 2.5\% TFAA + 2.5\% DFAA 70

Figure 4-1. Comparison of discharge capacity vs. cycle number obtained from HE-NCM/Graphite full cells containing the uncoated and $\mathrm{Al}_{2} \mathrm{O}_{3}$-coated HE-NCM electrodes. The capacity was calculated based on the active mass of HE-NCM electrodes. 86 
Figure 4-2. ICP-MS results obtained from HE-NCM/Graphite full cells containing the uncoated and $\mathrm{Al}_{2} \mathrm{O}_{3}$-coated HE-NCM electrodes.

Figure 4-3. Corresponding relative atomic concentrations from XPS spectra obtained from the HE-NCM electrodes and graphite electrodes. The total concentration of $\mathrm{Ni}, \mathrm{Mn}$ and $\mathrm{Co}$ is presented as metal concentration.

Figure 4-4. IR-ATR spectra obtained from the (a) HE-NCM electrodes and (b) graphite electrodes after 50 cycles. 91

Figure 4-5. The Nyquist plots obtained from graphite/graphite symmetric cells, in which graphite electrodes were collected from two identical HE$\mathrm{NCM} /$ Graphite full cells containing the uncoated and $\mathrm{Al}_{2} \mathrm{O}_{3}$-coated $\mathrm{HE}-\mathrm{NCM}$ electrodes. 92 


\title{
CHAPTER 1
}

\section{Generation and evolution of the solid electrolyte interphase of lithium ion batteries}

\author{
Satu Kristiina Heiskanen, Jongjung Kim, and Brett L. Lucht* \\ University of Rhode Island \\ 140 Flagg Rd., Beaupre, Kingston, RI 02881 \\ *Corresponding Author: blucht@chm.uri.edu
}

The following was published in Joule on October 16, 2019 and is presented here in manuscript format 


\begin{abstract}
A solid electrolyte interphase (SEI) is generated on the anode of lithium ion batteries during the first few charging cycles. The SEI provides a passivation layer on the anode surface which inhibits further electrolyte decomposition and affords the long calendar life required for many applications. However, the SEI remains poorly understood. Recent investigations of the structure of the initial SEI along with changes which occur to the SEI upon aging have been conducted. The investigations provide significant new insight into the structure and evolution of the anode SEI. The initial reduction products of ethylene carbonate (EC) are lithium ethylene dicarbonate (LEDC) and ethylene. However, the instability of LEDC generates an intricate mixture of compounds which greatly complicates the composition of the SEI. Mechanisms for the generation of the complicated mixture of products are presented along with the differences in the SEI structure in the presence of electrolyte additives.
\end{abstract}




\section{PROGRESS}

Initial reduction reactions of $\mathrm{LiPF}_{6} /$ carbonate electrolytes on graphite anode

In order to simplify the investigation of the SEI components, the initial reactions

of a two-component electrolyte, 1.0 $\mathrm{M} \mathrm{LiPF}_{6}$ in $\mathrm{EC}$, have been investigated utilizing a combination of ex-situ SEM, EDX, TEM, XPS, IR, NMR, and OEMS. ${ }^{10}$ The initial SEI is generated during formation cycling, the first 4-6 cycles, of commercial lithium ion batteries. The use of the single solvent simplifies characterization of the reduction products, while the use of EC insures formation of a stable SEI. As the potential decreases during lithiation, electrolyte decomposition products are deposited on the surface of the anode to form an initial SEI. The electrolyte decomposition products have been determined to contain carbon, fluorine, oxygen, and a low concentration of phosphorus via a combination of EDX and XPS. IR-ATR analysis is consistent with a film containing lithium ethylene dicarbonate (LEDC) as the primary organic component which is consistent with the XPS results. XPS also suggests that LiF is the primary fluorine containing species with a low concentration of lithium fluorophosphates, $\mathrm{Li}_{\mathrm{x}} \mathrm{PF}_{\mathrm{y}} \mathrm{O}_{\mathrm{z}}$. OEMS analysis of $1.0 \mathrm{M} \mathrm{LiPF}_{6}$ in $\mathrm{EC}$ provides consistent results with the observation of ethylene as the only gas evolved during the initial formation cycles. Thus, the initial SEI formed in 1.0 $\mathrm{M} \mathrm{LiPF}_{6}$ in EC is predominantly LEDC and LiF. ${ }^{11,12}$ These results are consistent with the mechanism proposed by Aurbach and co-workers and are also consistent with recent results reported by $\mathrm{Xu}$ and co-workers (Figure 1-1A). ${ }^{13,14}$ From these initial results, an SEI approximately $50 \mathrm{~nm}$ thick composed of LEDC and $\mathrm{LiF}$ is generated and can function as an effective 
passivating layer thereby preventing further electrolyte decomposition and graphite exfoliation, as summarized in Figure 1-1B.

\section{[FIGURE 1-1]}

Similar investigations of two-component linear carbonate electrolytes, $\mathrm{LiPF}_{6}$ in dialkyl carbonate, have also been investigated. ${ }^{15,16}$ Similar reactions are observed for the dialkyl carbonate solvents utilized in lithium ion battery electrolytes: dimethyl carbonate (DMC), diethyl carbonate (DEC) and ethyl methyl carbonate (EMC). The reduction of DMC results in the generation of lithium methyl carbonate (LMC), lithium methoxide, $\mathrm{CO}$, and methane. The reduction of DEC results in the generation of lithium ethyl carbonate (LEC), lithium ethoxide, $\mathrm{CO}$, and ethane. The most commonly used dialkyl carbonate, EMC, generates the most complicated mixture of components, LMC, LEC, lithium methoxide, lithium ethoxide, ethane, methane, and $\mathrm{CO}$, due to the asymmetry of the molecule. However, in most commercial lithium ion battery electrolytes the initial solvent reduction reactions are dominated by the reduction reaction of EC and therefore the contribution of dialkyl carbonates to the SEI composition is minimal suggesting that the primary components of the initial SEI in commercial lithium ion batteries are LEDC and LiF. ${ }^{15,17}$

While the initial SEI generated on the graphite anode is dominated by the direct reduction products of the salt and solvent, additional products can be generated via crossover reactions from the cathode. In particular, solvent oxidation from the cathode results in the generation of $\mathrm{CO}_{2}$ which diffuses to the anode and is subsequently 
reduced to form $\mathrm{Li}_{2} \mathrm{CO}_{3} .{ }^{18}$ The mechanism of $\mathrm{CO}_{2}$ reduction is unclear and will be discussed below, but the primary observed product is $\mathrm{Li}_{2} \mathrm{CO}_{3}$.

\section{Independent synthesis of SEI components}

In order to better understand the initial reduction reactions occurring at the graphite surface, lithium napthalenide has been utilized as a one-electron reducing agent to generate the reduction products of various carbonate solvents. Lithium napthalenide is readily prepared via the reaction of lithium metal with naphthalene and acts as a synthetic mimic for lithiated graphite. Upon reduction of EC with lithium napthalenide two products are observed: LEDC and ethylene. ${ }^{15}$ These are the same reduction products which were observed on the graphite anode with an EC electrolyte (Figure 1-1). This reaction occurs in high yield with no observable impurities. Initial investigations of DEC and DMC reduction using lithium napthalenide uncovered the generation LEC and LMC along with ethane and methane, however, further investigations suggest that lithium ethoxide, lithium methoxide, and carbon monoxide are all observed. ${ }^{16,19}$ While the reduction reactions of the linear carbonates are somewhat more complicated than those observed for the cyclic carbonates, the initial SEI forming reactions have been reported to be dominated by EC reduction products. ${ }^{4,6,10,15,17}$

Since $\mathrm{CO}_{2}$ has been reported to be a product of the oxidation of carbonate solvents on the surface of the cathode, the reaction of lithium napthalenide with $\mathrm{CO}_{2}$ has also been investigated. ${ }^{18,20,21}$ Unfortunately, the reaction of lithium napthalenide with $\mathrm{CO}_{2}$ is complicated by carboxylation of naphthalene to generate carboxylate derivatives of naphthalene. The primary product of the reaction is $\mathrm{Li}_{2} \mathrm{CO}_{3}$, but oddly 
$\mathrm{CO}$ is not observed as expected for the previously proposed reaction mechanism for the reduction of $\mathrm{CO}_{2}$. Thus, while the overall reduction mechanism for $\mathrm{CO}_{2}$ remains unclear, $\mathrm{Li}_{2} \mathrm{CO}_{3}$ is clearly the primary product deposited in the SEI.

Lithium napthalenide reductions of $\mathrm{LiPF}_{6}$ have also been investigated. ${ }^{22}$ The primary product observed is $\mathrm{LiF}$ along with a low concentration of lithium fluorophosphates and lithium fluorophosphides. While lithium fluorophosphides are observed in the absence of an oxygen source, in the presence of carbonate solvents the phosphides are rapidly converted to the phosphates. These results are consistent with the initially observed reduction products, LEDC and LiF, on the surface of the graphite anode. However, there are many reports that suggest that the SEI is a very complicated mixture of different components. In order to better understand the source of the differences between the initial SEI observed in these controlled experiments and the mature SEI observed by many researchers, further investigations have been conducted to develop an understanding of how different components evolve.

\section{Instability of initial SEI components on graphite anodes}

Previous investigations suggest that anode SEI in commercial lithium ion batteries is unstable and evolves over calendar life cycling or accelerated aging experiments. ${ }^{23-25}$ The evolution of the SEI has been reported to result in changes to the composition of the SEI. The changes typically include an increase in the concentration of inorganic species such as $\mathrm{LiF}$ and $\mathrm{Li}_{2} \mathrm{CO}_{3}$ and decreases in the relative concentration of organic species such as lithium alkyl carbonates. In addition, many investigations have concluded that the anode SEI is composed of an inner SEI dominated by inorganic species and an outer SEI dominated by organic 
species/solvent reduction products. ${ }^{13,26-29}$ However, the mechanisms of the changes in composition of the SEI are not understood. In an effort to better understand evolution of the SEI, detailed investigations of the thermal, hydrolytic, and acid mediated decomposition reactions of the independently generated SEI components have been conducted.

Lithium alkyl carbonates such as LEDC, LMC, and LEC have poor hydrolytic stability. In fact, independently prepared lithium alkyl carbonates readily decompose upon exposure to air over a few days. ${ }^{14,19}$ In addition, the incorporation of a low concentration of water to suspensions of lithium alkyl carbonates results in rapid decomposition of the lithium alkyl carbonates to $\mathrm{Li}_{2} \mathrm{CO}_{3}$, carbon dioxide and lithium alkoxides (Figure 1-2A). While the hydrolytic instability of lithium alkyl carbonates contributes to the evolution and increased complexity of the anode SEI upon aging, these reactions are limited in commercial cells which are prepared under rigorously anhydrous conditions. While lithium alkyl carbonates have poor hydrolytic stability, $\mathrm{Li}_{2} \mathrm{CO}_{3}$ has excellent hydrolytic stability as it can be purified by thermal treatment in water suggesting that $\mathrm{Li}_{2} \mathrm{CO}_{3}$ is a more stable SEI component than LEDC. ${ }^{30}$

\section{[FIGURE 1-2]}

Since lithium ion batteries are produced under rigorously anhydrous conditions, the stability of $\mathrm{Li}_{2} \mathrm{CO}_{3}$ and lithium alkyl carbonates have also been investigated in presence of $\mathrm{LiPF}_{6}$, a source of the strong Lewis acid $\mathrm{PF}_{5} .{ }^{31-35}$ Storage of $\mathrm{Li}_{2} \mathrm{CO}_{3}$ in the presence of $\mathrm{LiPF}_{6}$ in $\mathrm{DMC}$ results in the quantitative decomposition of $\mathrm{Li}_{2} \mathrm{CO}_{3}$ after 
only two days at $55^{\circ} \mathrm{C} .{ }^{36,37}$ The products of this decomposition reaction are $\mathrm{LiF}$, carbon dioxide, and lithium difluorophosphate (Figure 1-2B). Surprisingly, no lithium oxide is observed. Similar investigations have been conducted with LEDC. Upon storage of LEDC in the presence of $\mathrm{LiPF}_{6}$ in DMC, LEDC quantitatively decomposes at only $55^{\circ} \mathrm{C}$ after two days. However, the reaction mixture is much more complicated with $\mathrm{LEDC}$ than with $\mathrm{Li}_{2} \mathrm{CO}_{3}$. The decomposition products include $\mathrm{LiF}$, fluorophosphates, trimethyl phosphate, carbon dioxide, and oligoethylene oxides, as depicted in Figure 1-2C. It is important to note that many of the decomposition products of $\mathrm{Li}_{2} \mathrm{CO}_{3}$ or $\mathrm{LEDC}$ with $\mathrm{LiPF}_{6}$ are either gasses or are soluble in the electrolyte. This suggests that upon reaction of the lithium carbonates with $\mathrm{LiPF}_{6}$ the quantity of the insoluble SEI components are decreasing and the SEI is becoming more porous.

The thermal decomposition of pure LEDC has also been investigated via a combination of TGA-IR, IR-ATR and XPS. The thermal decomposition of pure LEDC occurs sequentially with increasing temperature. ${ }^{38}$ The initial thermal decomposition of LEDC results in the evolution of ethylene, leaving behind lithium peroxycarbonate $\left(\mathrm{Li}_{2} \mathrm{C}_{2} \mathrm{O}_{6}\right)$. The unstable lithium peroxycarbonate then reacts with LEDC to generate lithium propionate, lithium carbonate, carbon dioxide, and additional ethylene. Continued thermal treatment results in conversion of the lithium propionate to 3pentanone and lithium carbonate and then finally lithium oxide when temperatures exceed $700{ }^{\circ} \mathrm{C}$. The decomposition products are summarized in Figure 1-2D. The observation of the lithium propionate supports other reports of the presence of lithium carboxylates in the SEI which is surprising since there are no carbon atoms directly 
bonded to the carbonyl carbons of carbonate solvents and it was previously unclear how this new C-C bond was generated. ${ }^{5}$ Nonetheless, this observation provides an explanation for the generation of lithium carboxylates in the SEI.

To summarize, the initial SEI components generated from standard commercial electrolytes for lithium ion batteries are dominated by the reduction products of EC and $\mathrm{LiPF}_{6}, \mathrm{LEDC}$ and $\mathrm{LiF}$, respectively. However, the complexity of the SEI is the result of further decomposition reactions of LEDC into a very complicated mixture of components. ${ }^{39}$ The decomposition results in the generation of compounds which are insoluble in the electrolyte, soluble in the electrolyte, or gaseous. The insoluble components include lithium alkoxides, lithium fluorophosphates, polyethylene oxides, lithium carboxylates, $\mathrm{Li}_{2} \mathrm{CO}_{3}, \mathrm{Li}_{2} \mathrm{O}$, and $\mathrm{LiF}$. The soluble components include ethers, oligoethylene oxides, and fluorophosphates. The gaseous species include $\mathrm{CO}_{2}$ and ethylene. While some of the observed thermal decomposition reactions occur at high temperature $\left(>200^{\circ} \mathrm{C}\right)$, during charge and discharge the resistance of lithium ion transport through the SEI could lead to significant localized heating or the presence of transition metals could catalyze some of the thermal decomposition reactions. ${ }^{40}$ This complex mixture of components contains the vast majority of compounds reported to be present in the SEI suggesting by Occam's Razor that the subsequent decomposition of the initial products is the likely source of the complex SEI observed by many research groups. It is important to note that many of these decomposition reactions can be catalyzed by a low concentration of acidic impurities ( $\mathrm{HF}, \mathrm{PF}_{5}$, etc.) within the electrolyte which can partly explain the large variation of reported components between different research groups and cells cycled under different conditions. For 
example, many in-situ investigations of SEI formation occur under conditions where the ratio of electrolyte to electrode material is much higher than that used in commercial cells. Under these conditions the impurities are present at a higher effective concentration which would lead to more rapid decomposition of the initial SEI components and the observation of a more complicated SEI.

The observed decomposition reactions of the initial SEI components coupled with the observed changes to the SEI composition upon aging lead to the following proposed mechanism for the evolution of the SEI (Figure 1-3). The initial SEI is composed primarily LEDC and LiF. However, LEDC is unstable and decomposes to generate a complicated mixture of products, as described above. Since some of these components are soluble in the electrolyte or gasses. The remaining insoluble SEI becomes more porous. In addition, the residual insoluble components are predominantly inorganic: $\mathrm{LiF}, \mathrm{Li}_{2} \mathrm{CO}_{3}$, and $\mathrm{Li}_{2} \mathrm{O}$. The remaining insoluble components become the inner, more inorganic SEI. At the same time, since the SEI has become more porous, electrolyte can reach the surface of the graphite electrode resulting in further reduction of the electrolyte to generate additional LEDC and LiF. The new electrolyte reduction reactions result in the generation of the outer SEI. Repeated decomposition and reduction reactions at the anode result in a thickening of the SEI as the cells age with an overall increase in the content of insoluble inorganic species along with a layering of materials, and inner SEI composed primarily of inorganic species and an outer SEI primarily composed of solvent reduction products. Previous investigations have suggested that capacity loss and impedance growth associated with SEI thickening decrease with cycle number. ${ }^{24,41}$ The model proposed in this work is in 
agreement with these investigations since over time the inner SEI would be dominated by stable components, $\mathrm{LiF}$ and $\mathrm{Li}_{2} \mathrm{O}$, and $\mathrm{LEDC}$ decomposition would decrease. However, small volumetric changes of graphite upon lithiation and delithiation could contribute to some additional slow growth.

\section{[FIGURE 1-3]}

\section{Electrolyte additives}

There are numerous electrolyte additives that have been reported to improve the stability of the anode SEI generated from $\mathrm{LiPF}_{6} /$ carbonate electrolytes. Two of the most frequently investigated additives are VC and FEC. ${ }^{24,42-47}$ Both VC and FEC have been reported to be preferentially reduced on the anode to produce a "superior" SEI leading to improved cycle life for lithium-ion batteries. However, the source of the "superior" performance remains unclear.

The reduction reactions of $\mathrm{VC}$ have been reported to inhibit the reduction of EC resulting in a decrease in the generation of LEDC and ethylene. ${ }^{10,48} \mathrm{VC}$ is preferentially reduced to generate poly $(\mathrm{VC})$ and $\mathrm{CO}_{2} \cdot{ }^{21}$ As discussed above, the $\mathrm{CO}_{2}$ generated from the decomposition of $\mathrm{VC}$ is further reduced to generate $\mathrm{Li}_{2} \mathrm{CO}_{3}$. In addition to changing the composition of the SEI, TEM investigations of electrolytes containing VC suggest that the SEI is thinner than that observed for standard electrolyte formulations. Investigation of VC by reduction with lithium napthalenide provides similar results. ${ }^{48}$ The observed products include poly(VC) and $\mathrm{Li}_{2} \mathrm{CO}_{3}$. Interestingly, the polymerization of $\mathrm{VC}$ by lithium napthalenide is catalytic, 0.1 equivalent of lithium napthalenide will polymerize 1.0 equivalent of $\mathrm{VC}$. The 
polymerization of $\mathrm{VC}$ to make poly $(\mathrm{VC})$ has been reported by many research groups. However, the relative importance of poly $(\mathrm{VC})$ and $\mathrm{Li}_{2} \mathrm{CO}_{3}$ to the improved performance of the anode SEI is unclear. The use of $\mathrm{CO}_{2}$ as an electrolyte additive to generate a $\mathrm{Li}_{2} \mathrm{CO}_{3}$-rich $\mathrm{SEI}$ also provides a significant improvement in cycling performance. ${ }^{13,49}$

The initial reduction reactions of FEC containing electrolytes also inhibit the formation of LEDC and ethylene and many of the observed products are very similar to the reduction products of $\mathrm{VC}\left(\operatorname{poly}(\mathrm{VC}), \mathrm{CO}_{2}\right.$, and $\left.\mathrm{Li}_{2} \mathrm{CO}_{3}\right){ }^{10,48}$ However, additional reduction products $\mathrm{LiF}$ and $\mathrm{H}_{2}$ are also observed. TEM investigations of electrolytes containing FEC suggest that the SEI is thinner than that observed for standard electrolyte formulations without FEC, similar to that observed for electrolytes containing VC. The investigation of the reduction of FEC by lithium napthalenide provides similar results to those observed on graphite anodes in which reduction of FEC leads to the formation of poly $(\mathrm{VC}), \mathrm{Li}_{2} \mathrm{CO}_{3}, \mathrm{LiF}$, and $\mathrm{CO}_{2}$. Further investigations of the lithium napthalenide reduction of FEC under dilute conditions reveal that FEC is initially reduced to form $\mathrm{VC}$ and $\mathrm{LiF}$ and then the $\mathrm{VC}$ is further reduced to make poly- $\mathrm{VC}$ and $\mathrm{Li}_{2} \mathrm{CO}_{3}$. The polymerization reaction of $\mathrm{FEC}$ is stoichiometric and requires 1 equivalent of lithium napthalenide to convert 1 equivalent of FEC to poly(VC). In addition, the use of FEC with silicon or lithium metal electrodes results in the generation of nano-structured LiF particles. ${ }^{50,51}$ A related grainy SEI is observed on graphite anodes suggesting that incorporation of FEC may result in both a change to the composition and the morphology of the SEI. ${ }^{48}$ 
The differences in reduction products ( $\mathrm{LiF}$ for FEC) and reaction mechanism (catalytic for $\mathrm{VC}$ vs stoichiometric for FEC) contribute to the performance differences between VC and FEC. ${ }^{21}$ The differences in SEI structure are summarized in Figure 14A and $\mathrm{B}$. The preferential reduction of $\mathrm{VC}$ results in a decrease in the concentration of LEDC and an increase in the concentration of $\mathrm{Li}_{2} \mathrm{CO}_{3}$ in the anode SEI. In addition, poly $(\mathrm{VC})$ is also present in the SEI. Since the polymerization of $\mathrm{VC}$ is catalytic, the molecular weight of the poly(VC) is likely high with significant crosslinking. However, it is unclear at this time if the improved stability of the VC derived SEI results from the presence of the poly $(\mathrm{VC})$ or from the presence of the more stable $\mathrm{Li}_{2} \mathrm{CO}_{3}{ }^{52}$ The preferential reduction of FEC also results in a decrease in the concentration of LEDC and an increase in the concentration of $\mathrm{Li}_{2} \mathrm{CO}_{3}$ in the SEI. However, higher concentrations of $\mathrm{LiF}$ are also observed from the reduction of FEC to generate $\mathrm{LiF}$. While reduction of FEC results in the generation of poly(VC), the polymerization of FEC is a stoichiometric reaction which likely leads to the generation of lower molecular weight poly(VC) with less crosslinking. The different reduction reactions and products leads to the performance differences for VC and FEC.

[FIGURE 1-4] 


\section{PERSPECTIVES}

Since there is significant interest in utilizing lithium ion batteries for electric vehicles, the development of methods to generate a stable anode SEI which is a key factor for the performance of lithium ion batteries are essential. In addition, widespread implementation of electric vehicles will require lowering production costs and improving fast charging. The long time associated with formation cycling $(\sim 1$ week) is costly for manufacturers while the resistance associated with lithium ion transport through the SEI limits the charging rate for lithium ion batteries. Finally, the development of the next generation anode materials such as silicon or lithium metal is dependent upon the development of superior passivation layers to stabilize these high capacity anode materials. Thus, developing a better understanding of the formation mechanisms, decomposition mechanisms, and ion transport mechanisms of the anode SEI is imperative.

1. Role of current electrolytes in SEI stability. The initial development of electrolytes for lithium ion batteries primarily followed empirical observations. The community was fortunate to discover that EC actively passivates graphite which has enabled the lithium ion battery revolution. However, the instability of the SEI components leads to decomposition resulting in a thickening of the SEI, loss of capacity, and increased cell resistance. Improving the stability and lithium ion conductivity of the anode SEI will lead to improved performance of lithium ion batteries. 
2. Role of electrolyte additives in SEI function. Incorporation of electrolyte additives such as VC or FEC results in modification of the SEI composition and the generation of more stable SEI components, $\mathrm{Li}_{2} \mathrm{CO}_{3}$ and poly(VC). The improved stability of the SEI components impedes the decomposition, evolution, and thickening of the SEI. However, the development of a better understanding of the source of improved stability $\left(\mathrm{Li}_{2} \mathrm{CO}_{3}\right.$ vs poly $\left.(\mathrm{VC})\right)$ is critical for the development of superior electrolyte additives and the design of a superior anode SEI. While VC and FEC are used to improve the stability of the SEI, electrolyte additives have also been investigated to improve the lithium ion conductivity of the SEI for faster charging or improved low temperature performance. However, the mechanisms of how these additives function and how the SEI is modified are poorly understood. In order to develop the next generation of lithium ion batteries, an understanding of how electrolyte additives modify the composition, morphology, and lithium ion transport of the SEI must be established.

3. Role of formation cycling in SEI structure and stability. Commercial lithium ion batteries undergo a very carefully planned formation process to generate a "good" anode SEI. Formation cycling is a slow process encompassing the first 4-6 cycles which usually takes about a week and is a very costly process for manufacturers. However, it is still unknown why slow formation cycling is required. Most investigations suggest that the composition of the SEI does not depend upon the rate of initial formation cycling. The primary reduction product of EC is LEDC regardless of charging rate. Thus, the slow formation 
process most likely generates an SEI with a better morphology. Improving our understanding of the effect of formation cycling on the structure and properties of SEI is required to develop alternative formation methods which require less time and therefore reduced cost.

4. Role of morphology in SEI function. While the composition of the SEI on graphite anodes for lithium batteries has been thoroughly investigated for decades, the role of morphology in SEI performance has received less attention. However, recent investigations suggest that the nanostructure of the SEI may play a very important role in SEI performance. The utilization of advanced microscopy techniques including cryogenic TEM, ultra-high resolution SEM, and tip-enhanced Raman spectroscopy need to be utilized in combination with advanced computational methods to develop a better understanding of the role of nano-structure and nano-particle grain boundaries in lithium ion transport through the SEI. A future direction could involve methods to dope the interfaces of SEI particles to create highly lithium ion conducting channels through the SEI resulting in much faster charging rates.

5. Developing a pre-formed SEI on graphite anodes. Currently electrolyte additives are used to modify the SEI on commercial lithium ion batteries. However, a stronger understanding of the structure and function of the SEI could lead to methods to generate a pre-formed SEI on graphite anodes. The generation of the SEI results in a significant loss in capacity during the initial formation cycles in commercial cells $(\sim 10 \%)$. A pre-formed stable 
nanostructured film on the graphite surface could lead to a reduction in both initial capacity losses and the time required for initial formation cycling.

6. The SEI on silicon anodes. Silicon anodes which are considered to be a promising next generation anode material due to high reversible capacity have unique problems related to the large volumetric changes upon lithiation and delithiation. While the large volumetric changes cause significant mechanical problems, they also result in poor stability of the SEI. Thus, an optimal SEI for silicon anodes is different than one for graphite anodes. Both good ionic conductivity and good elasticity are needed for the SEI on silicon anodes. One of the most frequently utilized electrolyte additives for silicon anodes is FEC which generates and SEI with both high concentrations of $\mathrm{LiF}$ and an elastic polymer. Developing a better understanding of the surface stabilization imparted by this polymer inorganic composite surface film will lead to the design of superior interfacial polymer inorganic composite surface films and improved cycling performance for silicon anodes. These interfacial films could result from the decomposition reactions of electrolyte additives or from preformed interfaces. Reactions of binders with the surface of silicon anodes have also been reported to generate a pre-formed SEI which improves the performance of silicon anodes. Thus, designing superior binders for silicon anodes is another potentially interesting route.

7. The SEI on lithium metal anodes. There is significant interest in lithium metal anodes for lithium batteries due to the high theoretical capacity and low reduction potential. The initial reduction products of the electrolyte on lithium 
metal anodes are similar to those reported for graphite anodes, LEDC and LiF. However, LEDC has much poorer stability on lithium metal anodes leading to poor passivation. In addition, the generation of lithium dendrites is also a large problem for lithium metal anodes. Modification of the electrolyte has been reported to significantly improve the efficiency of lithium plating and stripping and inhibit dendrite growth. Most recent electrolytes developed for lithium metal anodes utilize formulations which generate high concentrations of LiF in the SEI. The presence of LiF presumably contributes to passivation of the lithium metal surface and inhibition of dendrite growth. However, the mechanism of these improvements is unclear. Developing a better understanding of the nanostructure of the LiF rich films and the mechanism of lithium ion transport and dendrite inhibition for the $\mathrm{LiF}$ rich surface films is critical for the development of the next generation of lithium batteries with lithium metal anodes. Surface pre-treatment of the lithium metal may also lead to large improvements in performance. However, the surface films must be sufficiently flexible to tolerate the volume changes associated with plating and stripping, but also sufficiently rigid to inhibit dendrite growth. Thus, polymer inorganic composite surface films are desired targets. 
ACKNOWLEDGEMENTS

We thank the Department of Energy-Established Program to Stimulate Competitive

Research (DOE-EPSCoR) for support of this research.

\section{DECLARATION OF INTEREST}

The authors declare no competing interests. 
FIGURES

a)
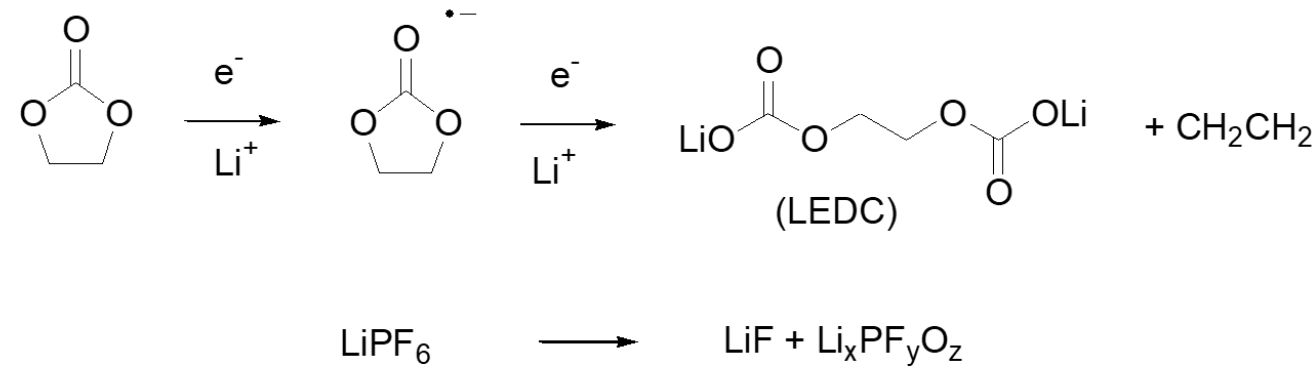

b)

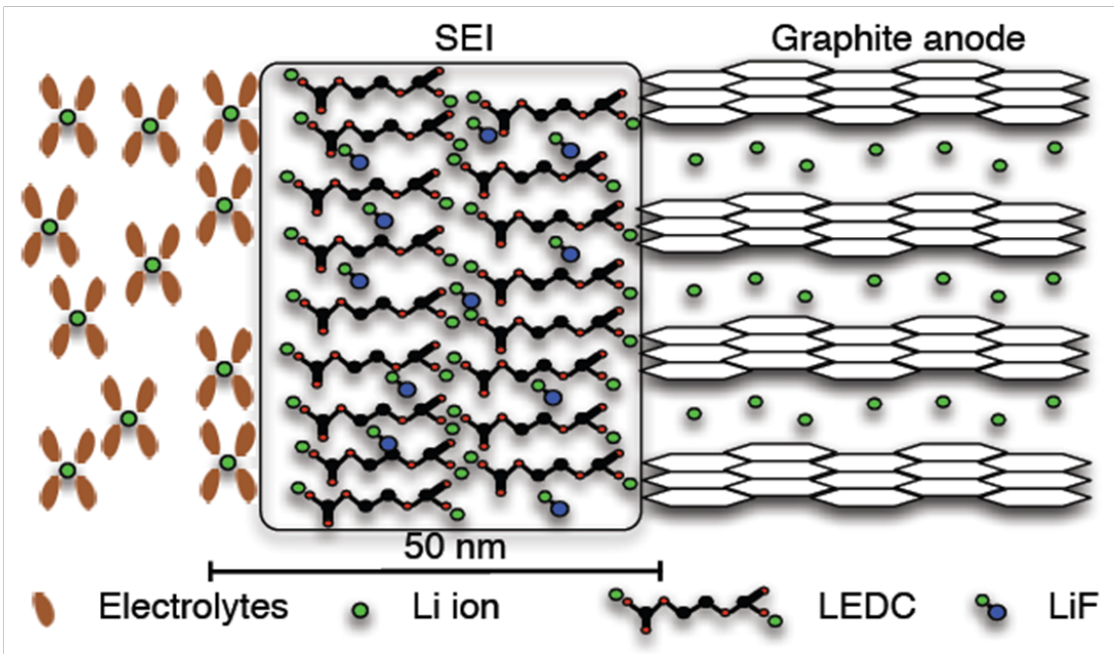

Figure 1-1. a) Initial reduction reactions of EC on the graphite electrode interface. b) Schematic figure of the initial SEI formed on graphite surface during the first cycle of a lithium ion battery.15 Figure 1-1. A) Initial reduction reactions of EC on the graphite 


$$
\begin{aligned}
& \mathrm{R}_{\mathrm{O}} \stackrel{\mathrm{O}}{\mathrm{H}} \stackrel{\mathrm{H}_{2} \mathrm{O}}{\longrightarrow} \quad \mathrm{Li}_{2} \mathrm{CO}_{3}+\mathrm{CO}_{2}+\mathrm{LiOR} \quad \mathrm{A} \\
& \mathrm{O}_{2} / \mathrm{H}^{+} / \mathrm{OH}^{-} \\
& \mathrm{Li}_{2} \mathrm{CO}_{3} \stackrel{\mathrm{LiPF}_{6}}{\Delta} \longrightarrow 2 \mathrm{CO}_{2}+4 \mathrm{LiF} \\
& \text { LEDC } \longrightarrow \mathrm{LiPF}_{6} \mathrm{LiF}+\mathrm{CO}_{2}+\mathrm{LiOCH}_{2} \mathrm{CH}_{2} \mathrm{OLi}+\mathrm{OP}\left(\mathrm{OCH}_{3}\right)_{3} \\
& \Delta
\end{aligned}
$$

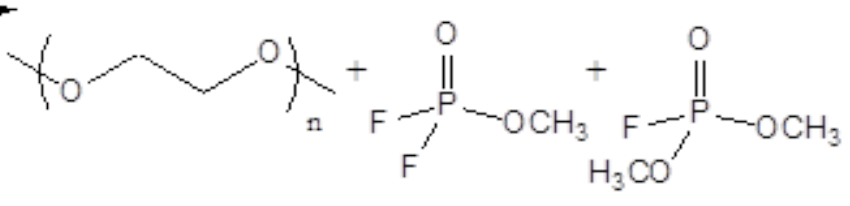

$$
\begin{aligned}
& \mathrm{LEDC} \longrightarrow \mathrm{Li}_{2} \mathrm{CO}_{3}+\mathrm{Li}_{2} \mathrm{O}+\mathrm{CO}_{2}+\mathrm{C}_{2} \mathrm{H}_{4}+\mathrm{CH}_{3} \mathrm{CH}_{2} \mathrm{CO}_{2} \mathrm{Li}
\end{aligned}
$$

Figure 1-2. The primary decomposition reactions of the SEI components lithium ethylene dicarbonate (LEDC) and $\mathrm{Li}_{2} \mathrm{CO}_{3}$. 


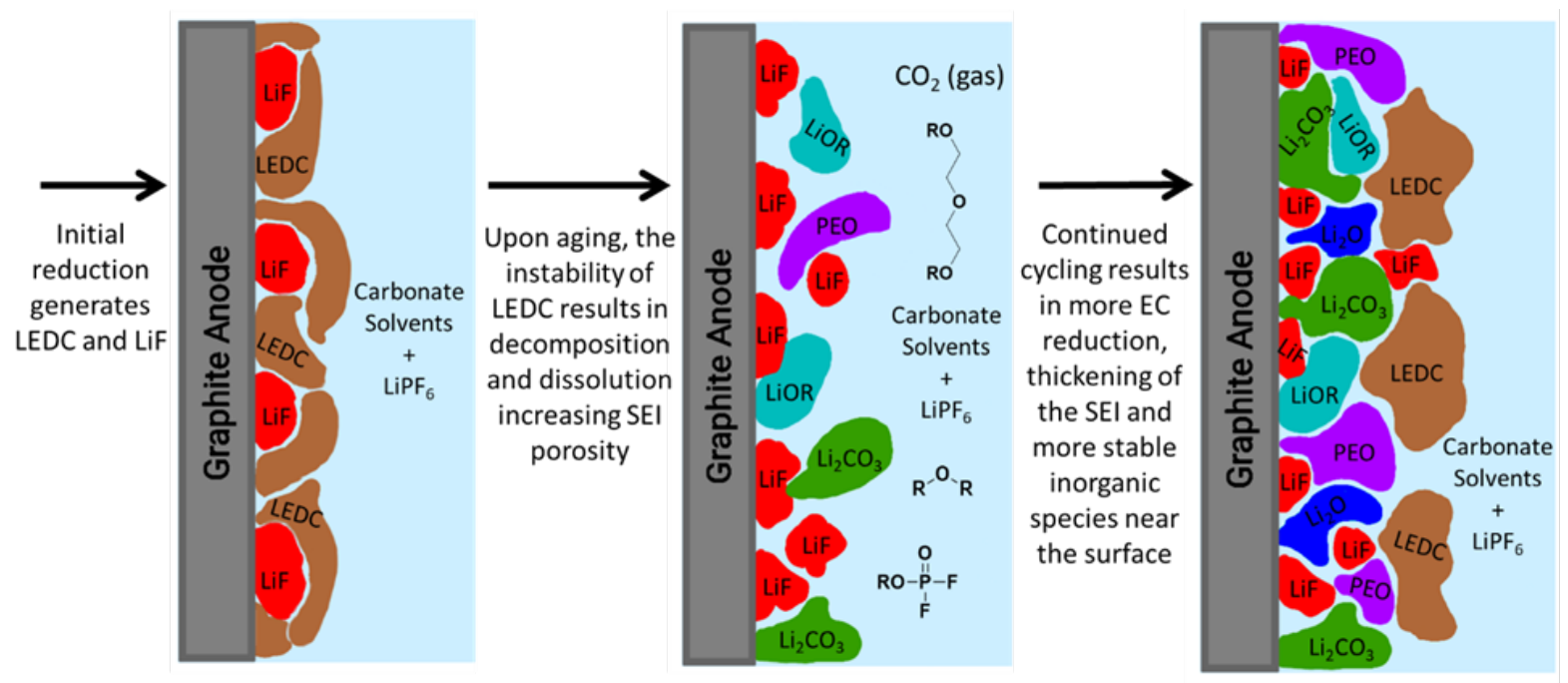

Figure 1-3. Schematic figure of the initial SEI formed on the graphite anode, the effect of acid mediated thermal decomposition reactions on the structure of the SEI, and the further reduction of electrolyte leading to the thickening of the SEI. 

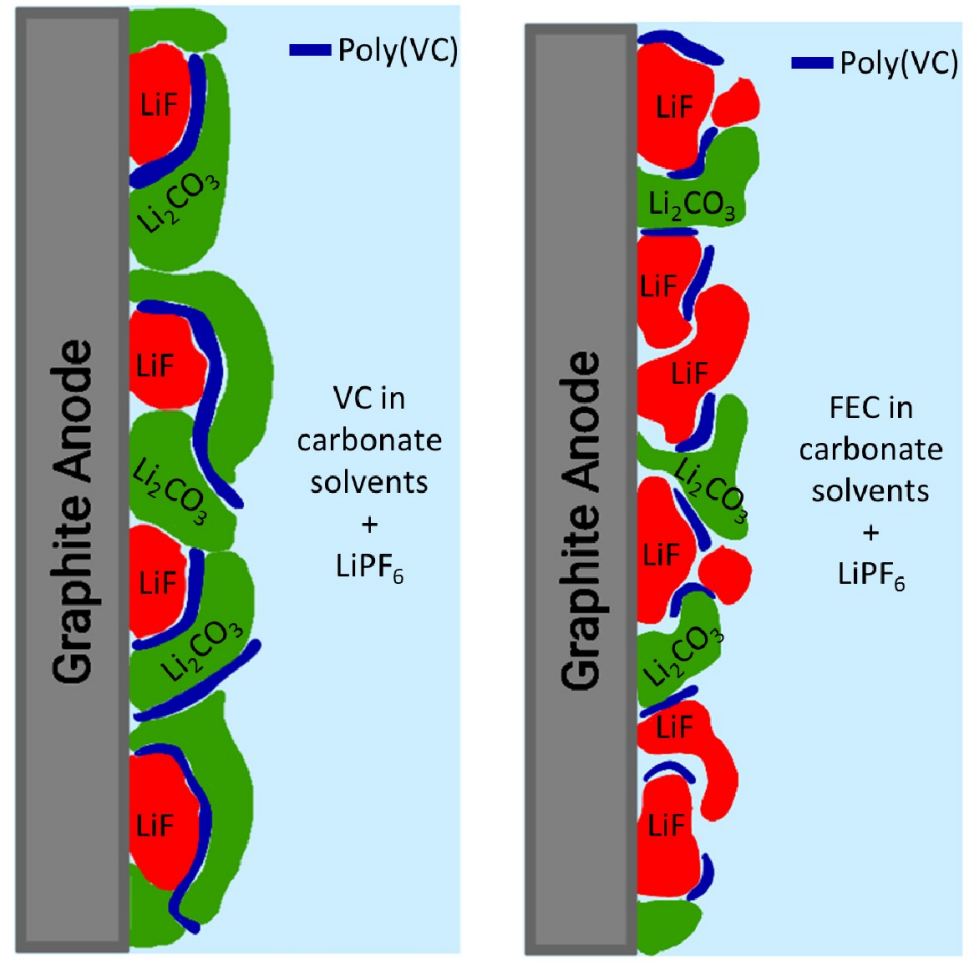

Figure 1-4. Schematic figures of the initial SEI generated on graphite anodes for electrolytes containing VC (left) or FEC (right). 


\section{REFERENCES}

(1) Fong, R.; von Sacken, U.; Dahn, J. R. Studies of Lithium Intercalation into Carbons Using Nonaqueous Electrochemical Cells. J. Electrochem. Soc. 1990, 137 (7), 2009-2013. https://doi.org/10.1149/1.2086855.

(2) Peled, E. The Electrochemical Behavior of Alkali and Alkaline Earth Metals in Nonaqueous Battery Systems-The Solid Electrolyte Interphase Model. J. Electrochem. Soc. 1979, 126 (12), 2047-2051. https://doi.org/10.1149/1.2128859.

(3) Aurbach, D.; Markovsky, B.; Shechter, A.; Ein-Eli, Y.; Cohen, H. A Comparative Study of Synthetic Graphite and Li Electrodes in Electrolyte Solutions Based on Ethylene Carbonate-Dimethyl Carbonate Mixtures. J. Electrochem. Soc. 1996, 143 (12), 3809-3820. https://doi.org/10.1149/1.1837300.

(4) $\mathrm{Xu}, \mathrm{K}$. Nonaqueous Liquid Electrolytes for Lithium-Based Rechargeable Batteries. Chem. Rev. 2004, 104 (10), 4303-4417.

https://doi.org/10.1021/cr030203g.

(5) Verma, P.; Maire, P.; Novák, P. A Review of the Features and Analyses of the Solid Electrolyte Interphase in Li-Ion Batteries. Electrochim. Acta 2010, 55 (22), 6332-6341. https://doi.org/10.1016/j.electacta.2010.05.072.

(6) $\mathrm{Xu}, \mathrm{K}$. Electrolytes and Interphases in Li-Ion Batteries and Beyond. Chem. Rev. 2014, 114 (23), 11503-11618. https://doi.org/10.1021/cr500003w. 
(7) Peled, E.; Menkin, S. Review-SEI: Past, Present and Future. J. Electrochem. Soc. 2017, 164 (7), A1703-A1719. https://doi.org/10.1149/2.1441707jes.

(8) Nanda, J.; Yang, G.; Hou, T.; Voylov, D. N.; Li, X.; Ruther, R. E.; Naguib, M.; Persson, K.; Veith, G. M.; Sokolov, A. P. Unraveling the Nanoscale Heterogeneity of Solid Electrolyte Interphase Using Tip-Enhanced Raman Spectroscopy. Joule 2019.

https://doi.org/https://doi.org/10.1016/j.joule.2019.05.026.

(9) Louli, A. J.; Ellis, L. D.; Dahn, J. R. Operando Pressure Measurements Reveal Solid Electrolyte Interphase Growth to Rank Li-Ion Cell Performance. Joule 2019, 3 (3), 745-761. https://doi.org/10.1016/j.joule.2018.12.009.

(10) Zhang, B.; Metzger, M.; Solchenbach, S.; Payne, M.; Meini, S.; Gasteiger, H. A.; Garsuch, A.; Lucht, B. L. Role of 1,3-Propane Sultone and Vinylene Carbonate in Solid Electrolyte Interface Formation and Gas Generation. J. Phys. Chem. C 2015, 119 (21), 11337-11348.

https://doi.org/10.1021/acs.jpcc.5b00072.

(11) Aurbach, D.; Gofer, Y.; Ben-Zion, M.; Aped, P. The Behaviour of Lithium Electrodes in Propylene and Ethylene Carbonate: Te Major Factors That Influence Li Cycling Efficiency. J. Electroanal. Chem. 1992, 339 (1-2), 451471. https://doi.org/10.1016/0022-0728(92)80467-I. 
(12) Zhuang, G. V.; Xu, K.; Yang, H.; Jow, T. R.; Ross, P. N. Lithium Ethylene Dicarbonate Identified as the Primary Product of Chemical and Electrochemical Reduction of EC in 1.2 M LiPF 6 /EC:EMC Electrolyte. $J$. Phys. Chem. B 2005, 109 (37), 17567-17573.

https://doi.org/10.1021/jp052474w.

(13) Aurbach, D.; Ein-Eli, Y.; Chusid (Youngman), O.; Carmeli, Y.; Babai, M.; Yamin, H. The Correlation Between the Surface Chemistry and the Performance of Li-Carbon Intercalation Anodes for Rechargable "RockingChair” Type Batteries. J. Electrochem. Soc. 1994, 141 (3), 603-611.

(14) Xu, K.; Zhuang, G. V.; Allen, J. L.; Lee, U.; Zhang, S. S.; Ross, P. N.; Jow, T. R. Syntheses and Characterization of Lithium Alkyl Mono- and Dicarbonates as Components of Surface Films in Li-Ion Batteries. J. Phys. Chem. B 2006, 110 (15), 7708-7719. https://doi.org/10.1021/jp0601522.

(15) Nie, M.; Chalasani, D.; Abraham, D. P.; Chen, Y.; Bose, A.; Lucht, B. L. Lithium Ion Battery Graphite Solid Electrolyte Interphase Revealed by Microscopy and Spectroscopy. J. Phys. Chem. C 2013, 117 (3), 1257-1267. https://doi.org/10.1021/jp3118055.

(16) Strehle, B.; Solchenbach, S.; Metzger, M.; Schwenke, K. U.; Gasteiger, H. A. The Effect of $\mathrm{CO} 2$ on Alkyl Carbonate Trans-Esterification during Formation of Graphite Electrodes in Li-Ion Batteries. J. Electrochem. Soc. 2017, 164 (12), A2513-A2526. https://doi.org/10.1149/2.1001712jes. 
(17) Liu, T.; Lin, L.; Bi, X.; Tian, L.; Yang, K.; Liu, J.; Li, M.; Chen, Z.; Lu, J.; Amine, K.; et al. In Situ Quantification of Interphasial Chemistry in Li-Ion Battery. Nat. Nanotechnol. 2019, 14 (1), 50-56.

https://doi.org/10.1038/s41565-018-0284-y.

(18) Xiong, D. J.; Ellis, L. D.; Nelson, K. J.; Hynes, T.; Petibon, R.; Dahn, J. R. Rapid Impedance Growth and Gas Production at the Li-Ion Cell Positive Electrode in the Absence of a Negative Electrode. J. Electrochem. Soc. 2016, 163 (14), A3069-A3077. https://doi.org/10.1149/2.1031614jes.

(19) Seo, D. M.; Chalasani, D.; Parimalam, B. S.; Kadam, R.; Nie, M.; Lucht, B. L. Reduction Reactions of Carbonate Solvents for Lithium Ion Batteries. ECS Electrochem. Lett. 2014, 3 (9), A91-A93. https://doi.org/10.1149/2.0021409eel.

(20) Heiskanen, S. K.; Lucht, B. L. Investigation of CO2 Reduction Products in Lithium Ion Batteries Using Model Systems. ECS Meet. Abstr. 2018, MA2018$01,496$.

(21) Michan, A. L.; Parimalam, B. S.; Leskes, M.; Kerber, R. N.; Yoon, T.; Grey, C. P.; Lucht, B. L. Fluoroethylene Carbonate and Vinylene Carbonate Reduction: Understanding Lithium-Ion Battery Electrolyte Additives and Solid Electrolyte Interphase Formation. Chem. Mater. 2016, 28 (22), 8149-8159. https://doi.org/10.1021/acs.chemmater.6b02282. 
(22) Parimalam, B. S.; Lucht, B. L. Reduction Reactions of Electrolyte Salts for Lithium Ion Batteries: LiPF 6 , LiBF 4 , LiDFOB, LiBOB, and LiTFSI. $J$. Electrochem. Soc. 2018, 165 (2), A251-A255.

https://doi.org/10.1149/2.0901802jes.

(23) Herstedt, M.; Abraham, D. P.; Kerr, J. B.; Edström, K. X-Ray Photoelectron Spectroscopy of Negative Electrodes from High-Power Lithium-Ion Cells Showing Various Levels of Power Fade. Electrochim. Acta 2004, 49 (28), 5097-5110. https://doi.org/10.1016/j.electacta.2004.06.021.

(24) Broussely, M.; Biensan, P.; Bonhomme, F.; Blanchard, P.; Herreyre, S.; Nechev, K.; Staniewicz, R. J. Main Aging Mechanisms in Li Ion Batteries. J. Power Sources 2005, 146 (1-2), 90-96. https://doi.org/10.1016/j.jpowsour.2005.03.172.

(25) Vetter, J.; Novák, P.; Wagner, M. R.; Veit, C.; Möller, K.-C.; Besenhard, J. O.; Winter, M.; Wohlfahrt-Mehrens, M.; Vogler, C.; Hammouche, A. Ageing Mechanisms in Lithium-Ion Batteries. J. Power Sources 2005, 147 (1-2), 269281. https://doi.org/10.1016/j.jpowsour.2005.01.006.

(26) Shi, S.; Lu, P.; Liu, Z.; Qi, Y.; Hector, L. G.; Li, H.; Harris, S. J. Direct Calculation of Li-Ion Transport in the Solid Electrolyte Interphase. J. Am. Chem. Soc. 2012, 134 (37), 15476-15487. https://doi.org/10.1021/ja305366r.

(27) Wang, A.; Kadam, S.; Li, H.; Shi, S.; Qi, Y. Review on Modeling of the Anode Solid Electrolyte Interphase (SEI) for Lithium-Ion Batteries. $n p j$ Comput. Mater. 2018, 4 (15), 1-26. https://doi.org/10.1038/s41524-018-00640 . 
(28) Edström, K.; Herstedt, M.; Abraham, D. P. A New Look at the Solid Electrolyte Interphase on Graphite Anodes in Li-Ion Batteries. J. Power Sources 2006, 153 (2), 380-384.

https://doi.org/10.1016/j.jpowsour.2005.05.062.

(29) Cao, C.; Abate, I. I.; Sivonxay, E.; Shyam, B.; Jia, C.; Moritz, B.; Devereaux, T. P.; Persson, K. A.; Steinrück, H. G.; Toney, M. F. Solid Electrolyte Interphase on Native Oxide-Terminated Silicon Anodes for Li-Ion Batteries. Joule 2019, 3 (3), 762-781. https://doi.org/10.1016/j.joule.2018.12.013.

(30) Caley, E. R.; Elving, P. J. Purification of Lithium Carbonate. In Inorganic Syntheses; Audrieth, L. F., Gibbs, C. F., Johnson, W. C., Perrin, H. C., Eds.; McGraw-Hill Book Company: New York City, 1939; Vol. 1, pp 1-2. https://doi.org/10.1002/9780470132326.ch26.

(31) Campion, C. L.; Li, W.; Lucht, B. L. Thermal Decomposition of LiPF6-Based Electrolytes for Lithium-Ion Batteries. J. Electrochem. Soc. 2005, 152 (12), A2327-A2334. https://doi.org/10.1149/1.2083267.

(32) Sloop, S. E.; Kerr, J. B.; Kinoshita, K. The Role of Li-Ion Battery Electrolyte Reactivity in Performance Decline and Self-Discharge. J. Power Sources 2003, 119-121, 330-337. https://doi.org/10.1016/S0378-7753(03)00149-6.

(33) Kim, J.; Lee, J. G.; Kim, H.; Lee, T. J.; Park, H.; Ryu, J. H.; Oh, S. M. Thermal Degradation of Solid Electrolyte Interphase (SEI) Layers by Phosphorus Pentafluoride (PF 5 ) Attack. J. Electrochem. Soc. 2017, 164 (12), A2418-A2425. https://doi.org/10.1149/2.0761712jes. 
(34) Wang, R.; Li, X.; Wang, Z.; Zhang, H. Electrochemical Analysis Graphite/Electrolyte Interface in Lithium-Ion Batteries: P-Toluenesulfonyl Isocyanate as Electrolyte Additive. Nano Energy 2017, 34 (February), 131140. https://doi.org/10.1016/j.nanoen.2017.02.037.

(35) Kim, J.; Kim, H.; Lee, J. G.; Jeong, H.; Ryu, J. H.; Oh, S. M. Communication—A Phosphorus Pentafluoride Scavenger to Suppress Solid Electrolyte Interphase Damage at Moderately Elevated Temperature. $J$. Electrochem. Soc. 2017, 164 (14), A3699-A3701. https://doi.org/10.1149/2.0691714jes.

(36) Parimalam, B. S.; MacIntosh, A. D.; Kadam, R.; Lucht, B. L. Decomposition Reactions of Anode Solid Electrolyte Interphase (SEI) Components with LiPF 6. J. Phys. Chem. C 2017, 121 (41), 22733-22738. https://doi.org/10.1021/acs.jpcc.7b08433.

(37) Kato, R.; Suzuki, H.; Sasahara, J.; Suzuki, H. METHOD FOR PRODUCING DIFLUOROPHOSPHATE, NON-AQUEOUS ELECTROLYTE FOR SECONDARY CELL AND NON-AQUEOUSELECTROLYTE SECONDARY CELL. US 9,593,016 B2, 2017.

(38) Yoon, T.; Milien, M. S.; Parimalam, B. S.; Lucht, B. L. Thermal Decomposition of the Solid Electrolyte Interphase (SEI) on Silicon Electrodes for Lithium Ion Batteries. Chem. Mater. 2017, 29 (7), 3237-3245. https://doi.org/10.1021/acs.chemmater.7b00454. 
(39) Young, B. T.; Heskett, D. R.; Nguyen, C. C.; Nie, M.; Woicik, J. C.; Lucht, B. L. Hard X-Ray Photoelectron Spectroscopy (HAXPES) Investigation of the Silicon Solid Electrolyte Interphase (SEI) in Lithium-Ion Batteries. ACS Appl. Mater. Interfaces 2015, 7 (36), 20004-20011. https://doi.org/10.1021/acsami.5b04845.

(40) Latz, A.; Zausch, J. Multiscale Modeling of Lithium Ion Batteries: Thermal Aspects. Beilstein J. Nanotechnol. 2015, 6 (1), 987-1007. https://doi.org/10.3762/bjnano.6.102.

(41) Yoshida, T.; Takahashi, M.; Morikawa, S.; Ihara, C.; Katsukawa, H.; Shiratsuchi, T.; Yamaki, J. Degradation Mechanism and Life Prediction of Lithium-Ion Batteries. J. Electrochem. Soc. 2006, 153 (3), A576. https://doi.org/10.1149/1.2162467.

(42) Abe, K.; Yoshitake, H.; Kitakura, T.; Hattori, T.; Wang, H.; Yoshio, M. Additives-Containing Functional Electrolytes for Suppressing Electrolyte Decomposition in Lithium-Ion Batteries. Electrochim. Acta 2004, 49 (26), 4613-4622. https://doi.org/10.1016/j.electacta.2004.05.016.

(43) Zhang, S. S. A Review on Electrolyte Additives for Lithium-Ion Batteries. J. Power Sources 2006, 162 (2), 1379-1394. https://doi.org/10.1016/j.jpowsour.2006.07.074.

(44) Etacheri, V.; Haik, O.; Goffer, Y.; Roberts, G. A.; Stefan, I. C.; Fasching, R.; Aurbach, D. Effect of Fluoroethylene Carbonate (FEC) on the Performance and Surface Chemistry of Si-Nanowire Li-Ion Battery Anodes. Langmuir 2012, 28 (1), 965-976. https://doi.org/10.1021/la203712s. 
(45) Aurbach, D.; Talyosef, Y.; Markovsky, B.; Markevich, E.; Zinigrad, E.; Asraf, L.; Gnanaraj, J. S.; Kim, H.-J. Design of Electrolyte Solutions for Li and LiIon Batteries: A Review. Electrochim. Acta 2004, 50 (2-3), 247-254. https://doi.org/10.1016/j.electacta.2004.01.090.

(46) Aurbach, D.; Gamolsky, K.; Markovsky, B.; Gofer, Y.; Schmidt, M.; Heider, U. On the Use of Vinylene Carbonate (VC) as an Additive to Electrolyte Solutions for Li-Ion Batteries. Electrochim. Acta 2002, 47 (9), 1423-1439. https://doi.org/10.1016/S0013-4686(01)00858-1.

(47) Haregewoin, A. M.; Wotango, A. S.; Hwang, B.-J. Electrolyte Additives for Lithium Ion Battery Electrodes: Progress and Perspectives. Energy Environ. Sci. 2016, 9 (6), 1955-1988. https://doi.org/10.1039/C6EE00123H.

(48) Nie, M.; Demeaux, J.; Young, B. T.; Heskett, D. R.; Chen, Y.; Bose, A.; Woicik, J. C.; Lucht, B. L. Effect of Vinylene Carbonate and Fluoroethylene Carbonate on SEI Formation on Graphitic Anodes in Li-Ion Batteries. $J$. Electrochem. Soc. 2015, 162 (13), A7008-A7014. https://doi.org/10.1149/2.0021513jes.

(49) Besenhard, J. O.; Wagner, M. W.; Winter, M.; Jannakoudakis, P. D.; Theodorido, E. Inorganic Film-Forming Electrolyte Additives Improving the Cycling Behaviour of Metallic Lithium Electrodes and the Self-Discharge of Carbon—Lithium Electrodes. J. Power Sources 1993, 44 (1-3), 413-420. 
(50) Brown, Z. L.; Jurng, S.; Nguyen, C. C.; Lucht, B. L. Effect of Fluoroethylene Carbonate Electrolytes on the Nanostructure of the Solid Electrolyte Interphase and Performance of Lithium Metal Anodes. ACS Appl. Energy Mater. 2018, 1 (7), 3057-3062. https://doi.org/10.1021/acsaem.8b00705.

(51) Nie, M.; Abraham, D. P.; Chen, Y.; Bose, A.; Lucht, B. L. Silicon Solid Electrolyte Interphase (SEI) of Lithium Ion Battery Characterized by Microscopy and Spectroscopy. J. Phys. Chem. C 2013, 117 (26), 1340313412. https://doi.org/10.1021/jp404155y.

(52) Schwenke, K. U.; Solchenbach, S.; Demeaux, J.; Lucht, B. L.; Gasteiger, H. A. The Impact of CO 2 Evolved from VC and FEC during Formation of Graphite Anodes in Lithium-Ion Batteries. J. Electrochem. Soc. 2019, 166 (10), A2035A2047. https://doi.org/10.1149/2.0821910jes. 


\title{
CHAPTER 2
}

\section{Surface reactions of electrolyte with $\mathrm{LiNi}_{x} \mathrm{Co}_{y} \mathrm{Mn}_{z} \mathrm{O}_{2}$ cathodes for lithium ion batteries}

\author{
Satu Kristiina Heiskanen and Brett L. Lucht ${ }^{\mathrm{Z}}$ \\ University of Rhode Island, Department of Chemistry, 140 Flagg Rd., Beaupre \\ zblucht@uri.edu
}

The following is written as a manuscript and is submitted to the Journal of the Electrochemical Society for publication. 


\begin{abstract}
Layered $\mathrm{LiNi}_{\mathrm{x}} \mathrm{Mn}_{\mathrm{y}} \mathrm{Co}_{\mathrm{z}} \mathrm{O}_{2}(\mathrm{NMC})$ cathode materials with a high nickel content are among the most commonly used in modern commercial lithium ion batteries due to the increased capacity, and lower cost due to low cobalt content. However, numerous investigations have shown that cathodes increased nickel content, such as $\mathrm{N}_{0.6} \mathrm{M}_{0.2} \mathrm{C}_{0.2}$ or $\mathrm{N}_{0.8} \mathrm{M}_{0.1} \mathrm{C}_{0.1}$ suffer from rapid capacity fade due to a thickened anode solid electrolyte interphase (SEI) and gas evolution from the cathode material during cycling the root causes of which remain uncertain. One proposed degradation mechanism is the transition metal catalyzed degradation of the anode SEI. We propose that a simultaneous acidic species induced degradation of the cathode passivation film occurs, dissolving the basic species present in the film, allowing further reduction of electrolyte components on the anode.
\end{abstract}




\section{INTRODUCTION}

The most widely utilized cathode materials for lithium ion batteries are layer transition metal oxides. $\mathrm{LiCoO}_{2}$ was the most frequently utilized cathode material in the first generation of lithium ion batteries. However, there is a significant interest in the use of $\mathrm{LiNi}_{\mathrm{x}} \mathrm{Mn}_{\mathrm{y}} \mathrm{Co}_{\mathrm{z}} \mathrm{O}_{2}(\mathrm{NMC})$ cathodes with high nickel content for advanced lithium ion batteries. The increased $\mathrm{Ni}$ content is desirable since it results in improved capacity and reduced cost due to reduction of cobalt content within the cathode material. Conversely, NMC cathodes with higher nickel content have reduced cycling stability. ${ }^{1}$ Additionally, there is an interest in increasing the energy density of NMC cathodes by increasing the voltage window from $4.2 \mathrm{~V}$ to 4.4 or $4.5 \mathrm{~V}$ vs $\mathrm{Li} / \mathrm{Li}^{+}$. However, cycling NMC cathodes to higher potential also results in a decrease in cycling stability. There have been a significant number of investigations as to the underlying causes of the cycling instabilities of nickel rich NMC or NMC cathodes cycled to high potential. In this perspective, we will focus our efforts on the reactions of surface of the cathode with electrolyte. We wish to acknowledge that there are other aspects of the cathode material which contribute to performance fade which will not be covered in this perspective; these include problems with lithium-nickel cation mixing in NMC materials with high nickel content and increased particle cracking and related increased surface area of cathode particles upon prolonged cycling. These topics have been recently reviewed and we direct the readers to the following references. $^{2,3}$ 


\section{CURRENT STATUS}

Current lithium ion batteries have excellent cycling stability under standard operating conditions. As the technology has developed, the desire for increased energy density and lower cost has driven interest in the cathode materials with both higher capacity and higher cutoff potential. However, this has resulted in a decrease in cycle and calendar life. One of the contributing factors to this performance fade is the reaction of the electrolyte with the surface of NMC cathode materials. However, at this time a strong understanding of the role of electrolyte in performance fade of NMC cathode materials is unclear. ${ }^{4-6}$

The most common cathode materials utilized in commercial lithium ion batteries are layered metal oxides. While the initial lithium metal oxide of interest was $\mathrm{LiCoO}_{2}$, the field has primarily shifted toward mixed metal oxides including $\mathrm{Ni}, \mathrm{Co}$, $\mathrm{Mn}$ and $\mathrm{Al}$. While $\mathrm{LiNi}_{0.8} \mathrm{Co}_{1.5} \mathrm{Al}_{0.5}$ and related materials have also been rigorously investigated, this perspective will focus on $\mathrm{LiNi}_{\mathrm{x}} \mathrm{Mn}_{\mathrm{y}} \mathrm{Co}_{\mathrm{z}} \mathrm{O}_{2}(\mathrm{NMC})$. Variation in initial capacity of NMC cycled to $4.2 \mathrm{~V}$ shows a clear trend to higher capacity with higher nickel content. Upon increasing the nickel content from $33 \%$ to $80 \%$ capacity increases from $155 \mathrm{mAh} / \mathrm{g}$ to $210 \mathrm{mAh} / \mathrm{g}$. However, this increase in capacity is coupled with both a slight increase in capacity fade and a larger increase in cell impedance upon cycling. Surprisingly, ex-situ surface analysis of NMC cathodes extracted after cycling reveals only small differences in the composition and thickness of the surface films for the NMC cathodes with different nickel contents. The similarity in surface films suggests that the capacity fade and impedance growth is not related to the decomposition reactions of the electrolyte on the NMC cathode surface. 
Analyses of the transition metal content by ICP-MS of extracted anodes cycled with NMC cathodes of different nickel content are also similar. All extracted anodes contain low concentrations of nickel, cobalt, and manganese but the difference in transition metal content is small for different cathodes and there does not appear to be a strong correlation of transition metal concentration with performance fade. Other possible degradation mechanisms include the evolution of oxygen gas and lithiumnickel cation mixing leading to a disordered phase in the cathode material, or surface reconstruction of the cathode material. ${ }^{7,8}$

The effect of cutoff voltage on NMC materials with different Ni contents has also been studied. Investigation of the cycling performance of NMC 111 cycled to either a moderate potential $(4.2 \mathrm{~V})$ or high cutoff potential $(4.5 \mathrm{~V})$, surprisingly revealed similar capacity fade for the cathodes cycled to the different potentials. However, the impedance growth for cathodes cycled to higher potential is much greater than that for cathodes cycled to lower potential. ${ }^{9}$ Electrochemical analysis of cathode-cathode and anode-anode symmetric cells, extracted from cycled full cells, clearly reveals that the impedance growth upon cycling is dominated by the cathode and that the impedance growth is significantly worse for cells cycled to high voltage. In order to develop a better understanding of the source of impedance growth, ex situ surface analysis was conducted. XPS analysis of the NMC surface reveals that surface metal oxide concentration is lower for cells cycled to $4.5 \mathrm{~V}$ than for cells cycled to $4.2 \mathrm{~V}$. This is consistent with more electrolyte decomposition to generate a thicker surface film for the cathode cycled to $4.5 \mathrm{~V}$. The surfaces of anodes were also analyzed by XPS which suggested that the surface films were very similar for cells cycled to either potential. It 
was also determined that anodes cycled to either potential contain low concentrations of transition metals but there was no clear trend in transition metal content as a function of cycling potential. Further analysis of the electrodes by IR-ATR provided supporting results. The surface of cathode cycled to $4.2 \mathrm{~V}$ contained only low concentrations of $\mathrm{Li}_{2} \mathrm{CO}_{3}$ and lithium alkyl carbonates, while cells cycled to $4.5 \mathrm{~V}$ contained stronger absorptions characteristic of lithium carbonates along with an additional peak consistent with polycarbonate at $1740 \mathrm{~cm}^{-1}$. The IR spectra of the anodes are very similar for cells cycled to either voltage, consistent with the XPS results.

Similar investigations were conducted on NMC 622 cathodes. Initial capacities were found to be higher for the cells cycled to higher potential (4.6V versus $4.3 \mathrm{~V}$ ). Unlike the observations for NMC 111, significantly more fading was observed for cells containing NMC 622 cycled to higher potential after 100 cycles. However, similar to observations for NMC 111 cells, initial cycling results in a significantly larger impedance increase for cells cycled to the higher potential than for cells cycled to the lower potential. The difference in impedance increases after 100 cycles. In an effort to develop a better understanding of the role of the electrolyte in the performance changes as a function of cutoff potential, GCMS analysis was conducted on electrolyte extracted from cycled NMC 622 cells. Initially after the first cycle there is a large increase in transesterification products, the conversion of ethyl methyl carbonate to dimethyl carbonate and diethyl carbonate, for cells cycled to either 4.3 or 4.6 V while the concentration of the transesterification products remains similar for cells cycled to both potentials. In addition, the concentration of transesterification 
products does not increase significantly with additional cycling for cells cycled at either 4.3 or $4.6 \mathrm{~V}$. Thus, there is a poor correlation between capacity fade and the side reaction of the electrolyte which generates transesterification products.

Related investigations have been conducted on cells containing cathodes with higher nickel content. NMC 811 cells were cycled to moderate and high potential, 4.2 and 4.6 V respectively (figure 2-1). Cells cycled to higher potential have significantly higher initial capacity, but the capacity fade is more severe than observed for NMC 111 or 622 cells. ${ }^{10}$ Similar to observations with NMC 111 and NMC 622 cells cycled to higher potentials have significant increases in cell impedance after cycling. In addition, there are large changes to the $\mathrm{dQ} / \mathrm{dV}$ plots for the NMC 811 cells cycled to higher potential. The increased impedance and changes to the $\mathrm{dQ} / \mathrm{dV}$ plots is likely related to changes in the $c$ parameter which leads to the generation of micro-cracks in the NMC 811 particles, as previously reported. ${ }^{11}$ Ex-situ surface analysis of the cathodes extracted from NMC 811 cells cycled to moderate and high potential was also conducted via a combination of XPS and IR-ATR, but the surface films were very similar for both cycling profiles suggesting that cathode surface film formation did not correlate with cutoff potential. In an effort to better understand the performance differences, the changes to the electrolyte were investigated. OEMS analysis of graphite-NMC 811 cells suggests similar quantities of alkyl carbonate transesterification reactions at both voltages $(4.2 \mathrm{~V}$ and $4.6 \mathrm{~V})$. However, for cells cycled to $4.6 \mathrm{~V}$, more $\mathrm{CO}_{2}$ evolution is observed, and oxygen evolution is initiated. ${ }^{12}$ No oxygen evolution is observed at lower potentials suggesting that cycling to higher potential results in irreversible changes to the bulk cathode materials, as described 
above. GCMS analysis of the extracted electrolytes confirms a large increase in transesterification products on first cycle with minimal increases in transesterification after first cycle. However, the concentration of transesterification products is similar for cells cycled to both 4.2 and $4.6 \mathrm{~V}$, consistent with results for NMC 622 cells and the OEMS results. Ex-situ surface analysis of the anodes reveals a thicker anode SEI with cells cycled to higher voltage, consistent with transition metal dissolution and damage to the anode SEI resulting in subsequent SEI thickening.

[Figure 2-1] 


\section{FUTURE NEEDS AND PROSPECTS}

Different research groups have reported different reactions of the electrolyte with NMC cathodes. However, the generally observed reactions are similar for all NMC cathodes cycled to high potential and are generally worse with higher Ni content. Some of these differences can be attributed to different materials suppliers or storage conditions of the NMC cathodes. ${ }^{13}$ NMC cathodes react slowly with dry air to generate surface films of $\mathrm{Li}_{2} \mathrm{CO}_{3}$ and different quantities of $\mathrm{Li}_{2} \mathrm{CO}_{3}$ and other surface differences could partially explain different trends for different research groups. We will attempt to summarize the various trends and propose areas for future investigation. It is important to note that there have been several reports on improved performance of NMC cathodes upon with pre-generated surface films such as $\mathrm{Al}_{2} \mathrm{O}_{3} .{ }^{14}$ This suggests that the surface of the cathode materials is very important for long term performance. Alternatively, several reports have suggested that the presence of electrolyte additives can significantly improve performance, suggesting that the electrolyte is also important.

The results discussed above suggest that while the reactions of electrolyte with the surface of NMC cathodes are important, but the build-up of electrolyte decomposition products on the surface of the cathode does not likely have a large impact on performance losses. The presence and thicknesses of surface films composed of electrolyte decomposition products poorly correlate with capacity loss and impedance. The impedance growth on the cathode more clearly correlates with the formation of a rock salt phase on the surface and related NMC particle cracking. ${ }^{7,15}$ 
While most of the impedance increases for NMC cells with high Ni content or cycled to high potential are observed on the cathode, capacity losses are typically attributed to the anode. As discussed above, SEI thickening on the anode upon cycling is dependent upon both the cut-off potential and Ni content of the cathode. The SEI thickening has typically been attributed to transition metal dissolution from the cathode and deposition on the anode. Several investigations reveal a correlation between capacity loss and transition metal content in the anode SEI. ${ }^{16}$ Alternatively, other research has reported poor correlation between transitional metal content and capacity loss when cells are cycled with electrolytes which contain additives.

Interestingly, several research groups have reported nearly stoichiometric dissolution of the different transition metals ( $\mathrm{Ni}, \mathrm{Mn}$, and $\mathrm{Co}$ ) from $\mathrm{NMC}$ cathodes depending upon the transition metal content. In addition, Mn deposition has been reported to result in greater damage to the anode SEI than Ni deposition (figure 2-2a). ${ }^{17}$ However, these results are inconsistent with observations of greater capacity loss for high $\mathrm{Ni}$ NMC since Mn dissolution, the more damaging transition metal, would be lowered since there is less Mn in the NMC. Thus, while transition metal dissolution and deposition, may contribute to damaging of the SEI and consequent capacity losses, it is not likely the primary source.

[Figure 2-2]

Alternatively, many researchers have commented that transition metal dissolution at the $\mathrm{NMC}$ cathode results from the generation of acidic species $\left(\mathrm{PF}_{5}, \mathrm{OPF}_{3}\right.$, and $\left.\mathrm{HF}\right)$ 
which result from electrolyte oxidation at the cathode at high potential. ${ }^{18}$ The same acidic species have been reported from the thermal decomposition of $\mathrm{LiPF}_{6} /$ carbonate electrolytes. ${ }^{19}$ Acidic species have been reported to rapidly accelerate the thermal decomposition of lithium alkyl carbonates the primary components of the anode SEI. ${ }^{20,21}$ Thus, the oxidative generation of the acidic species at the cathode interface followed by crossover to the anode and catalytic decomposition of the anode SEI is likely a significant contributor to capacity loss on the graphitic anode in graphite/NMC cells as shown in figure 2-2b, especially at high potential or high $\mathrm{Ni}$ content where electrolyte oxidation is problematic. ${ }^{22}$

The addition of electrolyte additives which either stabilize the anode SEI, such as vinylene carbonate (VC) or fluoroethylene carbonate (FEC), or scavenge acidic species such as $\mathrm{TMSP}^{23}$ would slow damage to the SEI and improve capacity, as reported. In addition, the presence of basic surface films such as $\mathrm{Al}_{2} \mathrm{O}_{3}$ would also remove acidic species from solution and thus consistent with reported improvements. Thus our suggestion related to the development of superior electrolyte formulations for NMC cathodes cycled to high potential or containing high $\mathrm{Ni}$ content is the development of both superior acid scavenging and SEI stabilizing electrolyte additives. 


\section{CONCLUSIONS}

In summary, while the transition metal content in the anode SEI correlates well with capacity fade for NMC cathodes cycled to high voltage and NMC cathodes containing high nickel content, it is unclear if the presence of the transition metal is the source of performance fade, or a coincidence. NMC particle cracking or NMC phase transitions appear to be the primary source of cathode impedance increases as opposed to the formation of the cathode electrolyte interphase thus the particle cracking and or phase transitions are the primary cause of impedance increases and related performance fade. Other researchers have reported that native surface impurities such as $\mathrm{Li}_{2} \mathrm{CO}_{3}$ or surface modifications such as alumina can inhibit transition metal dissolution or particle cracking. However, the mechanism of these modifications remains elusive. Finally, many investigations have focused on the effect of electrolyte additives on the performance of NMC cathodes at high potential, high Ni content, or both. While, some clear performance enhancements have been observed, the mechanisms of performance enhancement such as the formation of a stable cathode passivation layer, inhibition of transition metal dissolution, or inhibition of the side reactions of the electrolyte, is unclear. However, the changes in the surface of the cathode material likely have the largest impact on the performance of the NMC cathodes, but at this time the role of the electrolyte appears to be secondary.

\section{ACKNOWLEDGEMENTS}

The authors gratefully acknowledge funding from the BASF Electrochemistry Network and the fruitful collaborations formed within the Network. 


\section{FIGURES}
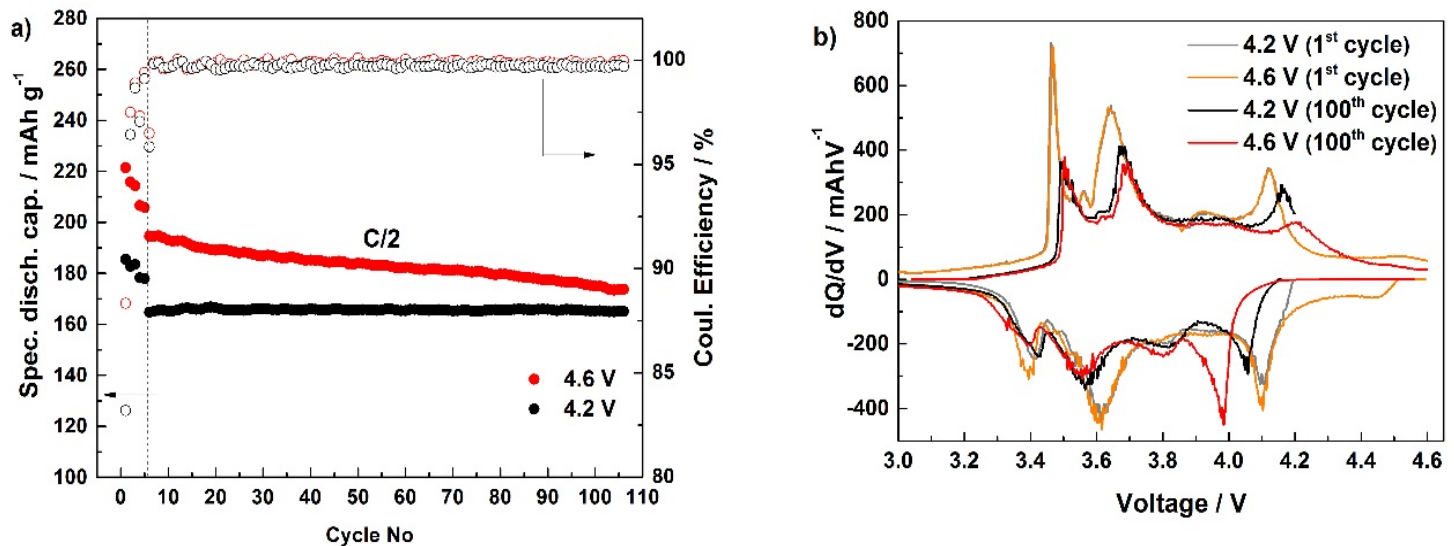

Figure 2-1. Electrochemical performance of Graphite/NCM811 cells cyced at different cut-off voltages of 4.2 and $4.6 \mathrm{~V}$, respectively. a) Galvanostatic cycling at a C-rate of $\mathrm{C} / 2$ after formation cycles at $\mathrm{C} / 20$ (1), C/10 (2-3) and $\mathrm{C} / 5$ (4-5), b) differential capacity plots of the $1^{\text {st }}$ and $100^{\text {th }}$ cycle. ${ }^{13}$ Figure reproduced with permission of J. Electrochem. Soc. 

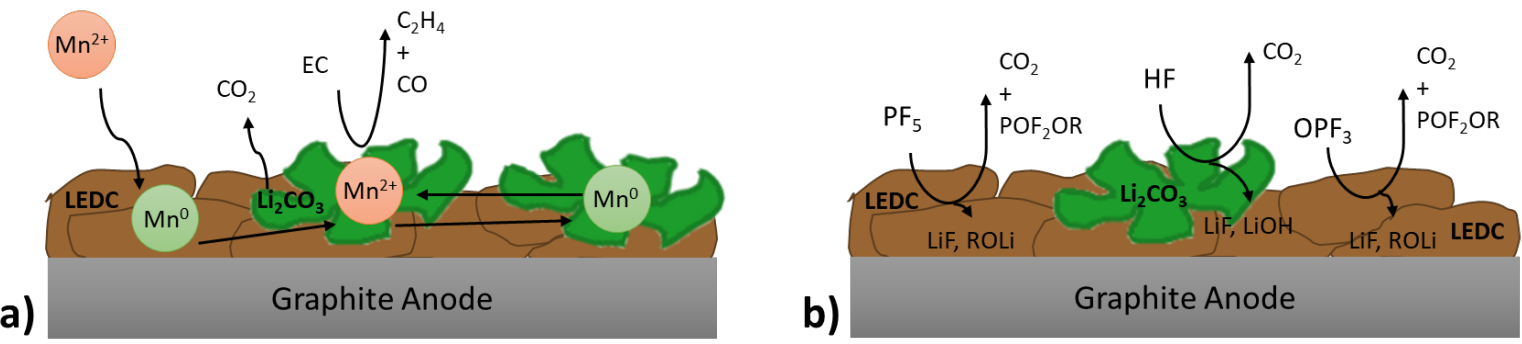

Figure 2-2. A schematic representation of the (a) manganese catalyzed degradation of the anode SEI adapted from Solchenbach et al17, and (b) acidic species induced decomposition of anode SEI components. 


\section{REFERENCES}

(1) Noh, H. J.; Youn, S.; Yoon, C. S.; Sun, Y. K. Comparison of the Structural and Electrochemical Properties of Layered Li[NixCoyMnz]O2 $(x=1 / 3,0.5,0.6$, 0.7, 0.8 and 0.85) Cathode Material for Lithium-Ion Batteries. J. Power Sources 2013, 233, 121-130. https://doi.org/10.1016/j.jpowsour.2013.01.063.

(2) Tian, C.; Lin, F.; Doeff, M. M. Electrochemical Characteristics of Layered Transition Metal Oxide Cathode Materials for Lithium Ion Batteries: Surface, Bulk Behavior, and Thermal Properties. Acc. Chem. Res. 2018, 51 (1), 89-96. https://doi.org/10.1021/acs.accounts.7b00520.

(3) Schipper, F.; Erickson, E. M.; Erk, C.; Shin, J.; Chesneau, F. F.; Aurbach, D. Review - Recent Advances and Remaining Challenges for Lithium Ion Battery Cathodes: I. Nickel-Rich, LiNixCoyMnzO2. J. Electrochem. Soc. 2017, 164 (1), A6220--A6228. https://doi.org/10.1149/2.0351701jes.

(4) Gilbert, J. A.; Shkrob, I. A.; Abraham, D. P. Transition Metal Dissolution, Ion Migration, Electrocatalytic Reduction and Capacity Loss in Lithium-Ion Full Cells. J. Electrochem. Soc. 2017, 164 (2), A389-A399. https://doi.org/10.1149/2.1111702jes.

(5) Jung, R.; Linsenmann, F.; Thomas, R.; Wandt, J.; Solchenbach, S.; Maglia, F.; Stinner, C.; Tromp, M.; Gasteiger, H. A. Nickel, Manganese, and Cobalt Dissolution from Ni-Rich NMC and Their Effects on NMC622-Graphite Cells. J. Electrochem. Soc. 2019, 166 (2), A378-A389. https://doi.org/10.1149/2.1151902jes. 
(6) Thompson, L. M.; Stone, W.; Eldesoky, A.; Smith, N. K.; McFarlane, C. R. M.; Kim, J. S.; Johnson, M. B.; Petibon, R.; Dahn, J. R. Quantifying Changes to the Electrolyte and Negative Electrode in Aged NMC532/Graphite LithiumIon Cells. J. Electrochem. Soc. 2018, 165 (11), A2732-A2740. https://doi.org/10.1149/2.0721811jes.

(7) Schipper, F.; Erickson, E. M.; Erk, C.; Shin, J.-Y.; Chesneau, F. F.; Aurbach, D. Review_-Recent Advances and Remaining Challenges for Lithium Ion Battery Cathodes. J. Electrochem. Soc. 2017, 164 (1), A6220-A6228. https://doi.org/10.1149/2.0351701jes.

(8) Sun, H.-H.; Ryu, H.-H.; Kim, U.-H.; Weeks, J. A.; Heller, A.; Sun, Y.-K.; Mullins, C. B. Beyond Doping and Coating: Prospective Strategies for Stable High-Capacity Layered Ni-Rich Cathodes. ACS Energy Lett. 2020, acsenergylett.0c00191. https://doi.org/10.1021/acsenergylett.0c00191.

(9) Liu, T.; Garsuch, A.; Chesneau, F.; Lucht, B. L. Surface Phenomena of High Energy Li ( Ni 1 / 3 Co 1 / 3 Mn 1 / 3 ) O 2 / Graphite Cells at High Temperature and High Cutoff Voltages. J. Power Sources 2014, 269, 920-926. https://doi.org/10.1016/j.jpowsour.2014.07.051.

(10) Laszczynski, N.; Solchenbach, S.; Gasteiger, H. A.; Lucht, B. L. Understanding Electrolyte Decomposition of Graphite/NCM811 Cells at Elevated Operating Voltage. J. Electrochem. Soc. 2019, 166 (10), A1853A1859. https://doi.org/10.1149/2.0571910jes. 
(11) Li, J.; Shunmugasundaram, R.; Doig, R.; Dahn, J. R. In Situ X-Ray Diffraction Study of Layered Li-Ni-Mn-Co Oxides: Effect of Particle Size and Structural Stability of Core-Shell Materials. Chem. Mater. 2016, 28 (1), 162-171. https://doi.org/10.1021/acs.chemmater.5b03500.

(12) Laszczynski, N.; Solchenbach, S.; Gasteiger, H. A.; Lucht, B. L. Understanding Electrolyte Decomposition of Graphite/NCM811 Cells at Elevated Operating Voltage. J. Electrochem. Soc. 2019, 166 (10), A1853A1859. https://doi.org/10.1149/2.0571910jes.

(13) Jung, R.; Morasch, R.; Karayaylali, P.; Phillips, K.; Maglia, F.; Stinner, C.; Shao-Horn, Y.; Gasteiger, H. A. Effect of Ambient Storage on the Degradation of Ni-Rich Positive Electrode Materials (NMC811) for Li-Ion Batteries. J. Electrochem. Soc. 2018, 165 (2), A132-A141. https://doi.org/10.1149/2.0401802jes.

(14) Xiong, D. J.; Hynes, T.; Ellis, L. D.; Dahn, J. R. Effects of Surface Coating on Gas Evolution and Impedance Growth at Li[Ni x Mn y Co 1-x-y ]O 2 Positive Electrodes in Li-Ion Cells . J. Electrochem. Soc. 2017, 164 (13), A3174A3181. https://doi.org/10.1149/2.0991713jes.

(15) Mao, Y.; Wang, X.; Xia, S.; Zhang, K.; Wei, C.; Bak, S.; Shadike, Z.; Liu, X.; Yang, Y.; Xu, R.; et al. High-Voltage Charging-Induced Strain, Heterogeneity, and Micro-Cracks in Secondary Particles of a Nickel-Rich Layered Cathode Material. Adv. Funct. Mater. 2019, 29 (18), 1-11. https://doi.org/10.1002/adfm.201900247. 
(16) Gilbert, J. A.; Shkrob, I. A.; Abraham, D. P. Transition Metal Dissolution, Ion Migration, Electrocatalytic Reduction and Capacity Loss in Lithium-Ion Full Cells. J. Electrochem. Soc. 2017, 164 (2), A389-A399. https://doi.org/10.1149/2.1111702jes.

(17) Solchenbach, S.; Hong, G.; Freiberg, A. T. S.; Jung, R.; Gasteiger, H. A. Electrolyte and SEI Decomposition Reactions of Transition Metal Ions Investigated by On-Line Electrochemical Mass Spectrometry. J. Electrochem. Soc. 2018, 165 (14), A3304-A3312. https://doi.org/10.1149/2.0511814jes.

(18) Solchenbach, S.; Metzger, M.; Egawa, M.; Beyer, H.; Gasteiger, H. A. Quantification of PF 5 and POF 3 from Side Reactions of LiPF 6 in Li-Ion Batteries . J. Electrochem. Soc. 2018, 165 (13), A3022-A3028. https://doi.org/10.1149/2.0481813jes.

(19) Campion, C. L.; Li, W.; Lucht, B. L. Thermal Decomposition of LiPF6-Based Electrolytes for Lithium-Ion Batteries. J. Electrochem. Soc. 2005, 152 (12), A2327-A2334. https://doi.org/10.1149/1.2083267.

(20) Parimalam, B. S.; MacIntosh, A. D.; Kadam, R.; Lucht, B. L. Decomposition Reactions of Anode Solid Electrolyte Interphase (SEI) Components with LiPF 6. J. Phys. Chem. C 2017, 121 (41), 22733-22738. https://doi.org/10.1021/acs.jpcc.7b08433.

(21) Heiskanen, S. K.; Kim, J.; Lucht, B. L. Generation and Evolution of the Solid Electrolyte Interphase of Lithium-Ion Batteries. Joule 2019, 3 (10), 23222333. https://doi.org/10.1016/j.joule.2019.08.018. 
(22) Jung, R.; Metzger, M.; Maglia, F.; Stinner, C.; Gasteiger, H. A. Chemical versus Electrochemical Electrolyte Oxidation on NMC111, NMC622, NMC811, LNMO, and Conductive Carbon. J. Phys. Chem. Lett. 2017, 8 (19), 4820-4825. https://doi.org/10.1021/acs.jpclett.7b01927.

(23) Guéguen, A.; Bolli, C.; Mendez, M. A.; Berg, E. J. Elucidating the Reactivity of Tris(Trimethylsilyl)Phosphite and Tris(Trimethylsilyl)Phosphate Additives in Carbonate Electrolytes - A Comparative Online Electrochemical Mass Spectrometry Study. ACS Appl. Energy Mater. 2020, 3 (1), 290-299. https://doi.org/10.1021/acsaem.9b01551. 


\title{
CHAPTER 3
}

\section{Fluorinated acetic anhydrides as electrolyte additives to improve cycling performance of the lithium metal anode}

\author{
Satu Kristiina Heiskanen and Brett L. Lucht ${ }^{\mathrm{Z}}$ \\ University of Rhode Island, Department of Chemistry, 140 Flagg Rd., Beaupre \\ zblucht@uri.edu
}

This manuscript is in the process of being submitted to the Journal of the Electrochemical Society. 


\begin{abstract}
The investigation of novel fluorinated electrolyte additives for lithium metal anodes has been conducted. Two acetic anhydride derivatives, difluoroacetic anhydride (DFAA) and trifluoroacetic anhydride (TFAA), were investigated in electrolytes composed of LiPF6 in ethylene carbonate (EC) and ethyl methyl carbonate (EMC). The addition of either DFAA or TFAA results in a significant improvement in capacity retention and reversibility of lithium plating. Ex-situ surface analysis (XPS, ATR-FT-IR) suggests that incorporation of either TFAA or DFAA results in a lithium carboxylate rich SEI which inhibits SEI degradation resulting in superior cycling performance.
\end{abstract}




\section{INTRODUCTION}

Improvements in the reversibility of the plating and stripping of lithium metal in carbonate-based electrolytes has drawn significant interest. ${ }^{1-3}$ Lithium metal as an anode has the potential to increase the anodic capacity of lithium batteries up to 3860 $\mathrm{mAh} / \mathrm{g}$ and would not require a host material. However, the practical application of the lithium metal anode especially in carbonate electrolytes is severely hindered by dendrite growth as well as the formation of electronically isolated lithium metal domains. ${ }^{4}$ Furthermore, the inherent volume change of the anode material leads to mechanical stress resulting in mechanical fracturing of the solid electrolyte interphase (SEI) and allowing for continuous electrolyte reduction. The use of electrolyte additives can help to significantly to limit the severity of these detrimental reactions.

The preferential reduction of electrolyte additives over the electrolyte solvents or salt can be utilized to form a modified SEI allowing for improved plating and stripping efficiencies in carbonate electrolytes. Some examples of additives which have been investigated in carbonate electrolytes include fluoroethylene carbonate (FEC) ${ }^{5}$, vinylene carbonate $(\mathrm{VC})^{6}$, and lithium difluorophosphate (LiDFOB) $)^{7,8}$. These additives are thought to improve performance by forming a more elastic or more stable SEI on the surface of the lithium metal and improve the plating behavior of the lithium metal. Fluorinated electrolyte additives such as FEC and LiDFOB increase the amount of $\mathrm{LiF}$ in the $\mathrm{SEI}$ and the presence of nanostructured $\mathrm{LiF}$ has been reported to improve the uniformity of lithium metal plating.

In this study, we explore two fluorinated acetic anhydride derivatives, difluoroacetic anhydride (DFAA) and trifluoroacetic anhydride (TFAA) as electrolyte 
additives. The performance of several electrolyte formulations containing DFAA and TFAA have been investigated electrochemically in $\mathrm{Cu} \mid \mathrm{LiFePO} 4$ cells and by ex situ surface analysis of the plated lithium metal. The benefit of using a $\mathrm{Cu} \mid \mathrm{LiFePO}_{4}$ cell composition is that the lithium metal anode is generated in situ preventing premature reaction with the electrolyte with the lithium metal anode and contain a limited amount of lithium metal compared to a lithium foil. ${ }^{7,9}$ This investigation reveals that both TFAA and DFAA improve the reversibility of lithium plating in carbonate electrolyte, and ex situ surface analysis of the plated lithium metal electrodes by X-ray Photoelectron Spectroscopy (XPS) suggests that the additives increase the stability of the solid electrolyte interphase (SEI) to the electrolyte solvents.

\section{EXPERIMENTAL}

\section{Cell Construction}

Coin cells (CR2032) were assembled in an argon filled glovebox $\left(<1\right.$ ppm $\left.\mathrm{H}_{2} \mathrm{O}\right)$ with a crimping pressure of 1500 psi. Single-sided lithium iron phosphate $\left(\mathrm{LiFePO}_{4}\right.$, LFP) cathodes (91\% active material, 9\% PVdF binder and conductive carbon) were obtained from MTI, cut outside the glovebox and then dried under vacuum overnight at $110^{\circ} \mathrm{C}$ prior to cell assembly. Copper foil current collectors for the anode were cut from copper foil cleaned with a 1-minute sonication in $1 \mathrm{M} \mathrm{HCl}$, followed by subsequent 1-minute sonication in two portions of isopropanol and under vacuum overnight at $110^{\circ} \mathrm{C}$ prior to cell assembly. The cells were constructed with $\mathrm{Cu}$ foil current collector $(15 \mathrm{~mm})$, two Celgard 2325 separators $(19 \mathrm{~mm})$, LFP cathode material $(13.7 \mathrm{~mm})$, and $100 \mu \mathrm{L}$ of electrolyte. 
Cycling was conducted on an Arbin Instruments BT2000 battery cycler at $25^{\circ} \mathrm{C}$. The cycling procedure consisted of plating Li metal at $0.1 \mathrm{~mA} / \mathrm{cm}^{2}$ (approx. $\mathrm{C} / 20$ rate, where $\mathrm{C}$ represents the theoretical capacity of $\mathrm{LiFePO}_{4}$ ) with subsequent stripping and plating at $0.4 \mathrm{~mA} / \mathrm{cm}^{2}$ (approx. $\mathrm{C} / 4$ rate), within a voltage window of $2.0-4.0 \mathrm{~V}$. There was a rest period of one hour between cell construction and the beginning of the cycling protocol.

Electrolytes investigated were all based on a $1.2 \mathrm{M} \mathrm{LiPF}_{6}$ in EC:EMC (3:7) obtained from BASF (denoted as STD). Trifluoroacetic anhydride (99+\%, Acros, denoted as TFAA) and difluoroacetic anhydride $(98+\%$, TCI America, denoted as DFAA) were used without further purification. Difluoroacetic anhydride (DFAA) concentrations of $0.5 \%, 1 \%, 2.5 \%$, and $5 \%$, trifluoroacetic anhydride (TFAA) concentrations of $2.5 \%, 5 \%, 10 \%$, and $15 \%$, as well as a mixture of $2.5 \%$ each of DFAA and TFAA were prepared in an argon-filled glovebox and stirred on a magnetic stir plate for two days before use.

XPS measurements were done using a Thermo-Fisher k-Alpha spectrometer utilizing aluminum $\mathrm{k} \alpha$ radiation $(\mathrm{h} v=1486.6 \mathrm{eV})$ under ultra-high vacuum conditions $\left(<1 \times 10^{-12} \mathrm{~atm}\right)$ with a measured spot size of $400 \mu \mathrm{m}$. Lithium metal was deposited onto $\mathrm{Cu}$ foil according to the first charge procedure outlined in the electrochemistry section (charge to $4.0 \mathrm{~V}$ at $\mathrm{C} / 20$ rate, stripped at $\mathrm{C} / 4$ rate, and again plated at $\mathrm{C} / 4$ rate) and held at rest for approximately 4 hours to allow equilibration before disassembly in an argon-filled glovebox. Electrodes were washed with $3 \times 500 \mu \mathrm{L}$ extra dry dimethyl carbonate $(99+\%$, Acros, DMC) and dried under vacuum overnight. Samples were transferred into to the instrument with a vacuum transfer stage module to avoid 
exposure to air. The binding energy was corrected based on the F1s spectrum, assigning $\mathrm{LiF}$ to $685 \mathrm{eV}$.

ATR-IR spectra were obtained on a Bruker Tensor 27, using a Pike MIRacle horizontal ATR accessory equipped with a diamond/ZnSe crystal in a nitrogen-filled glovebox to prevent oxygen and water exposure of the samples. There is no evidence of nitrogen reacting with the plated lithium within the timeframe of measurement. Background and sample spectra were obtained with 256 scans for ATR spectra and a resolution of $4 \mathrm{~cm}^{-1}$. Atmospheric compensation routines for both water and carbon dioxide were used to remove or reduce remaining interferences. 


\section{RESULTS AND DISCUSSION}

\section{[FIGURE 3-1]}

Two fluorinated compounds, difluoroacetic anhydride (DFAA) and trifluoroacetic anhydride (TFAA), were investigated as electrolyte additives for improving the cycling performance of $\mathrm{Cu} / \mathrm{LFP}$ cells. The concentration of DFAA was varied from 0.5 to $5 \mathrm{wt} \%$, to determine the optimal concentration of the additive for improving the reversibility of lithium plating and stripping. Cycling performance of these cells is shown in figure 3-1. The first cycle stripping capacity (figure 3-1a) was improved for all concentrations of DFAA, with the cell containing $1 \%$ DFAA having the highest first cycle stripping capacity of $100 \mathrm{mAh} / \mathrm{g}$. However, the optimal concentration for the sum of reversibly cycled lithium (figure 3-1c) over the first 50 cycles was determined to be $2.5 \%$ DFAA by weight. The sum of reversibly cycled lithium was improved to $800 \mathrm{mAh} / \mathrm{g}$, compared to $80 \mathrm{mAh} / \mathrm{g}$ observed for the standard electrolyte formulation. The improved reversibility is consistent with a more efficient plating and stripping mechanism. Overall the addition of difluoroacetic anhydride causes an almost fivefold increase in the initial stripping capacity as well as a tenfold increase in the sum of reversibly cyclable lithium.

\section{[FIGURE 3-2]}

The cycling performance of $\mathrm{Cu} / \mathrm{LiFePO}_{4}$ cells was also investigated in the presence of trifluoroacetic anhydride (TFAA) as shown in figure 3-2. The initial stripping capacity and capacity retention are improved by addition of TFAA. However, the performance improvements are observed at higher concentrations of 
TFAA than were observed for DFAA. While the initial stripping capacity is improved fivefold, from $19 \mathrm{mAh} / \mathrm{g}$ to $\sim 105 \mathrm{mAh} / \mathrm{g}$ for all concentrations of TFAA investigated, the best capacity retention is observed for cells containing $10 \%$ TFAA (figure 3-2a). The sum of reversibly cyclable lithium is increased more than tenfold from $78 \mathrm{mAh} / \mathrm{g}$ to $946 \mathrm{mAh} / \mathrm{g}$ for cells containing $10 \%$ TFAA (figure 3-2c). In an effort to confirm the importance of the fluorination of TFAA and DFAA, Cu/LFP cells were prepared with 2.5 and $5 \%$ acetic anhydride. The capacity retention and cycling performance were nearly identical to that for cells cycled with the standard electrolyte, confirming the importance of fluorination to performance improvements.

[FIGURE 3-3]

The voltage profile for the first plating step is provided in figure 3-3 and demonstrates the difference in the electrochemical behavior of the different electrolyte additives. Electrolytes containing either DFAA or TFAA show a plateau during the first plating at approximately $1.3 \mathrm{~V}$, indicating electrochemical reduction of the additive onto the anode. An electrolyte containing 10\% TFAA shows a smooth even plating curve, while the electrolyte containing 2.5\% DFAA shows a longer plateau at $1.3 \mathrm{~V}$ despite the lower concentration of the additive, and the plateau at about $3.5 \mathrm{~V}$ is uneven.

[FIGURE 3-4]

Considering that the reversibility of lithium plating and the initial stripping capacities are higher in the cells cycled with electrolyte containing TFAA and the rate of capacity loss is lower in cells cycled with DFAA, a synergistic effect of the two additives was investigated using an electrolyte containing $2.5 \%$ by weight of both 
DFAA and TFAA. The stripping capacities and sum of reversibly cycled lithium is shown in figure 3-4. As expected, the combination of additives provides better overall performance than either individual additive. The combination of $2.5 \%$ DFAA and $2.5 \%$ TFAA has better initial stripping capacity than 5\% DFAA although it is still lower than 5\% TFAA (figure 3-4a). The combination of additives provides a comparable sum of reversibly cycled lithium over the first 50 cycles (figure $3-4 b$ ). The highest sum of reversibly cycled lithium is for the cell containing 5\% DFAA (611 $\mathrm{mAh} / \mathrm{g})$ followed by the combination of $2.5 \%$ DFAA and $2.5 \%$ TFAA $(579 \mathrm{mAh} / \mathrm{g})$ and then the cell 5\% TFAA has the lowest sum of reversibly cycled lithium (538 $\mathrm{mAh} / \mathrm{g})$. Unfortunately, the combination of additives does not result in an improvement in performance over the single additives.

[FIGURE 3-5]

In order to understand the source of the observed electrochemical improvements, the surface films formed on the lithium metal anodes has been investigated by XPS. The $\mathrm{C} 1 \mathrm{~s}, \mathrm{O} 1 \mathrm{~s}$ and F1s spectra of the lithium plated in STD, 5\% DFAA, 5\% TFAA and $2.5 \%$ DFAA $+2.5 \%$ TFAA are presented in figure $3-6$. Interestingly, the $\mathrm{C} 1 \mathrm{~s}, \mathrm{O} 1 \mathrm{~s}$ and F1s spectra are similar for the lithium metal anodes plated in the presence of $5 \%$ DFAA, $5 \%$ TFAA, or $2.5 \%$ of DFAA and TFAA after the second plating. There are some small variations in SEI composition between the different electrolytes, consistent with the observed performance differences. The C1s spectra contain peaks corresponding to $-\mathrm{CO}_{3}$ at $290.1 \mathrm{eV},-\mathrm{CO}_{2}$ at $289.0, \mathrm{C}-\mathrm{O}$ at $286.7 \mathrm{eV}$ and $\mathrm{C}-\mathrm{C} / \mathrm{C}-\mathrm{H}$ at 285.0 eV consistent with the generation of $\mathrm{RCO}_{2} \mathrm{Li}, \mathrm{ROCO}_{2} \mathrm{Li}$ and $\mathrm{Li}_{2} \mathrm{CO}_{3}$. The peaks characteristic of lithium carboxylates $\left(-\mathrm{CO}_{2} \mathrm{Li}\right)$ at $289.0 \mathrm{eV}$ are stronger for the cells 
containing either TFAA or DFAA, consistent with reduction of the additives on the lithium metal surface. The O1s spectrum contains a broad peak composed of several overlapping species centered at $\sim 531.8 \mathrm{eV}$, consistent with a mixture of C-O and $\mathrm{C}=\mathrm{O}$, consistent with the $\mathrm{C} 1$ s spectra. ${ }^{9,10}$ A peak corresponding to $\mathrm{Li}_{2} \mathrm{O}$ is also observed at $528 \mathrm{eV}$ in the $\mathrm{O} 1 \mathrm{~s}$ spectrum for only the electrode cycled with the STD electrolyte. More visible changes are observed in the F1s spectra. While a single F1s peak is observed at $685 \mathrm{eV}$ characteristic of LiF for the lithium metal anode plated with the standard electrolyte, an additional peak is observed at $687 \mathrm{eV}$ consistent with C-F containing species for cells cycled with either TFAA or DFAA. The presence of C-F containing species is consistent with reduction of the DFAA or TFAA on the surface of the plated lithium. Surprisingly, the $\mathrm{C}-\mathrm{F}$ peak associated with the $\mathrm{CF}_{3}$ group is not observed in the $\mathrm{C} 1 \mathrm{~s}$ spectrum at $294 \mathrm{eV}$. However, this could be due to the decomposition of the $\mathrm{CF}_{3}$ group to generate $\mathrm{LiF}$ and other $\mathrm{C}-\mathrm{F}$ containing species. Only very weak peaks are observed in the P2p spectrum (not shown) consistent with very low concentrations of $\mathrm{Li}_{\mathrm{x}} \mathrm{PF}_{\mathrm{y}} \mathrm{O}_{\mathrm{z}}$.

\section{[FIGURE 3-6]}

ATR-IR spectra of lithium plated on copper foil were acquired after the second plating for the STD, 5\% DFAA, 5\% TFAA, and 2.5\% TFAA + 2.5\% DFAA electrolytes are shown in figure 3-5. The highly reactive nature of lithium metal requires the use of a diamond/ZnSe ATR crystal, which has inherent spectral artefacts at $1570 \mathrm{~cm}^{-1}$ and $1340 \mathrm{~cm}^{-1}$, as previously reported. ${ }^{9}$ The spectrum of the lithium metal anode plated with the standard electrolyte contains strong absorptions at 1450 and $1490 \mathrm{~cm}^{-1}$ characteristic of $\mathrm{Li}_{2} \mathrm{CO}_{3} .{ }^{10}$ In addition, a broad peak characteristic of 
lithium alkyl carbonates $\left(\mathrm{ROCO}_{2} \mathrm{Li}\right)$ is observed at $1660 \mathrm{~cm}^{-1}$. Incorporation of either TFAA or DFAA results in significant changes to the IR spectra on the lithium metal surfaces. The relative intensity of the $\mathrm{Li}_{2} \mathrm{CO}_{3}$ peaks are diminished and the relative intensity of the lithium alkyl carbonate peaks are increased. In addition, new absorptions are observed at $\sim 1600 \mathrm{~cm}^{-1}$ characteristic of lithium carboxylates $\left(\mathrm{RCO}_{2} \mathrm{Li}\right)$ which is consistent with observations by XPS. The combination of XPS and IR-ATR provides significant insight into the differences in SEI composition. Lithium plated with the standard electrolyte has an SEI which consists primarily of $\mathrm{Li}_{2} \mathrm{CO}_{3}$ with a low concentration of lithium alkyl carbonates. Alternatively, lithium plated with either TFAA or DFAA has high concentrations of lithium carboxylates and lithium alkyl carbonates and low concentrations of $\mathrm{Li}_{2} \mathrm{CO}_{3}$. Since $\mathrm{Li}_{2} \mathrm{CO}_{3}$ has been reported to be a decomposition product of lithium alkyl carbonates it appears that the presence of DFAA or TFAA slows SEI degradation via the generation of the more stable lithium carboxylates. ${ }^{11}$ 


\section{CONCLUSION}

In this study we demonstrate that both trifluoroacetic anhydride and difluoroacetic anhydride utilized as electrolyte additives improve the reversibility of lithium plating in $\mathrm{Cu} \mid \mathrm{LiFePO}_{4}$ cells. The concentrations of TFAA and DFAA were optimized for cycling performance in EC:EMC electrolytes. DFAA has optimized performance at lower concentrations, $2.5 \%$ by weight, and enables a slower rate of capacity fade compared to both TFAA, and the standard electrolyte. Conversely, TFAA is optimal at higher concentrations, $10 \%$ by weight, and enables an improved initial stripping capacity, delayed capacity fade, and the largest amount of reversibly

cycled lithium. Additionally, we investigated a possible synergistic effect of DFAA and TFAA. Combining the two additives at $2.5 \%$ by weight each improves rate of capacity fade when compared to either DFAA or TFAA alone. Furthermore, the initial stripping capacity and sum of reversibly cycled lithium were increased when lithium was plated and stripped in the presence of $2.5 \%$ by weight of DFAA and TFAA. Surprisingly, the molecular composition of the SEI is similar for all of the electrolytes, suggesting that the performance differences may be related to particle morphology as opposed to molecular composition.

\section{ACKNOWLEDGEMENTS}

The authors wish to gratefully thank the BASF for funding this work. 
FIGURES

(a)

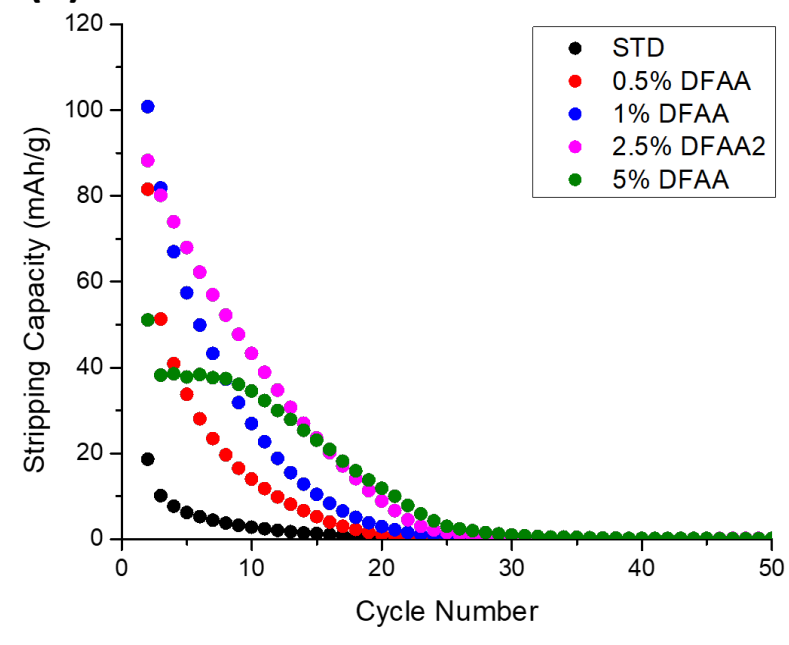

(b)

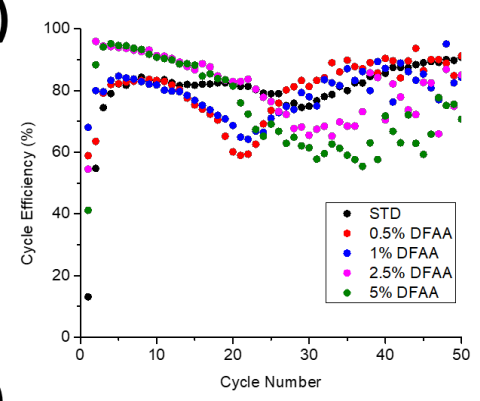

(c)

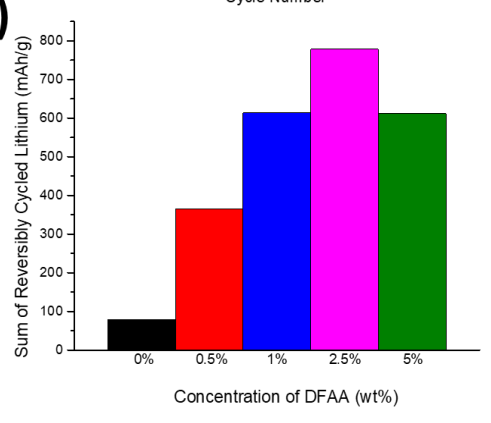

Figure 3-1. (a) Stripping specific capacity vs. cycle number for the STD, $0.5 \%$ DFAA, 1\%DFAA, 2.5\% DFAA, and 5\% DFAA, (b) corresponding cycle efficiency vs. cycle number, and (c) sum of reversibly cycled lithium over the first 50 cycles for each electrolyte. 
(b)

(a)

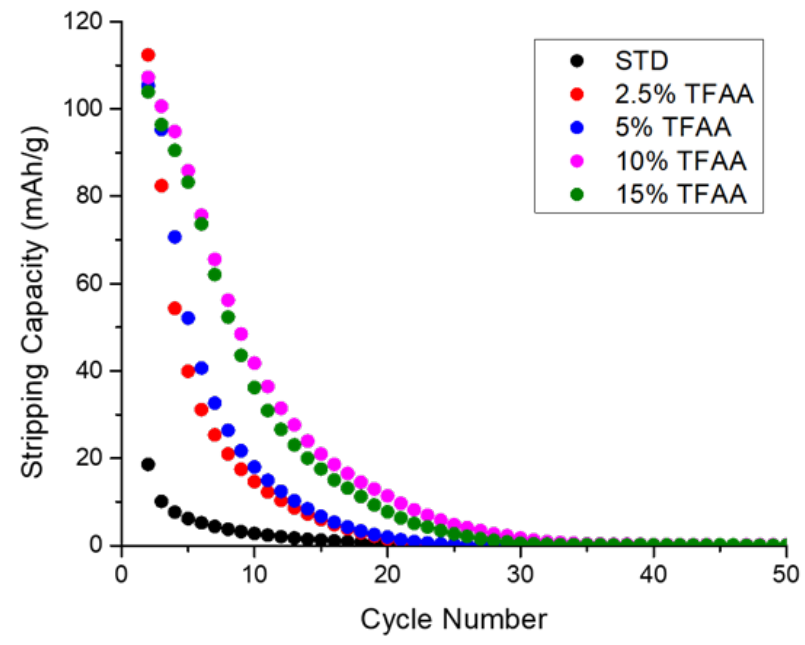

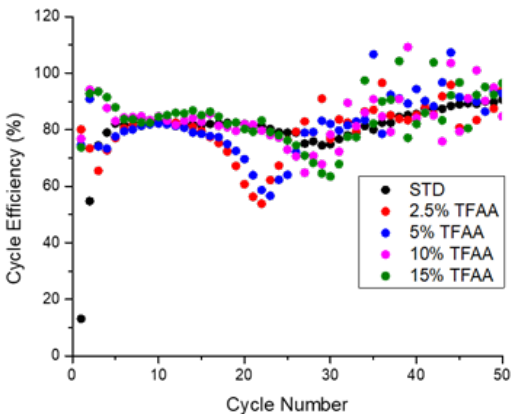

(c)

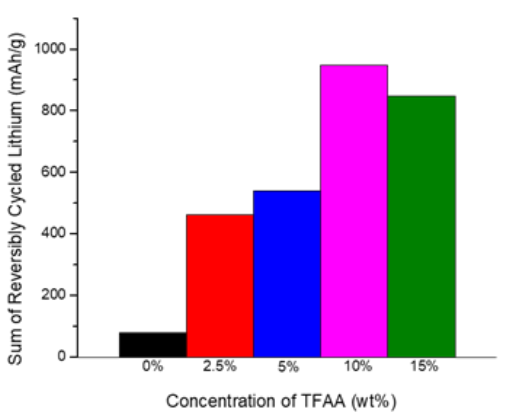

Figure 3-2.(a) Stripping specific capacity vs. cycle number for the STD, 2.5\% TFAA, $5 \%$ TFAA, 10\% TFAA, and 15\% TFAA, (b) corresponding cycle efficiency vs. cycle number, and (c) sum of reversibly cycled lithium over the first 50 cycles for each electrolyte. 


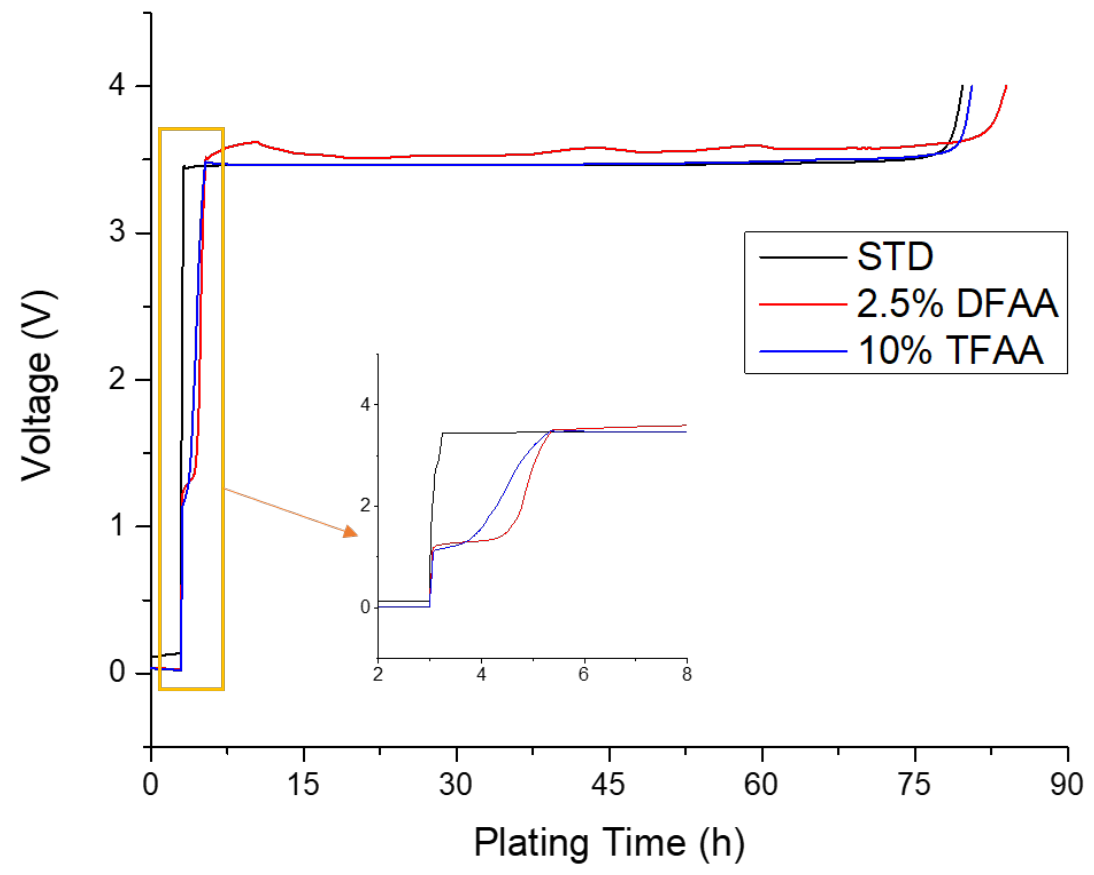

Figure 3-3. Voltage profile of the first charge/plating of a STD 2.5\% DFAA, and 10\% TFAA, with the inset showing the plateaus more clearly. 

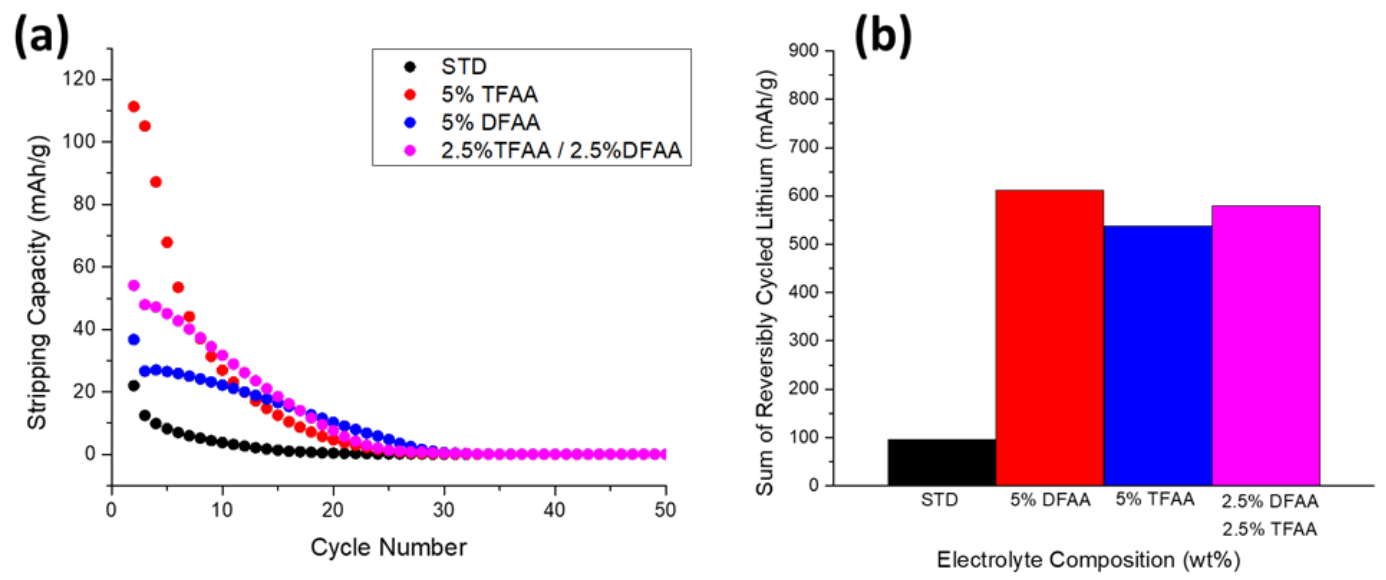

Figure 3-4. (a) Stripping specific capacity vs. cycle number for the STD, 5\% TFAA, $5 \%$ DFAA, and $2.5 \%$ DFAA $+2.5 \%$ TFAA, and (b) sum of reversibly cycled lithium over the first 50 cycles for each electrolyte. 

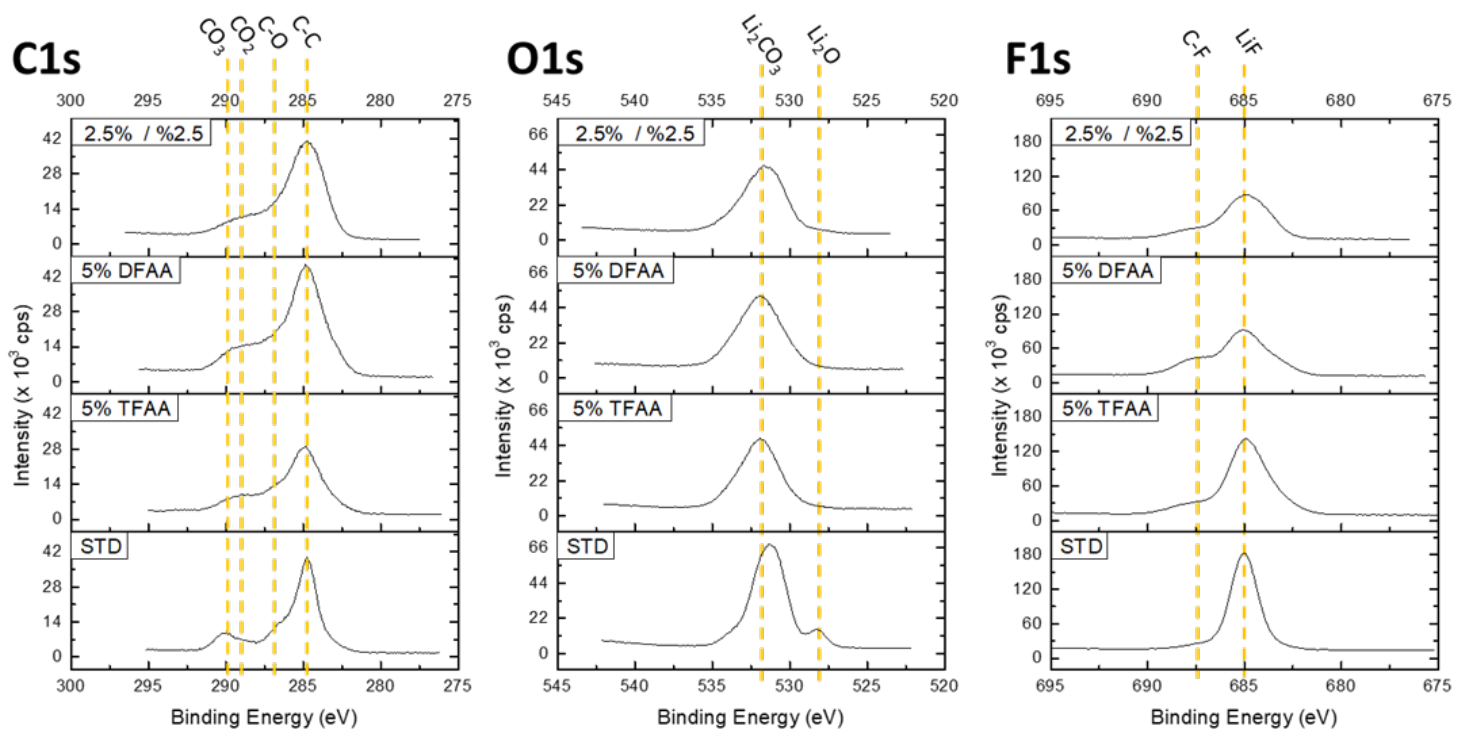

Figure 3-5. C1s, O1s, F1s and P2p XPS spectra after the second plating of lithium on copper foil in STD, 5\% TFAA, 5\% DFAA, and 2.5\% DFAA + 2.5\% TFAA. 


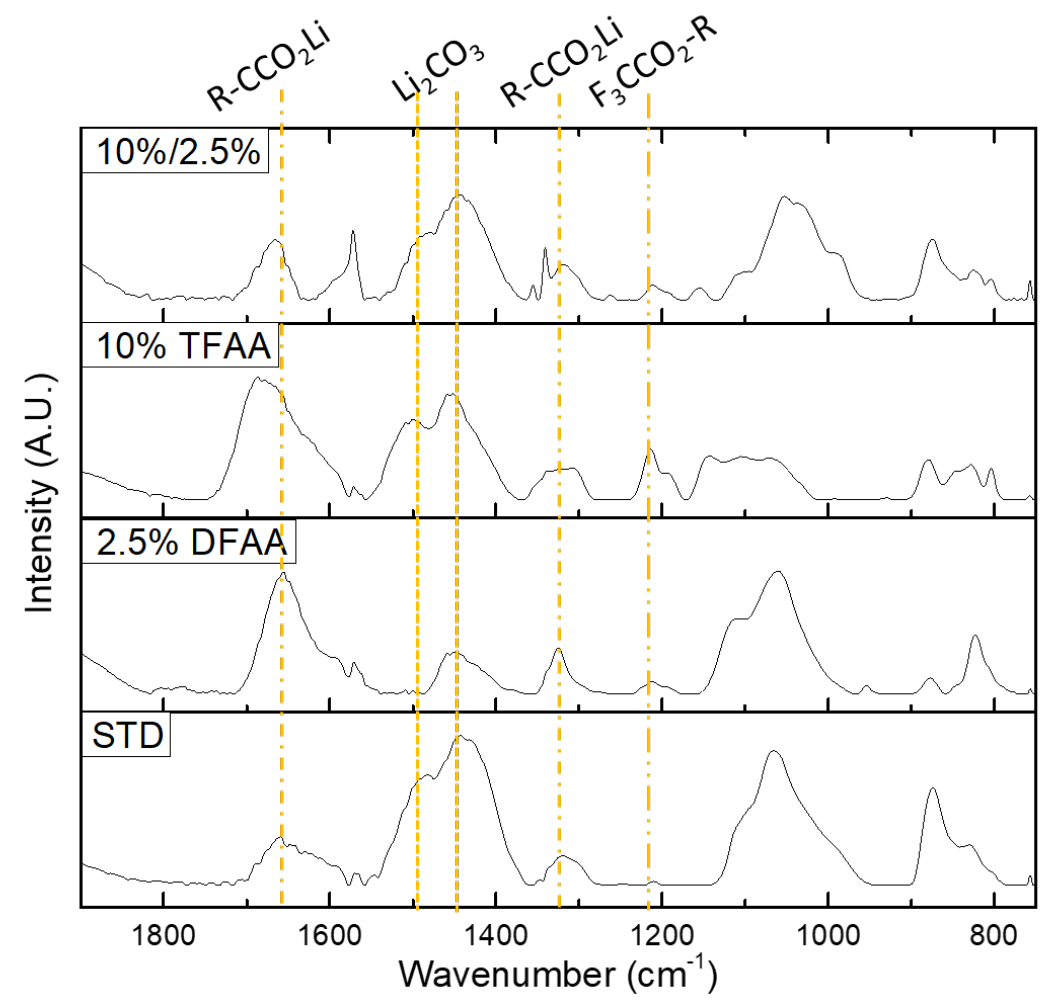

Figure 3-6. ATR-FT-IR spectra in the $1900-800 \mathrm{~cm}^{-1}$ region of lithium plated in STD, 5\% DFAA, 5\% TFAA, and 2.5\% TFAA + 2.5\% DFAA. 


\section{REFERENCES}

(1) Ue, M.; Uosaki, K. Recent Progress in Liquid Electrolytes for Lithium Metal Batteries. Curr. Opin. Electrochem. 2019, 17, 106-113.

https://doi.org/10.1016/j.coelec.2019.05.001.

(2) Aurbach, D. Introduction to the Focus Issue on Selected Papers from IMLB 2018. J. Electrochem. Soc. 2019, 166 (3), Y3-Y4. https://doi.org/10.1149/2.0691903jes.

(3) Liu, J.; Bao, Z.; Cui, Y.; Dufek, E. J.; Goodenough, J. B.; Khalifah, P.; Li, Q.; Liaw, B. Y.; Liu, P.; Manthiram, A.; et al. Pathways for Practical High-Energy Long-Cycling Lithium Metal Batteries. Nature Energy. March 25, 2019, pp 180186. https://doi.org/10.1038/s41560-019-0338-x.

(4) Fang, C.; Wang, X.; Meng, Y. S. Key Issues Hindering a Practical Lithium-Metal Anode. Trends Chem. 2019, 1 (2), 152-158. https://doi.org/10.1016/j.trechm.2019.02.015.

(5) Brown, Z. L.; Jurng, S.; Nguyen, C. C.; Lucht, B. L. Effect of Fluoroethylene Carbonate Electrolytes on the Nanostructure of the Solid Electrolyte Interphase and Performance of Lithium Metal Anodes. ACS Appl. Energy Mater. 2018, 1 (7), 3057-3062. https://doi.org/10.1021/acsaem.8b00705.

(6) Aurbach, D.; Gamolsky, K.; Markovsky, B.; Gofer, Y.; Schmidt, M.; Heider, U. On the Use of Vinylene Carbonate (VC) as an Additive to Electrolyte Solutions for Li-Ion Batteries. Electrochim. Acta 2002, 47 (9), 1423-1439. https://doi.org/10.1016/S0013-4686(01)00858-1. 
(7) Jurng, S.; Brown, Z. L.; Kim, J.; Lucht, B. L. Effect of Electrolyte on the Nanostructure of the Solid Electrolyte Interphase (SEI) and Performance of Lithium Metal Anodes. Energy Environ. Sci. 2018, 11 (9), 2600-2608. https://doi.org/10.1039/c8ee00364e.

(8) Liu, B.; Zhang, J. G.; Xu, W. Advancing Lithium Metal Batteries. Joule 2018, 2 (5), 833-845. https://doi.org/10.1016/j.joule.2018.03.008.

(9) Brown, Z. L.; Jurng, S.; Lucht, B. L. Investigation of the Lithium Solid Electrolyte Interphase in Vinylene Carbonate Electrolytes Using Cu||LiFePO 4 Cells . J. Electrochem. Soc. 2017, 164 (9), A2186-A2189. https://doi.org/10.1149/2.0021712jes.

(10) Seo, D. M.; Nguyen, C. C.; Young, B. T.; Heskett, D. R.; Woicik, J. C.; Lucht, B. L. Characterizing Solid Electrolyte Interphase on Sn Anode in Lithium Ion Battery. J. Electrochem. Soc. 2015, 162 (13), A7091-A7095. https://doi.org/10.1149/2.0121513jes.

(11) Yoon, T.; Milien, M. S.; Parimalam, B. S.; Lucht, B. L. Thermal Decomposition of the Solid Electrolyte Interphase (SEI) on Silicon Electrodes for Lithium Ion Batteries. Chem. Mater. 2017, 29 (7), 3237-3245. https://doi.org/10.1021/acs.chemmater.7b00454. 


\title{
CHAPTER 4
}

\section{Minimized Metal Dissolution from High-Energy Nickel Cobalt Manganese Oxide Cathodes with $\mathrm{Al}_{2} \mathrm{O}_{3}$ coating and Its Effects on Electrolyte Decomposition on Graphite Anodes}

\author{
Sunhyung Jurng, Satu Kristiina Heiskanen, K. W. D. Kaveendi Chandrasiri, \\ Maheeka Yapa Abeywardana and Brett L. Lucht ${ }^{\mathrm{Z}}$ \\ zblucht@chm.uri.edu \\ Department of Chemistry, University of Rhode Island, Kingston, Rhode Island \\ 02881, USA
}

This manuscript has been published in the Journal of the Electrochemical Society on August 7, 2019. 


\section{ABSTRACT}

High-energy nickel cobalt manganese oxides (usually called, "Lithium-rich layered oxides") have been studied intensively as cathode materials for lithium-ion batteries. However, several hurdles need to be overcome to adopt these cathodes in commercial lithium-ion batteries. The undesired transition metal dissolution from these cathodes is one of the key challenges, especially because it brings not only capacity loss in full cells but also the degradation of graphitic anodes. The dissolved metal ions in the electrolytes induces additional electrolyte decomposition, therefore changes the surface chemistry of anodes. Herein, aluminum oxide $\left(\mathrm{Al}_{2} \mathrm{O}_{3}\right)$ coating was applied to high-energy nickel cobalt manganese oxides (HE-NCM, $\mathrm{Li}_{1.33} \mathrm{Ni}_{0.27} \mathrm{Co}_{0.13} \mathrm{Mn}_{0.60} \mathrm{O}_{2+\mathrm{d}}$ ) by atomic layer deposition (ALD) and its effects on HE$\mathrm{NCM} /$ graphite full cells were investigated. HE-NCM/graphite full cells have better cycling performance and efficiency when $\mathrm{HE}-\mathrm{NCM}$ is coated with $\mathrm{Al}_{2} \mathrm{O}_{3}$. ICP-MS measurements show that the $\mathrm{Al}_{2} \mathrm{O}_{3}$ coating can effectively prevent transition metal dissolution from HE-NCM. Through XPS and FT-IR results, the surface film on HE$\mathrm{NCM}$ cathodes does not change significantly with the $\mathrm{Al}_{2} \mathrm{O}_{3}$ coating even after 50 cycles, however the surface film on graphite anodes shows a significant difference. When cycled with the uncoated HE-NCM cathodes, the surface chemistry of the graphite anode has strong features of salt decomposition products $\left(\mathrm{Li}_{\mathrm{x}} \mathrm{PF}_{\mathrm{y}} \mathrm{O}_{\mathrm{z}}\right)$ and oligo or poly carbonates. This suggests the dissolved metal ions result in additional electrolyte decomposition, especially $\mathrm{LiPF}_{6}$ salt. Due to the increased SEI thickness, the resistance of graphite electrodes cycled with the uncoated HE-NCM is higher than that of graphite electrodes cycled with the $\mathrm{Al}_{2} \mathrm{O}_{3}$-coated HE-NCM. The improved 
cycling performance of $\mathrm{HE}-\mathrm{NCM} /$ graphite cells with $\mathrm{Al}_{2} \mathrm{O}_{3}$ coating can be attributed to the minimized resistance increase on graphite as well as the suppression of cathode active material loss. 


\section{INTRODUCTION}

Because of their high capacity $\left(>240 \mathrm{mAh} \mathrm{g}^{-1}\right)$, high-energy nickel cobalt manganese oxides (usually called, "Lithium-rich layered oxides") are considered as promising cathode candidates for the next-generation lithium-ion batteries. ${ }^{1-3}$ However, several hurdles need to be overcome to adopt these cathodes into commercial lithium-ion batteries. The undesired transition metal dissolution from these cathodes is one of the key challenges, since it not only damages the structural stability of cathodes but also alters the composition of solid electrolyte interphase (SEI) on the surface of anodes. ${ }^{4-7}$ The previous report about the capacity recovery of NCM cathodes collected from full cells suggests the deterioration of anode is the main cause of full cell degradation. ${ }^{8}$

Although transition metal dissolution from various cathodes has been studied in half cells extensively, ${ }^{9-13}$ the effect of transition metal dissolution on the SEI layer of anode has not been well-established. Dissolved transition metal ions accumulate on the anode, where they induce additional side reactions of electrolyte, continuous SEI growth and further the loss of active lithium. ${ }^{6,14}$ It is reported that an electrolyte containing Mn ions generates a non-passivating SEI on the anode surface from the model experiments ${ }^{15}$ and also transition metal ions are electrochemically reduced on the surface of anode leading to metal deposition ${ }^{16}$. The effect of transition metal ions on the composition and stability of the SEI on the anode has not been well addressed.

Surface coatings of cathode materials with various inert metal oxides including $\mathrm{Al}_{2} \mathrm{O}_{3}$ is one of the most common approach to suppress transition metal dissolution from cathodes. ${ }^{17-19} \mathrm{Al}_{2} \mathrm{O}_{3}$ coating provides a stable protection layer on the cathode 
surface and prevents interfacial degradation of the cathode. It has been reported that an $\mathrm{Al}_{2} \mathrm{O}_{3}$ coating can minimize transition metal dissolution from cathodes. ${ }^{20,21}$

In this work, an $\mathrm{Al}_{2} \mathrm{O}_{3}$ coating was applied on high-energy nickel cobalt manganese oxide (HE-NCM, $\mathrm{Li}_{1.33} \mathrm{Ni}_{0.27} \mathrm{Co}_{0.13} \mathrm{Mn}_{0.60} \mathrm{O}_{2+\mathrm{d}}$ ) cathodes by atomic layer deposition (ALD) and the effect on HE-NCM/graphite full cells were investigated. Changes in cycling performance of full cells due to the effect of transition metal dissolution on both electrodes are presented. To understand the effects of transition metal dissolution on the surface film of each electrode, both surface films were analyzed using X-ray photoelectron spectroscopy (XPS) and infrared spectra with attenuated total reflectance (IR-ATR) upon cycling. A possible mechanism for degradation of HE-NCM/graphite full cells is discussed based on the findings.

\section{EXPERIMENTAL}

\section{Coin Cell Preparation}

HE-NCM electrodes were prepared using a composition of 93 wt.\% HE-NCM (with/without $\mathrm{Al}_{2} \mathrm{O}_{3}$ coating), 3 wt.\% conductive carbon, and 4 wt.\% polyvinylidene fluoride (PVdF) binder. Each slurry was mechanically blended with N-methyl-2pyrrolidone (NMP) solvent in a nitrogen-filled glove box and pasted onto aluminum foil. Both HE-NCM powders and graphite electrodes were supplied from a commercial supplier as battery grade.

2032-type coin cells containing HE-NCM positive electrodes (13.7 mm diameter), PP/PE/PP separators (19 mm diameter, Celgard 2325) and graphite negative electrodes (14 mm diameter) were assembled in an argon glove box (M- 
Braun) with oxygen and water contents $<1 \mathrm{ppm}$. Both HE-NCM and graphite electrodes were punched to a specific diameter, and dried at $110^{\circ} \mathrm{C}$ under vacuum overnight before cell assembly. The average active mass loading and areal capacity of HE-NCM electrodes are $7.3 \mathrm{mg} \mathrm{cm}^{-2}$ and $1.83 \mathrm{mAh} \mathrm{cm}^{-2}$, respectively. The $\mathrm{n} / \mathrm{p}$ ratio is controlled within a range of 1.05 to 1.1 , using the $1^{\text {st }}$ charge capacity of HE-NCM and graphite (330 and $372 \mathrm{mAh} / \mathrm{g}$ ). $100 \mu \mathrm{L}$ of $1.2 \mathrm{M} \mathrm{LiPF}_{6}$ in EC:EMC is used as an electrolyte for each cell.

\section{Electrochemical Testing}

Galvanostatic cycling of HE-NCM/graphite cells was conducted using an Arbin BT2000 battery cycler in a constant temperature oven $\left(25^{\circ} \mathrm{C}\right)$. The cycling procedure consists of three steps; (i) $10 \mathrm{~mA} / \mathrm{g}$ within $2.0-4.8 \mathrm{~V}$ ( $1^{\text {st }}$ cycle), (ii) $20 \mathrm{~mA} / \mathrm{g}$ within 2.0-4.6 $\mathrm{V}\left(2^{\text {nd }}-5^{\text {th }}\right.$ cycle), and (iii) $40 \mathrm{~mA} / \mathrm{g}$ within $2.0-4.6 \mathrm{~V}$ (the prolonged cycle). Each current was calculated based on the active mass of HE-NCM electrode. A 6-hour rest period was also introduced at the beginning of each cycling protocol to confirm uniform wetting of all cell components.

\section{Inductively Coupled Plasma Mass Spectrometry (ICP-MS)}

An iCAP Q ICP-MS instrument (Thermo Scientific) with He KED interference reduction system was used for ICP-MS measurements. After cycling and allowing to equilibrate for 48 hours, the HE-NCM/graphite cells were disassembled in an argon glove box. Without the HE-NCM electrodes, all other cell parts were sealed in $15 \mathrm{~mL}$ centrifuge vials and centrifuged at 2200 RPM for 10 minutes to collect as much of the 
electrolyte as possible. After centrifuging, the cell parts were removed from the vial and the graphite electrodes were separately dissolved in $10 \mathrm{~mL}$ of $2 \% \mathrm{HNO}_{3}$ solution to extract metal ions from graphite. The extracted solution and collected electrolyte were combined again and filtered for the ICP-MS measurements. A three-point calibration was conducted in $2 \% \mathrm{HNO}_{3}$ before each sample set.

X-ray Photoelectron Spectroscopy (XPS)

A K-alpha spectrometer (Thermo Scientific) using Al K $\alpha$ radiation (hv $=1486.6$ $\mathrm{eV})$ under ultra-high vacuum $\left(<1 \times 10^{-12} \mathrm{~atm}\right)$ was used for XPS measurements. The measuring spot size and pass energy were $400 \mu \mathrm{m}$ in diameter and $60 \mathrm{eV}$ for this instrument. After equilibration for 48 hours, the HE-NCM/graphite cells were disassembled in an argon glove box. Each electrode was washed with battery grade EMC to remove the electrolyte residue, dried overnight under vacuum, and transferred in an air-free container to the XPS chamber. The PVdF $(688 \mathrm{eV})$ and LiF peaks $(685$ $\mathrm{eV})$ were used as reference peaks for HE-NCM and graphite to correct the binding energy scale for all spectra, respectively. Relative atomic concentrations were calculated from the integration of each XPS peak, upon consideration of respective atomic sensitivity factors. An argon flood gun was used as needed to avoid charge accumulation on samples.

Infrared Spectra with Attenuated Total Reflectance (IR-ATR)

A Bruker Tensor 27 equipped with an attenuated total reflection (ATR) system and LaDTG detector was used for IR measurements. After cycling and allowing 
equilibration for 48 hours, the HE-NCM/graphite cells were disassembled in an argon glove box. Each electrode was washed with battery grade EMC, dried overnight under vacuum, and transferred in a closed container to a nitrogen-filled glove box. The spectra were acquired with a resolution of $4 \mathrm{~cm}^{-1}$ and 256 scans in the nitrogen glove box. An atmospheric compensation and baseline correction were applied to all spectra.

\section{RESULTS AND DISCUSSION}

[Figure 4-1]

The galvanostatic cycling performance of the HE-NCM/graphite full cells is provided in figure 4-1 with discharging capacity, normalized based on the active mass of HE-NCM. The $\mathrm{Al}_{2} \mathrm{O}_{3}$ coating on HE-NCM clearly improves the capacity retention of HE-NCM/graphite full cells. The HE-NCM/graphite cells containing the uncoated or $\mathrm{Al}_{2} \mathrm{O}_{3}$-coated HE-NCM electrode show similar discharging capacity after the precycling step $\left(6^{\text {th }}\right.$ cycle, $\left.\sim 240 \mathrm{mAh} / \mathrm{g}\right)$, however the capacity of the cell containing uncoated HE-NCM decays faster upon prolonged cycling. This rapid decay is consistent with a loss of cyclable lithium ions during cycling when HE-NCM is not coated with $\mathrm{Al}_{2} \mathrm{O}_{3}$. Since there is no excess lithium in the HE-NCM/graphite full cells, any lithium loss directly affects the cycling performance of the cells.

[Figure 4-2]

The ICP-MS results for quantification of metal dissolution provide insight into the source of cycling performance decay of HE-NCM/graphite cells (figure 4-2). The 
transition metal dissolution from the uncoated HE-NCM electrode is four times higher than the transition metal dissolution from the $\mathrm{Al}_{2} \mathrm{O}_{3}$ coated $\mathrm{HE}-\mathrm{NCM}$ electrode. This suggests that the $\mathrm{Al}_{2} \mathrm{O}_{3}$ coating stabilizes the surface structure of HE-NCM and prevents transition metal dissolution from HE-NCM into electrolytes. ${ }^{17,22,23}$ It is reported that transition metal dissolution from cathode has a detrimental effect on graphite anode and overall cell performance, yet the specific mechanism is not fully established. ${ }^{24,25}$

To elaborate the effect of metal dissolution on the surface chemistry of full cells, the surface film on both HE-NCM and graphite electrodes was investigated using XPS analysis (figures 4-3 to 4-5). While the surface modification was applied to HE-NCM positive electrodes, the surface films developed on the uncoated and $\mathrm{Al}_{2} \mathrm{O}_{3}$-coated HENCM are very similar even after 50 cycles (figure 4-3). Before cycling (pristine, grey lines), both electrodes have strong features of PVdF in the C 1s (291 eV, figure 4-3a and $3 \mathrm{~d}$ ) and $\mathrm{F}$ 1s spectra (688 eV, Fig. $3 \mathrm{c}$ and $3 \mathrm{f}){ }^{26}$ In the $\mathrm{O}$ 1s spectra, the $\mathrm{Al}_{2} \mathrm{O}_{3}$ coated HE-NCM has a distinct shoulder around $531.8 \mathrm{eV}$ (Fig. 3e), suggested to come from the $\mathrm{Al}_{2} \mathrm{O}_{3}$ coating, consistent with the presence of the corresponding peak in the $\mathrm{Al} 2 \mathrm{p}$ spectrum at $74 \mathrm{eV}$ (figure 4-3h) ${ }^{26,27}$ After cycling, $\mathrm{C}-\mathrm{O}(533.5 \mathrm{eV})$ and $\mathrm{C}=\mathrm{O}$ $(531.8 \mathrm{eV})$ peaks in the $\mathrm{O} 1 \mathrm{~s}$ spectra grow on both electrodes, ${ }^{28-30}$ indicating the decomposition of carbonate solvents (figures 4-3b and 4-3e). These peaks are relatively greater intensity on the uncoated HE-NCM, implying more electrolyte decomposition has occurred on the electrode surface. A broad peak characteristic of $\mathrm{Li}_{x} \mathrm{PF}_{\mathrm{y}} \mathrm{O}_{z}$ (around 686-687 eV) and a small LiF peak $(685 \mathrm{eV})$ are also observed on both electrodes after cycling (figures 4-3c and 4-3f). ${ }^{26}$ Although these changes provide 
evidence for electrolyte decomposition on HE-NCM positive electrodes, it is suggested the surface of HE-NCM is not completely passivated upon prolonged electrochemical cycling. Even after 50 cycles, the peaks characteristic of PVdF and bulk metal oxide $(530 \mathrm{eV})$ can be observed from the HE-NCM surface. ${ }^{26,31}$ Further, the relative atomic concentrations calculated from the corresponding XPS spectra of HE-NCM (figure 4-5a), illustrate that the surface of HE-NCM electrode does not change significantly upon cycling.

[Figure 4-3 to Figure 4-5]

Interestingly, the surface chemistry of graphite appears to be more altered by the $\mathrm{Al}_{2} \mathrm{O}_{3}$ coating on HE-NCM than the surface of the HE-NCM itself (figure 4-4 and figure 4-5b). The relative atomic concentration of graphite changes notably upon cycling (figure 4-5b). The relative concentration of fluorine increases significantly on the surface of graphite when cycled with the uncoated HE-NCM. However, the surface of graphite cycled with the $\mathrm{Al}_{2} \mathrm{O}_{3}$-coated $\mathrm{HE}-\mathrm{NCM}$ is relatively stable over the first 50 cycles. While the relative atomic concentrations show a large difference, the XPS spectra from two graphite electrodes contain similar peaks (figure 4-4). This denotes that the types of electrolyte decomposition products do not change, however, the relative ratio of the different decomposition products on the graphite surface are altered. Both graphite electrodes have $\mathrm{C}-\mathrm{O}$ and $\mathrm{C}=\mathrm{O}$ features $(286.8 \& 289 \mathrm{eV}$ in the $\mathrm{C} 1 \mathrm{~s}$ and $531.8 \& 533.5 \mathrm{eV}$ in $\mathrm{O} 1 \mathrm{~s}$ spectra) as well as a $\mathrm{LiF}$ peak $(685 \mathrm{eV}$ in the $\mathrm{F}$ 1s). ${ }^{28-30}$ The F 1s spectrum for the graphite electrode cycled with the uncoated HE- 
NCM contains an intense peak characteristic of $\mathrm{Li}_{x} \mathrm{PF}_{y} \mathrm{O}_{z}(686-687 \mathrm{eV}),{ }^{26}$ which increases upon prolonged cycling. The P $2 p$ spectra also shows broad peaks characteristic of $\mathrm{Li}_{x} \mathrm{PF}_{\mathrm{y}} \mathrm{O}_{z}(134-135 \mathrm{eV})$ and $\mathrm{LiPF}_{6}(136-138 \mathrm{eV}) .{ }^{32,33}$ Overall, more $\mathrm{LiPF}_{6}$ salt decomposition occurs on the surface of graphite when cycled with the uncoated HE-NCM.

The IR-ATR spectra for both HE-NCM and graphite electrodes after 50 cycles are provided in figure 4-6. As with the XPS results described above, the IR spectra for the uncoated and $\mathrm{Al}_{2} \mathrm{O}_{3}$-coated HE-NCM after 50 cycles are very similar (figure 4-6a). Most of the features in the spectra of both HE-NCM electrodes are attributed to PVdF binder (a 800-1300 $\mathrm{cm}^{-1}$ region, peaks at $1400 \mathrm{~cm}^{-1}$ and $\left.1740 \mathrm{~cm}^{-1}\right),{ }^{34}$ supporting the XPS result for HE-NCM electrodes (figure 4-3). However, the IR spectra for the graphite electrodes cycled with the uncoated and $\mathrm{Al}_{2} \mathrm{O}_{3}$-coated $\mathrm{HE}-\mathrm{NCM}$ reveal some notable differences (figure 4-6b). While both spectra contain peaks characteristic of $\operatorname{LEDC}\left(1652,1400,1315,1100\right.$, and $\left.825 \mathrm{~cm}^{-1}\right)$ and $\mathrm{Li}_{2} \mathrm{CO}_{3}\left(1490,1433\right.$ and $875 \mathrm{~cm}^{-}$ $\left.{ }^{1}\right),{ }^{35-37}$ the graphite cycled with the uncoated HE-NCM contains additional features of oligo or poly carbonate $\left(1750,1300\right.$, and $\left.1260 \mathrm{~cm}^{-1}\right) \cdot{ }^{38}$ The oligo carbonates are likely generated on the uncoated cathode surface from electrolyte oxidation and then cross over to the anode where they are reduced and deposited. Consistent with the XPS results (figure 4-4g), a strong peak is observed at $840 \mathrm{~cm}^{-1}$ on the graphite cycled for the uncoated HE-NCM which is characteristic of the P-F bond ${ }^{39}$ suggesting the presence of $\mathrm{Li}_{x} \mathrm{PF}_{y} \mathrm{O}_{z}$ and the residual $\mathrm{LiPF}_{6}$. This further supports $\mathrm{LiPF}_{6}$ salt decomposition is a major component of the SEI evolution on graphite when it is cycled with the uncoated HE-NCM. ${ }^{40}$ 
[Figure 4-6]

With the above surface analysis results (XPS and IR), it can be concluded that metal dissolution from HE-NCM leads to the additional electrolyte decomposition on the surface of graphite. To further understand the effect on the degradation of graphite, the resistance of graphite was measured using the electrochemical impedance spectroscopy (EIS). In figure 4-7, Nyquist plots of graphite/graphite symmetric cells, in which graphite electrodes were collected from HE-NCM/graphite cells are provided. After the $1^{\text {st }}$ cycle, the resistance of graphite electrodes is almost identical whether they were cycled with the uncoated or $\mathrm{Al}_{2} \mathrm{O}_{3}$-coated HE-NCM electrodes. Upon the cycling, however, the resistance of graphite cycled with the uncoated HE$\mathrm{NCM}$ has increased significantly while the one of graphite cycled with the $\mathrm{Al}_{2} \mathrm{O}_{3}$ coated HE-NCM is stabilized. Therefore, it is reasonable to infer that metal dissolution from HE-NCM eventually increases the resistance of graphite and further causes the full cell degradation.

[Figure 4-7]

\section{CONCLUSION}

The influence of aluminum oxide $\left(\mathrm{Al}_{2} \mathrm{O}_{3}\right)$ coating on to high-energy nickel cobalt manganese oxides ( $\mathrm{HE}-\mathrm{NCM}, \mathrm{Li}_{1.33} \mathrm{Ni}_{0.27} \mathrm{Co}_{0.13} \mathrm{Mn}_{0.60} \mathrm{O}_{2+\mathrm{d}}$ ) has been investigated in $\mathrm{HE}-\mathrm{NCM}$ /graphite full cells. $\mathrm{Al}_{2} \mathrm{O}_{3}$ coating on $\mathrm{HE}-\mathrm{NCM}$ improves the cycle performance of HE-NCM/graphite full cells and effectively prevents the transition metal dissolution from HE-NCM into electrolytes. Ex-situ surface analysis on HE- 
NCM and graphite electrodes reveals that the surface chemistry of HE-NCM is not significantly altered with $\mathrm{Al}_{2} \mathrm{O}_{3}$ coating, however, the surface chemistry of graphite is affected significantly. When cycled with the $\mathrm{Al}_{2} \mathrm{O}_{3}$-coated $\mathrm{HE}-\mathrm{NCM}$, the surface of graphite is stable over the first 50 cycles, while the surface of graphite cycled with the uncoated HE-NCM has strong features of $\mathrm{LiPF}_{6}$ salt decomposition products and oligo or poly carbonates. The results suggest transition metal dissolution catalyzes additional electrolyte decomposition on the graphite surface. The additional electrolyte decomposition induces the resistance increase of graphite and further affects full cell performance. The improved cycling performance can be attributed to the prevention of transition metal dissolution from HE-NCM resulting in minimized resistance increase on the graphite anode.

CONFLICTS OF INTEREST

There are no conflicts of interest

\section{ACKNOWLEDGEMENTS}

The authors gratefully acknowledge funding from the BASF electrochemistry network 
FIGURES

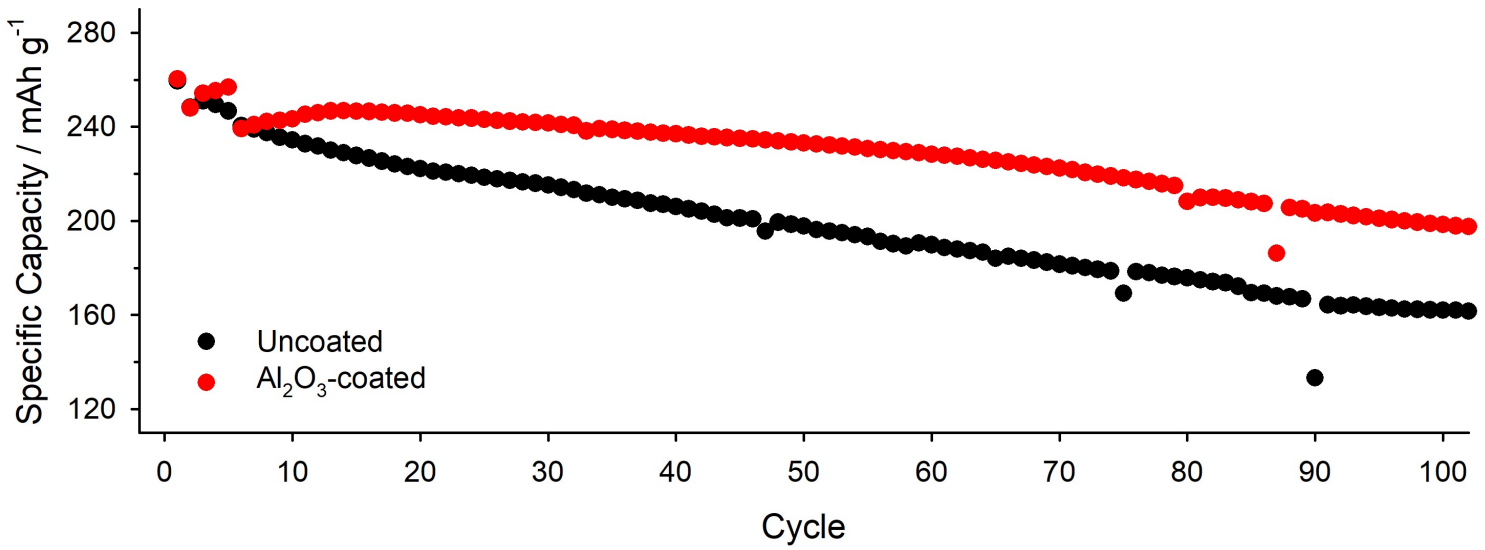

Figure 4-1. Comparison of discharge capacity vs. cycle number obtained from HE$\mathrm{NCM} /$ Graphite full cells containing the uncoated and $\mathrm{Al}_{2} \mathrm{O}_{3}$-coated $\mathrm{HE}-\mathrm{NCM}$ electrodes. The capacity was calculated based on the active mass of HE-NCM electrodes. 


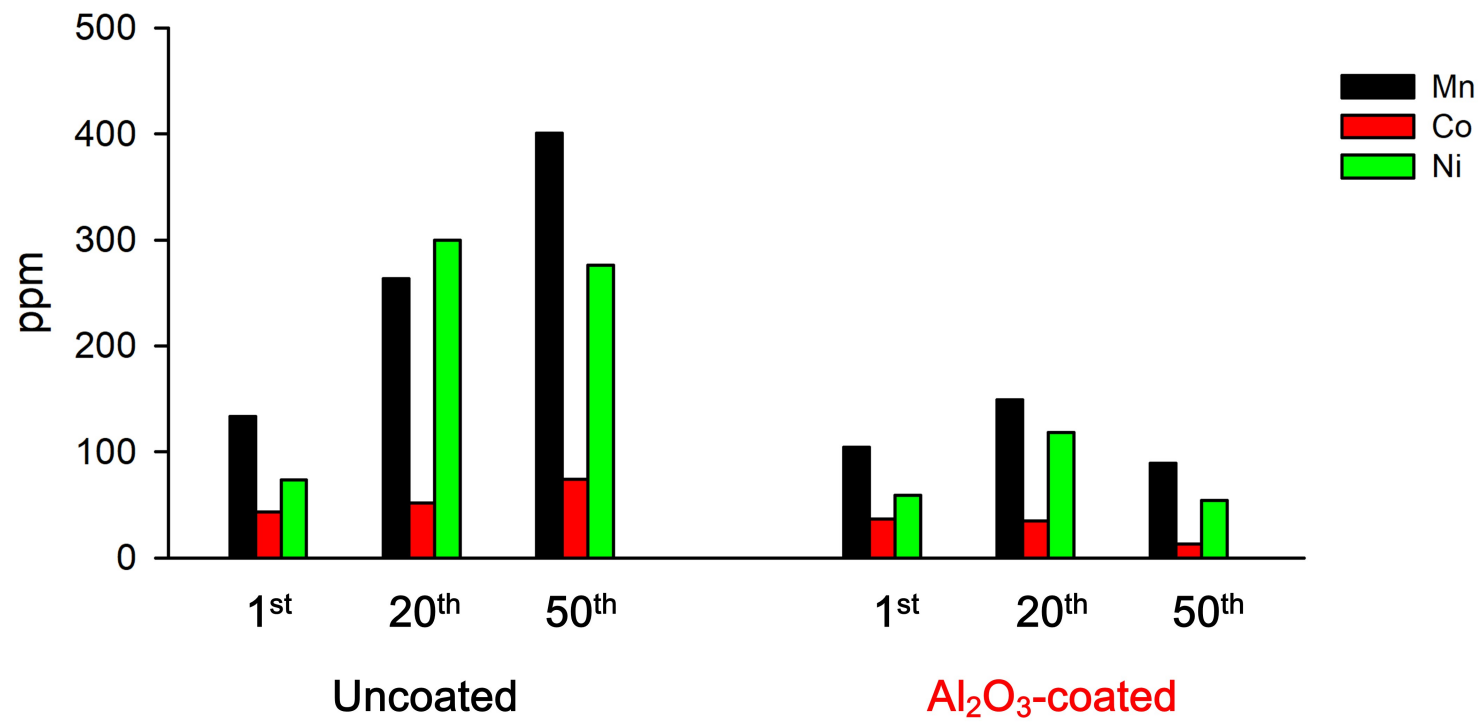

Figure 4-2. ICP-MS results obtained from HE-NCM/Graphite full cells containing the uncoated and $\mathrm{Al}_{2} \mathrm{O}_{3}$-coated $\mathrm{HE}-\mathrm{NCM}$ electrodes. 


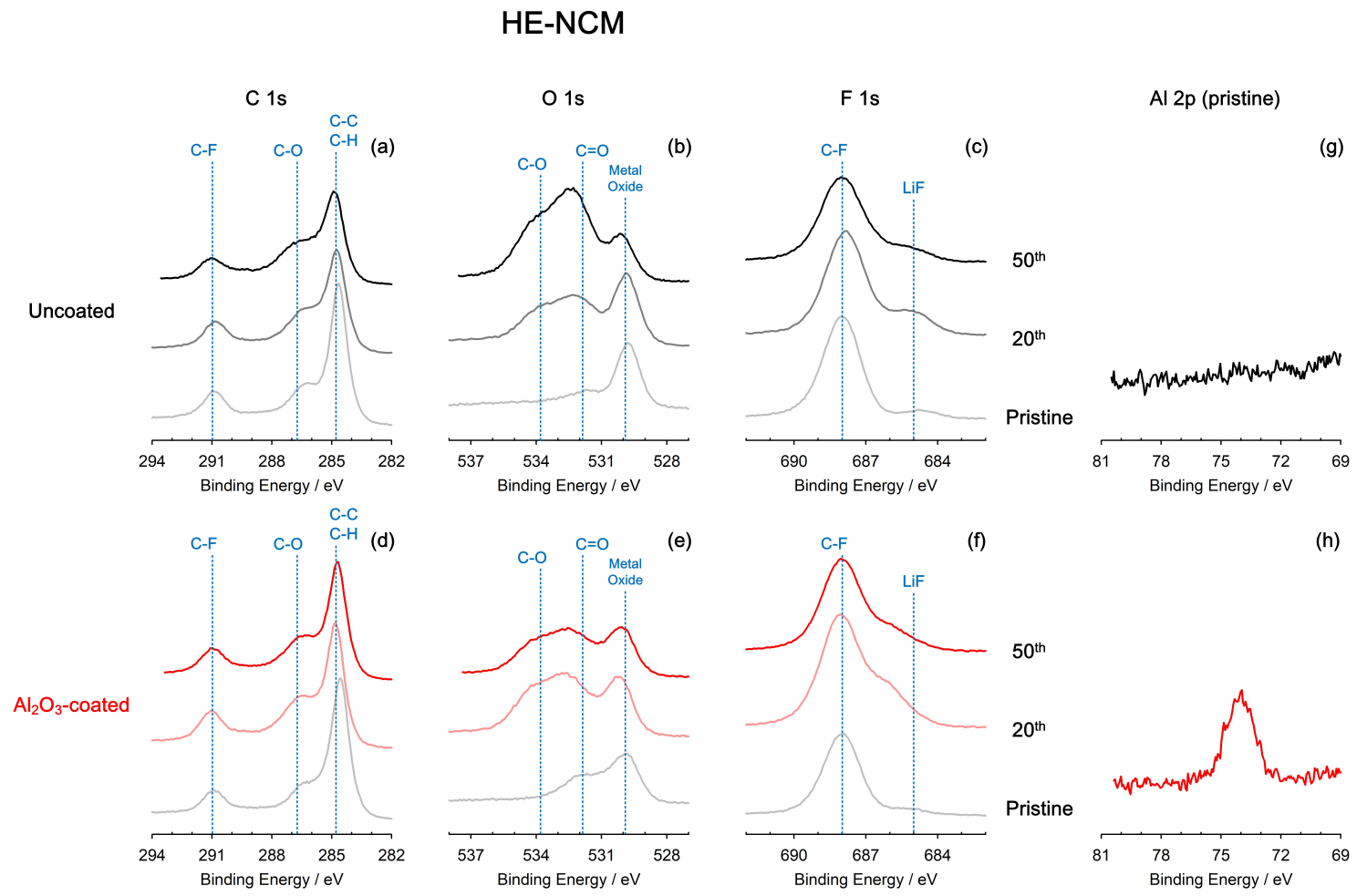

Figure 4-3. XPS spectra obtained from the uncoated and $\mathrm{Al}_{2} \mathrm{O}_{3}$-coated $\mathrm{HE}-\mathrm{NCM}$ electrodes collected from HE-NCM/Graphite full cells. 


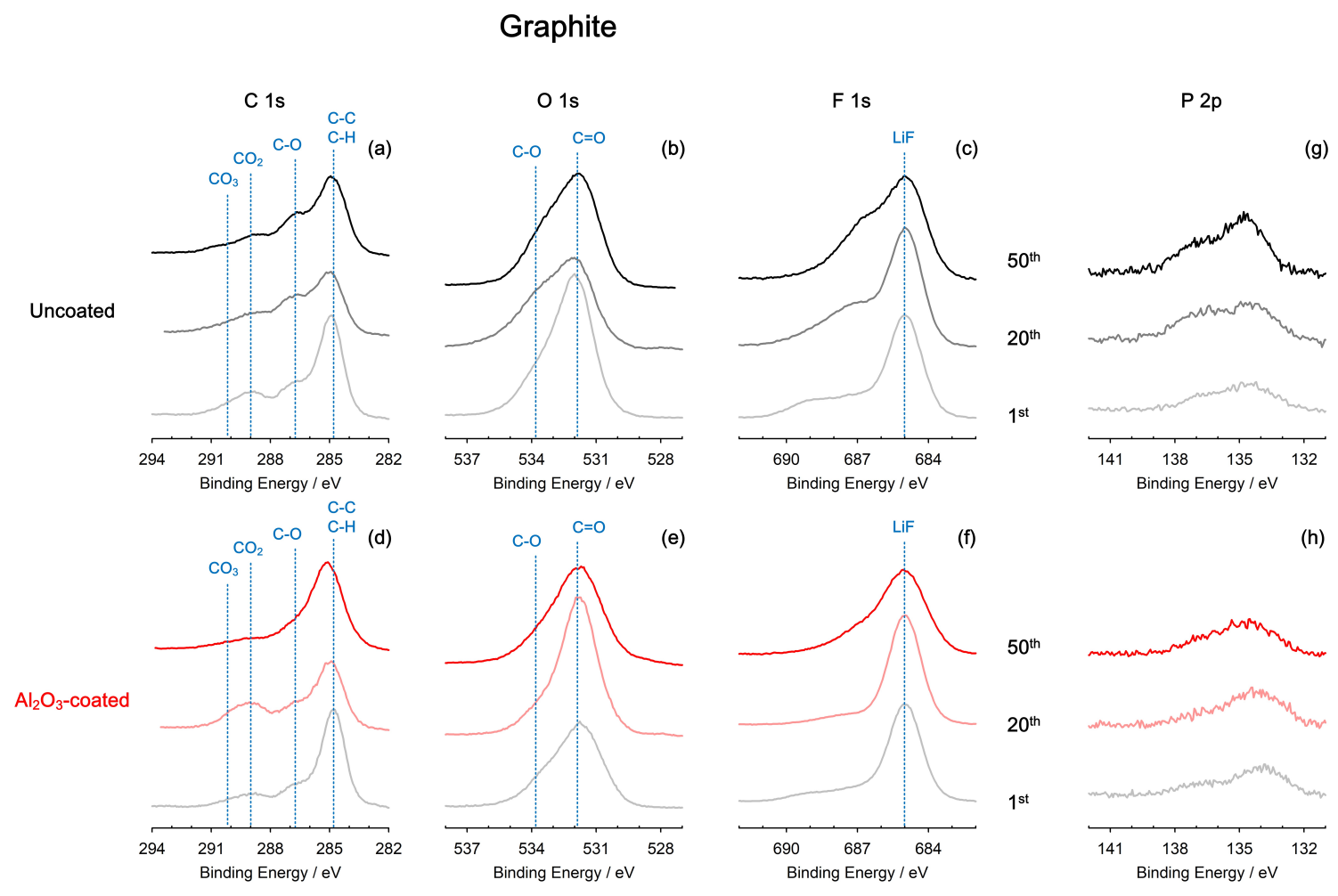

Figure 4-4. XPS spectra obtained from the graphite electrodes collected from HE-

NCM/Graphite full cells. 
(a) HE-NCM

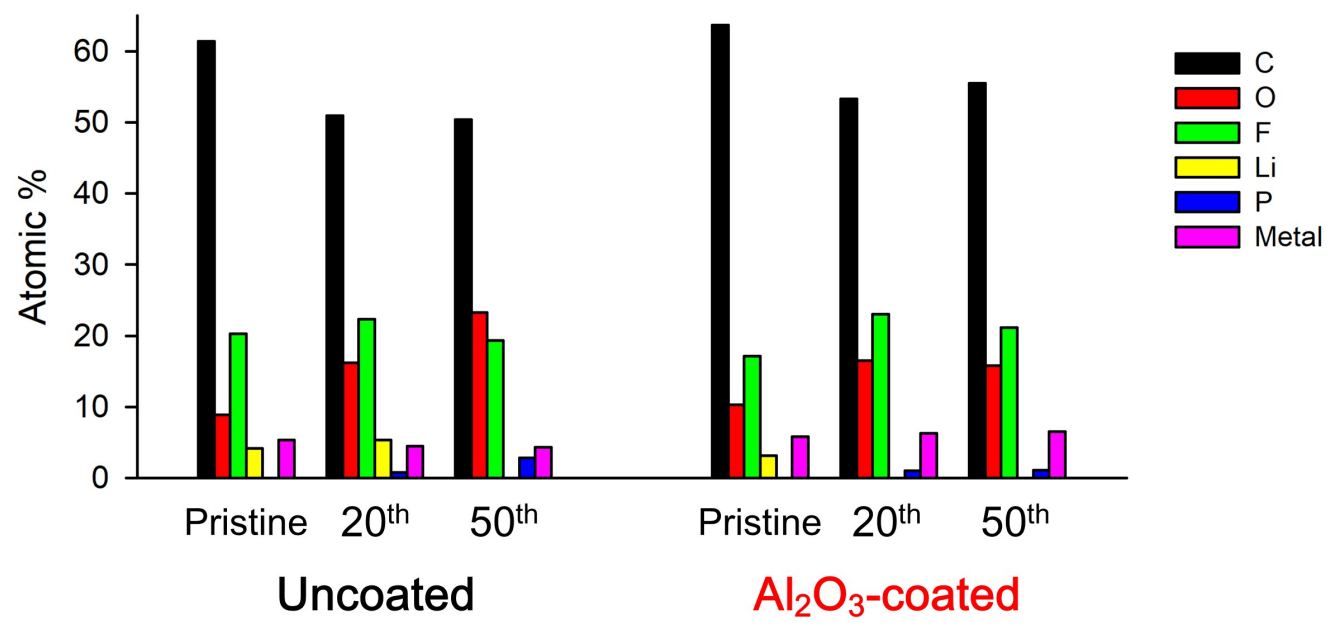

(b) Graphite

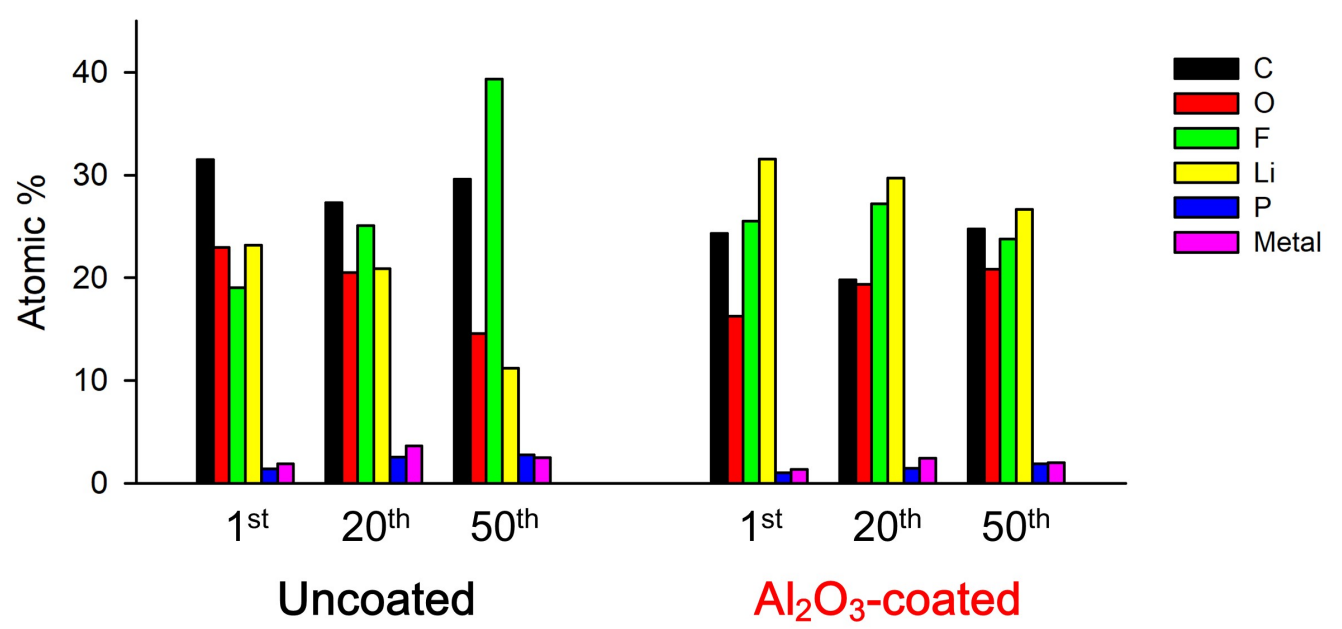

Figure 4-3. Corresponding relative atomic concentrations from XPS spectra obtained from the HE-NCM electrodes and graphite electrodes. The total concentration of $\mathrm{Ni}$, $\mathrm{Mn}$ and Co is presented as metal concentration. 
(a) HE-NCM

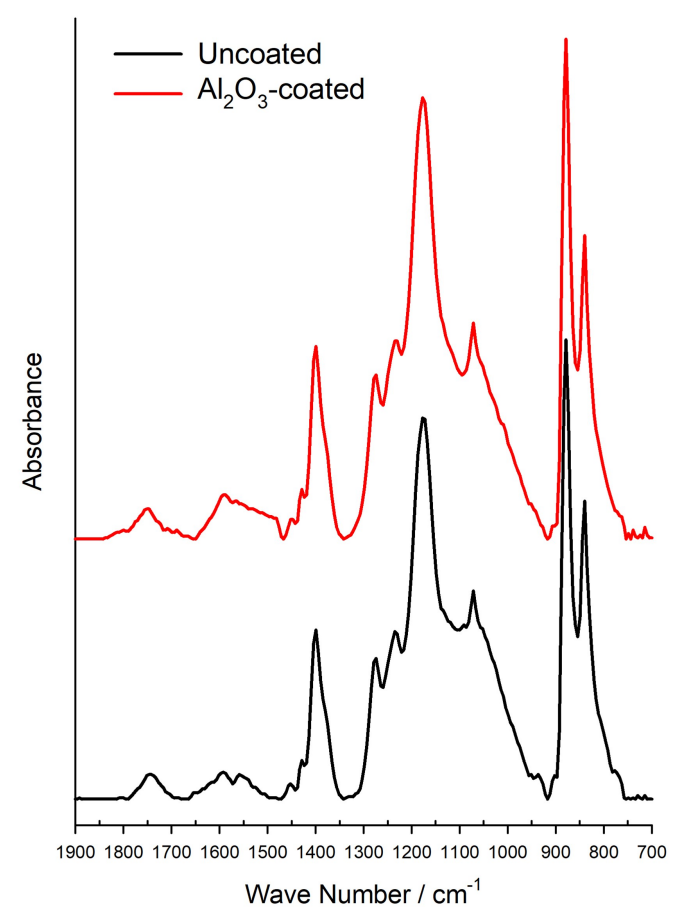

(b) Graphite

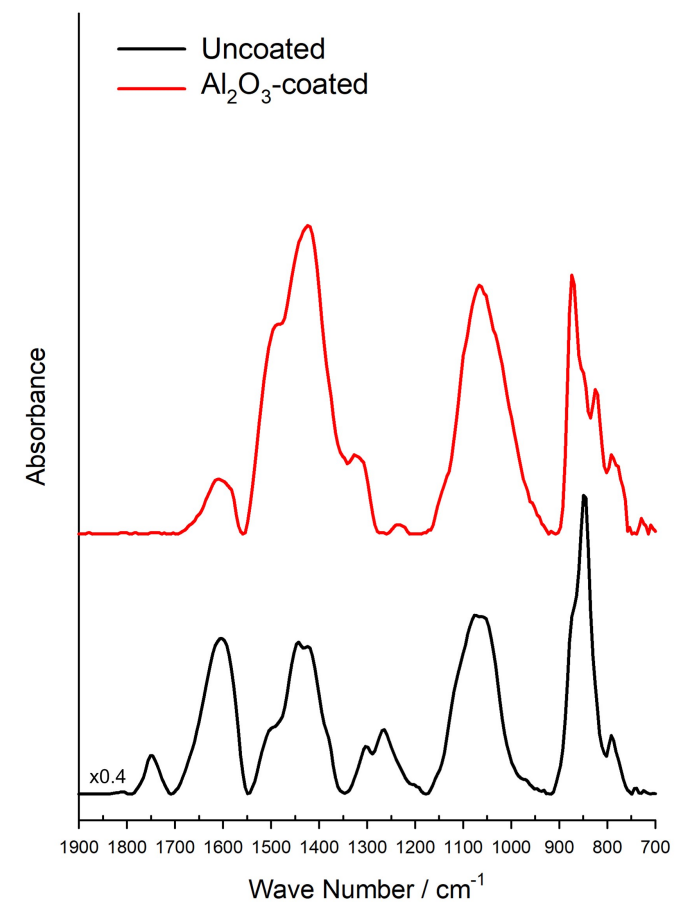

Figure 4-4. IR-ATR spectra obtained from the (a) HE-NCM electrodes and (b) graphite electrodes after 50 cycles. 

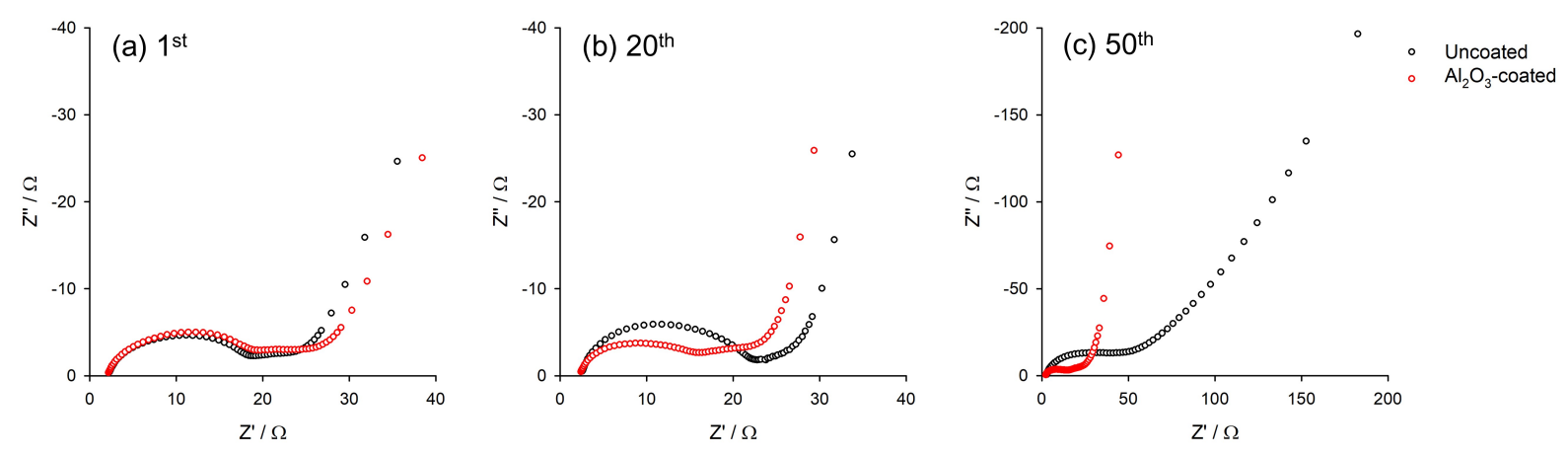

Figure 4-5. The Nyquist plots obtained from graphite/graphite symmetric cells, in which graphite electrodes were collected from two identical HE-NCM/Graphite full cells containing the uncoated and $\mathrm{Al}_{2} \mathrm{O}_{3}$-coated $\mathrm{HE}-\mathrm{NCM}$ electrodes. 


\section{REFERENCES}

1. X. D. Xiang, J. C. Knight, W. S. Li, and A. Manthiram, Journal of Physical Chemistry C, 118 (38), 21826-21833 (2014).

2. A. Manthiram, J. C. Knight, S. T. Myung, S. M. Oh, and Y. K. Sun, Advanced Energy Materials, 6 (1), (2016).

3. P. K. Nayak, J. Grinblat, E. Levi, B. Markovsky, and D. Aurbach, J. Power Sources, 318 9-17 (2016).

4. H. Liu, K. J. Harris, M. Jiang, Y. Wu, G. R. Goward, and G. A. Botton, $A C S$ Nano, 12 (3), 2708-2718 (2018).

5. C. Zhan, T. Wu, J. Lu, and K. Amine, Energy \& Environmental Science, 11 (2), 243-257 (2018).

6. T. Joshi, K. Eom, G. Yushin, and T. F. Fuller, J. Electrochem. Soc., 161 (12), A1915-A1921 (2014).

7. X. Li, M. Xu, Y. Chen, and B. L. Lucht, J. Power Sources, 248 1077-1084 (2014).

8. H. Zheng, Q. Sun, G. Liu, X. Song, and V. S. Battaglia, J. Power Sources, 207 $134-140$ (2012).

9. D. R. Gallus, R. Schmitz, R. Wagner, B. Hoffmann, S. Nowak, I. Cekic-Laskovic, R. W. Schmitz, and M. Winter, Electrochim. Acta, 134 393-398 (2014).

10. N. P. W. Pieczonka, Z. Liu, P. Lu, K. L. Olson, J. Moote, B. R. Powell, and J.-H. Kim, The Journal of Physical Chemistry C, 117 (31), 15947-15957 (2013).

11. M. Evertz, F. Horsthemke, J. Kasnatscheew, M. Börner, M. Winter, and S. Nowak, J. Power Sources, 329 364-371 (2016). 
12. J. Park, J. H. Seo, G. Plett, W. Lu, and A. M. Sastry, Electrochem. Solid-State Lett., 14 (2), A14-A18 (2011).

13. M. Wohlfahrt-Mehrens, C. Vogler, and J. Garche, J. Power Sources, 127 (1), 5864 (2004).

14. C. Zhan, J. Lu, A. Jeremy Kropf, T. Wu, A. N. Jansen, Y. K. Sun, X. Qiu, and K. Amine, Nat Commun, 42437 (2013).

15. C. Delacourt, A. Kwong, X. Liu, R. Qiao, W. L. Yang, P. Lu, S. J. Harris, and V. Srinivasan, J. Electrochem. Soc., 160 (8), A1099-A1107 (2013).

16. S. Komaba, N. Kumagai, and Y. Kataoka, Electrochim. Acta, 47 (8), 1229-1239 (2002).

17. J. Cho, Y. J. Kim, and B. Park, Chem. Mater., 12 (12), 3788-3791 (2000).

18. S.-T. Myung, K. Izumi, S. Komaba, H. Yashiro, H. J. Bang, Y.-K. Sun, and N. Kumagai, The Journal of Physical Chemistry C, 111 (10), 4061-4067 (2007).

19. D. Mohanty, K. Dahlberg, D. M. King, L. A. David, A. S. Sefat, D. L. Wood, C. Daniel, S. Dhar, V. Mahajan, M. Lee, and F. Albano, Sci Rep, 626532 (2016).

20. X. Huang, K. Chen, and Y. Liu, J. Electrochem. Soc., 166 (3), A5081-A5089 (2019).

21. Y. J. Kim, J. Cho, T.-J. Kim, and B. Park, J. Electrochem. Soc., 150 (12), (2003).

22. D. H. Snydacker, M. Aykol, S. Kirklin, and C. Wolverton, J. Electrochem. Soc., 163 (9), A2054-A2064 (2016).

23. P. F. Yan, J. M. Zheng, X. F. Zhang, R. Xu, K. Amine, J. Xiao, J. G. Zhang, and C. M. Wang, Chem. Mater., 28 (3), 857-863 (2016). 
24. J. A. Gilbert, I. A. Shkrob, and D. P. Abraham, J. Electrochem. Soc., 164 (2), A389-A399 (2017).

25. J. Wandt, A. Freiberg, R. Thomas, Y. Gorlin, A. Siebel, R. Jung, H. A. Gasteiger, and M. Tromp, Journal of Materials Chemistry A, 4 (47), 18300-18305 (2016).

26. S. Verdier, L. El Ouatani, R. Dedryvere, F. Bonhomme, P. Biensan, and D. Gonbeau, J. Electrochem. Soc., 154 (12), A1088-A1099 (2007).

27. X. Zhang, I. Belharouak, L. Li, Y. Lei, J. W. Elam, A. Nie, X. Chen, R. S. Yassar, and R. L. Axelbaum, Advanced Energy Materials, 3 (10), 1299-1307 (2013).

28. Y.-C. Lu, A. N. Mansour, N. Yabuuchi, and Y. Shao-Horn, Chem. Mater., 21 (19), 4408-4424 (2009).

29. R. Dedryvère, S. Laruelle, S. Grugeon, L. Gireaud, J. M. Tarascon, and D. Gonbeau, J. Electrochem. Soc., 152 (4), A689-A696 (2005).

30. A. M. Andersson and K. Edstrom, J. Electrochem. Soc., 148 (10), A1100-A1109 (2001).

31. R. Alcántara, G. F. Ortiz, P. Lavela, J. L. Tirado, W. Jaegermann, and A. Thißen, J. Electroanal. Chem., 584 (2), 147-156 (2005).

32. M. Herstedt, D. P. Abraham, J. B. Kerr, and K. Edstrom, Electrochim. Acta, 49 (28), 5097-5110 (2004).

33. A. M. Andersson, D. P. Abraham, R. Haasch, S. MacLaren, J. Liu, and K. Amine, J. Electrochem. Soc., 149 (10), A1358-A1369 (2002).

34. S. W. Song, G. V. Zhuang, and P. N. Ross, J. Electrochem. Soc., 151 (8), A1162A1167 (2004). 
35. K. Xu, G. V. Zhuang, J. L. Allen, U. Lee, S. S. Zhang, P. N. Ross, Jr., and T. R. Jow, J. Phys. Chem. B, 110 (15), 7708-7719 (2006).

36. B. S. Parimalam, A. D. MacIntosh, R. Kadam, and B. L. Lucht, Journal of Physical Chemistry C, 121 (41), 22733-22738 (2017).

37. P. Verma, P. Maire, and P. Novak, Electrochim. Acta, 55 (22), 6332-6341 (2010).

38. L. Yang, B. Ravdel, and B. L. Lucht, Electrochem. Solid-State Lett., 13 (8), A95A97 (2010).

39. R. Marom, O. Haik, D. Aurbach, and I. C. Halalay, J. Electrochem. Soc., 157 (8), A972-A983 (2010).

40. W. Li and B. L. Lucht, J. Power Sources, 168(1), 258-264 (2007). 